\title{
Insights on Human Small Heat Shock Proteins and Their Alterations in Diseases
}

\author{
B. Tedesco ${ }^{1,2}$, R. Cristofani ${ }^{1}$, V. Ferrari ${ }^{1}$, M. Cozzi ${ }^{1}$, P. Rusmini ${ }^{1}$, E. Casarotto ${ }^{1}$, \\ M. Chierichetti ${ }^{1}$, F. Mina ${ }^{1}$, M. Galbiati ${ }^{1}$, M. Piccolella ${ }^{1}$, V. Crippa ${ }^{1}$ and A. Poletti ${ }^{1 *}$
}

${ }^{1}$ Dipartimento di Scienze Farmacologiche e Biomolecolari, Università degli Studi di Milano, Milan, Italy, ${ }^{2}$ Unit of Medical Genetics and Neurogenetics, Fondazione IRCCS Istituto Neurologico Carlo Besta, Milan, Italy

\section{OPEN ACCESS}

Edited by:

Alok Kumar Panda,

KIIT University, India

Reviewed by:

Nikolai B. Gusev,

Lomonosov Moscow State University,

Russia

Swasti Raychaudhuri,

Centre for Cellular \& Molecular Biology

(CCMB), India

${ }^{*}$ Correspondence:

A. Poletti

angelo.poletti@unimi.it

Specialty section:

This article was submitted to Protein Folding, Misfolding and

Degradation,

a section of the journal

Frontiers in Molecular Biosciences

Received: 23 December 2021

Accepted: 19 January 2022

Published: 25 February 2022

Citation:

Tedesco B, Cristofani R, Ferrari V, Cozzi M, Rusmini P, Casarotto E, Chierichetti M, Mina F, Galbiati M, Piccolella M, Crippa $V$ and Poletti $A$ (2022) Insights on Human Small Heat Shock Proteins and Their Alterations

in Diseases.

Front. Mol. Biosci. 9:842149. doi: 10.3389/fmolb.2022.842149
The family of the human small Heat Shock Proteins (HSPBs) consists of ten members of chaperones (HSPB1-HSPB10), characterized by a low molecular weight and capable of dimerization and oligomerization forming large homo- or hetero-complexes. All HSPBs possess a highly conserved centrally located $\alpha$-crystallin domain and poorly conserved $\mathrm{N}$ and C-terminal domains. The main feature of HSPBs is to exert cytoprotective functions by preserving proteostasis, assuring the structural maintenance of the cytoskeleton and acting in response to cellular stresses and apoptosis. HSPBs take part in cell homeostasis by acting as holdases, which is the ability to interact with a substrate preventing its aggregation. In addition, HSPBs cooperate in substrates refolding driven by other chaperones or, alternatively, promote substrate routing to degradation. Notably, while some HSPBs are ubiquitously expressed, others show peculiar tissue-specific expression. Cardiac muscle, skeletal muscle and neurons show high expression levels for a wide variety of HSPBs. Indeed, most of the mutations identified in HSPBs are associated to cardiomyopathies, myopathies, and motor neuropathies. Instead, mutations in HSPB4 and HSPB5, which are also expressed in lens, have been associated with cataract. Mutations of HSPBs family members encompass base substitutions, insertions, and deletions, resulting in single amino acid substitutions or in the generation of truncated or elongated proteins. This review will provide an updated overview of disease-related mutations in HSPBs focusing on the structural and biochemical effects of mutations and their functional consequences.

Keywords: HSPBs, proteostasis, aggregation, neuropathy, muscle disease

\section{INTRODUCTION}

Small Heat Shock Proteins (sHSPs or HSPBs) are a subset of chaperones characterized by low molecular weight $(\mathrm{MW})(14-43 \mathrm{kDa})$, highly conserved and described in all kingdoms and also in some viruses (Caspers et al., 1995; Maaroufi and Tanguay, 2013). In mammals, HSPBs consist of ten members (HSPB1-HSPB10) (Table1) (Kappé et al., 2003; Kappé et al., 2010). HSPBs are structurally defined by the presence of an $\alpha$-crystallin domain (ACD) in the central region of their sequence (Figure 1). The ACD is a highly conserved $80-90$ amino acids (AA)-long domain consisting of $8 \beta$ strands, which fold in a $\beta$-sandwich structure (van Montfort et al., 2001). Outside the ACD, HSPBs share a poor similarity of both the N-terminal and the C-terminal domains (NTD, CTD), except for the presence of a SRLFDQxFG motif in the NTD of the HSPBs B1, B4, B5, B6, B8, and a I/V-X-I/V 
TABLE 1 | Nomenclature and properties of HSPBs. The table lists HSPBs, their alternative names and properties. The molecular weight (MW), aminoacidic length (AA) and oligomerization propensity are reported. The presence of the SRLFDQxFG and the IN-X-IN motifs are reported. NTD and CTD refer to the N and C-terminal domains, respectively; N/A means not assessed.

\begin{tabular}{|c|c|c|c|c|c|c|}
\hline HUGO name & Alternative names & MW (kDa) & AA & SRLFDQxFG motif & $\mathrm{I} / \mathrm{V}-\mathrm{X}-\mathrm{I} / \mathrm{V}$ & Assemblies \\
\hline HSPB1 & HSP27; HSP28 & 22,783 & 205 & + & CTD & Oligomers \\
\hline HSPB2 & MKBP & 20,233 & 182 & - & CTD & Small oligomers \\
\hline HSPB3 & HSPL27 & 16,966 & 150 & - & NTD & Small oligomers \\
\hline HSPB4 & aA-Crystallin; CRYAA & 19,909 & 173 & + & NTD/CTD & Oligomers \\
\hline HSPB5 & aB-Crystallin; CRYAB & 20,159 & 175 & + & NTD/CTD & Oligomers \\
\hline HSPB6 & HSP2O; p20 & 17,136 & 160 & + & NTD & Dimers \\
\hline HSPB7 & cVHSP & 18,611 & 170 & - & - & Dimers \\
\hline HSPB8 & HSP22; H11; E2IG1 & 21,604 & 196 & + & - & Dimers \\
\hline HSPB9 & CT51 & 17,486 & 159 & - & - & N/A \\
\hline HSPB10 & ODF1 & 28,366 & 250 & - & - & $\mathrm{N} / \mathrm{A}$ \\
\hline
\end{tabular}

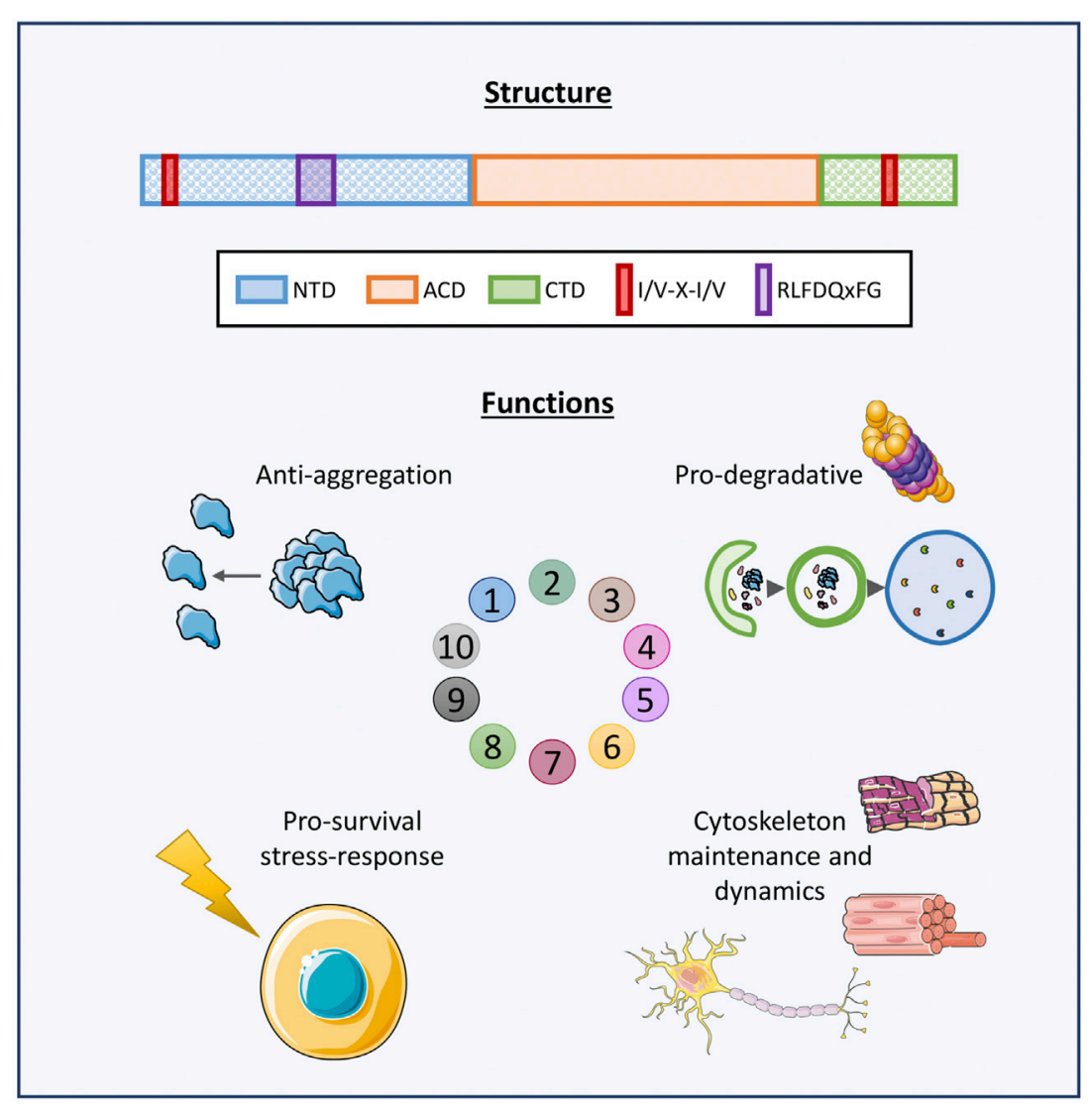

FIGURE 1 | Graphical representation of HSPBs structure and main functions. Schematic representation of human HSPBs structure, from Cristofani et al. (2021). The orange box represents the conserved $\alpha$-crystallin domain (ACD); the blue and green boxes represent the variable N-terminus and C-terminus domains (NTD, CTD, respectively); the red box indicates the IN-X-IN domains localizing at the NTD and/or CTD in several HSPBs; the purple box indicates the RLFDQxFG motif conserved in HSPBs. HSPBs functions include i) anti-aggregation activity against misfolded and aggregation-prone substrate and ii) cooperation with the degradative systems for substrate disposal, iii) protection against stressors and antiapoptotic activities, iv) cytoskeletal maintenance and dynamics. Servier Medical Art templates, which are licensed under a Creative Commons Attribution 3.0 Unported License were used in this figure; https://smart.servier.com.

motif in the CTD of HSPBs B1, B2, B4 and B5 (Pasta et al., 2003; Kriehuber et al., 2010; Poulain et al., 2010).

HSPBs act as ATP-independent holdases, avoiding misfolded substrates aggregation (Leroux et al., 1997). Also, HSPBs indirectly interact with ATP-dependent chaperones with foldase activity, such as Heat Shock Protein 70 (HSP70/ HSPA), for the refolding process (Jakob et al., 1993; Garrido et al., 2012). Another primary feature of HSPBs is their dynamic homo- or hetero-dimerization and oligomerization. Some HSPBs can form oligomers of 4 and up to 40 monomers, reaching MW of 


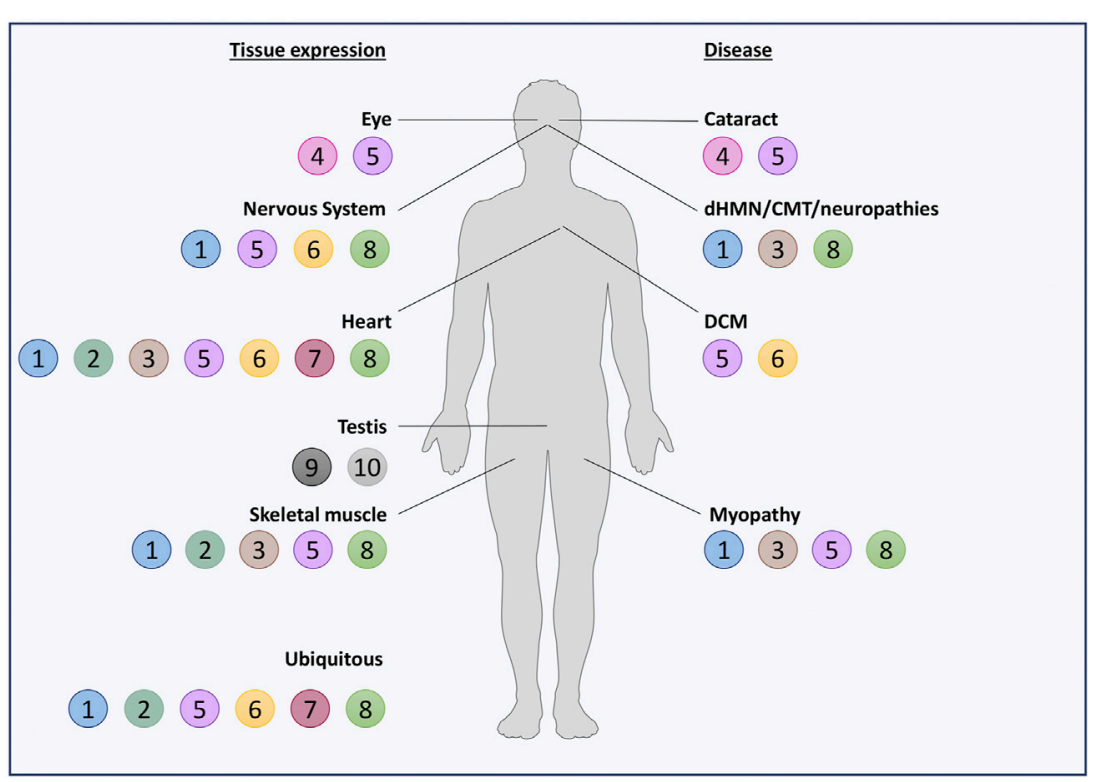

FIGURE 2 | Schematic representation of HSPBs tissue expression and related diseases. HSPBs are represented as beads and numbered based on HUGO nomenclature. On the left, HSPBs tissue expression is reported: most of HSPBs are expressed ubiquitously, but predominantly in certain tissues; other HSPBs show a tissue-specific expression. On the right, diseases in which HSPBs mutations have been identified are reported. Servier Medical Art templates, which are licensed under a Creative Commons Attribution 3.0 Unported License, were used in this figure; https://smart.servier.com.

$900 \mathrm{kDa}$. All three ACD, NTD and CTD are fundamental for oligomerization and function. In particular, the ACD is responsible for dimer formation, while the NTD and the CTD promote the stabilization of oligomeric and dimeric structures. For instance, it has been observed that truncation of the NTD causes the formation of smaller HSPBs oligomers, while the absence of the I/V-X-I/V motif in the CTD of HSPBs B3, B6, $\mathrm{B} 8$ is thought to explain their low oligomerization propensity (Boelens, 2020). In response to environmental stimuli, a dynamic change in subunit composition of oligomers can occur, changing the affinity for substrates binding, and therefore the functional activity of oligomers (van Montfort et al., 2001; Basha et al., 2012; Mymrikov et al., 2020). HSPBs exert several activities in cells (Figure 1). First, HSPBs, acting as holdase chaperones, prevent protein aggregation and help in refolding. Second, HSPBs promote substrates routing to the degradative pathways, autophagy and the Ubiquitin Proteasome System (UPS) (Parcellier et al., 2006; Carra et al., 2008a; Zhang et al., 2010). Third, HSPBs interact with the cytoskeleton components regulating their assembly and assuring structural integrity (Wettstein et al., 2012). Fourth, HSPBs are key players in the response to cellular stress and apoptosis, by regulating enzymes involved in oxidative stress response, participating in redox metabolism and blocking the activity of pro-apoptotic factors (Arrigo, 2007; Acunzo et al., 2012).

Noteworthily, half of the HSPBs (B1, B2, B5, B6, B7, and B8) are ubiquitously expressed, while the others show a tissue-specific expression (Figure 2). However, also the ubiquitously expressed HSPBs show higher levels in certain cell types, such as neurons, skeletal and cardiac muscle cells, suggesting a need of these cells for selective HSPBs activities. In fact, mutations in HSPBs affect these cells, causing neuropathies, myopathies, and/or cardiomyopathies (Figure 3; Supplementary Material).

Here we will discuss the general and the specific properties of each HSPB, underlining how they selectively contribute to the typical response to cell stresses and how the reported mutations impact on their structure, stability, and function in disease.

\section{HSPB1}

HSPB1 is a $23 \mathrm{kDa}$ protein constitutively and widely expressed in all human tissues. HSPB1 has been first described upregulated in HeLa cells upon heat shock (Arrigo and Welch, 1987). HSPB1 is mainly found in polydisperse oligomers of $400-600 \mathrm{kDa}$ and its phosphorylation, dimerization, and oligomerization have been extensively studied (Arrigo, 2017). HSPB1 dimerization can be affected by the intracellular redox conditions, which modulate the formation of a disulphide bond between cysteine residues (C137) at the dimer interface in the $\beta 7$ strand of the ACD (Zavialov et al., 1998; Diaz-Latoud et al., 2005; Mymrikov et al., 2010; Baranova et al., 2011; Chalova et al., 2014a; Rajagopal et al., 2015; Alderson et al., 2019). HSPB1 exerts several functions under physiological or stressed conditions: it indirectly cooperates in refolding or degradation of substrates through the UPS or autophagy (Zhang et al., 2010; Minoia et al., 2014; Haidar et al., 2019; Gonçalves et al., 2021); it interacts with cytoskeletal elements, modulating their correct assembly and preventing their damage (Miron et al., 1991; Perng et al., 1999); it plays an anti-apoptotic activity at multiple levels, by interfering with the pro-apoptotic proteins Bax and Bid and by sequestering the cytochrome $c$ released from mitochondria, hence inhibiting the caspase cascade (Bruey et al., 


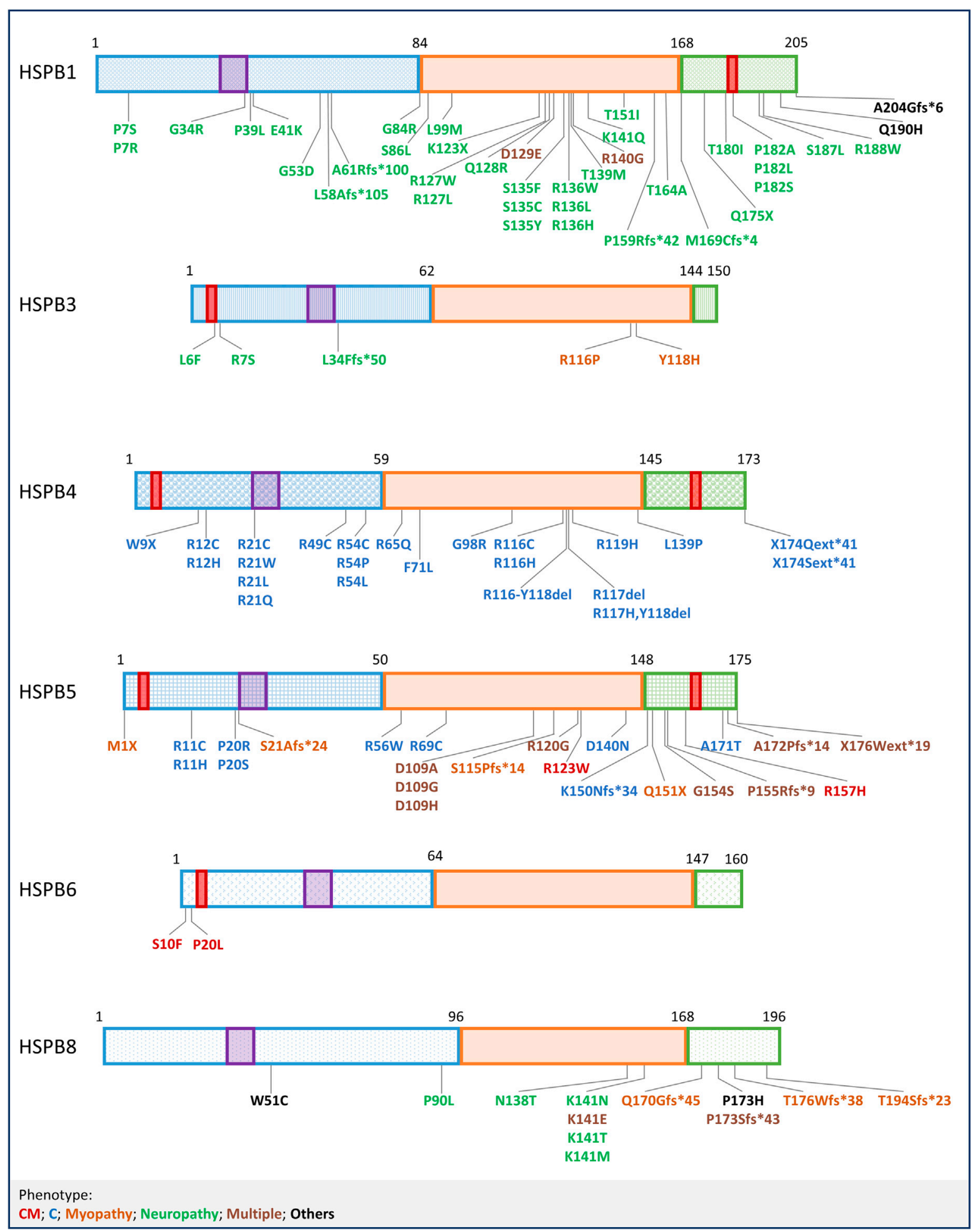

FIGURE 3 | Mutations in HSPBs. Graphical representation of HSPBs structure and mutations, based on Figure 1. Mutations are labelled with colors corresponding to the phenotypes reported at the bottom. $\mathrm{CM}=$ Cardiomyopathy, $\mathrm{C}=$ Cataract; Multiple (phenotypes) refers to mutations that have been linked to more than one phenotype, in combination or not; Others refer to mutations not included in the list. 
2000; Pandey et al., 2000; Paul et al., 2010). All HSPB1 activities reflect its role in protection against several stressors such as thermal, oxidative, and proteotoxic stress. In the nervous system, HSPB1 protects cells from misfolded protein toxicity exerted by disease-associated mutant proteins, such as Huntingtin (HTT) carrying an elongated polyglutamine (polyQ) tract, the mutated Superoxide Dismutase 1 (SOD1) and $\alpha$-synuclein (SNCA), which are able to cause neurodegeneration (Wyttenbach et al., 2002; Zourlidou et al., 2004; An et al., 2009). HSPB1 acts also in a non-cell autonomous fashion in neuroprotection. Indeed, HSPB1 upregulation has been described in astrocytes derived from transgenic (TG) mice carrying a mutated form of SOD1, while its overexpression promotes motoneurons (MNs) survival (Heilman et al., 2017). In skeletal and cardiac muscle, HSPB1 protects the cytoskeleton from structural damage (Lavoie et al., 1995; Bryantsev et al., 2002; Collier et al., 2019).

It is thus extremely relevant to underline that more than 30 mutations related to neuromuscular diseases have been identified in HSPB1, representing the most frequent cause of hereditary neuropathies, like distal Hereditary Motor Neuropathy type II (dHMNII) and Charcot-Marie-Tooth type 2 (CMT2) diseases. These disorders are characterized by adult onset and slow progression rate, but patients carrying HSPB1 mutated gene may show additional and more severe symptoms beside motor neuropathy, such as sensory involvement, cerebellar ataxia, spasticity and myopathic features. Some HSPB1 mutations even associate with a rapidly progressive phenotype that resembles Amyotrophic Lateral Sclerosis (ALS) (Capponi et al., 2016). HSPB1 mutations are mainly inherited dominantly and occur along the whole HSPB1 sequence. Despite the well evaluated clinical phenotypes, the biochemical and functional characterization for most of these HSPB1 mutations is still missing, and the molecular mechanisms at the basis of HSPB1-related neuropathies are not straightforward. Nevertheless, efforts have been made to decipher the dysfunctions at the basis of this multitude of HSPB1 mutations. Since the major aspect regulating HSPB1 activity relies on its self-association and dissociation, dimerization and oligomerization dynamics have been investigated as one of the primary features possibly altered in the mutant protein. In vitro, biochemical studies on HSPB1 mutations falling in different regions of the protein sequence revealed a common tendency to form larger oligomers, often accompanied by a decreased chaperone activity in respect to the HSPB1 wild-type (WT); in vitro analyses also reported a destabilization of the quaternary structure of mutated HSPB1 (Nefedova et al., 2013a; Nefedova et al., 2013b; Chalova et al., 2014b; Muranova et al., 2015; Alderson et al., 2021). Clustering HSPB1 mutations through a domain-dysfunction linkage is not unequivocal, due to contrasting observations resulted from different techniques and assays used to study mutations localized in the same HSPB1 region (Almeida-Souza et al., 2010; Ylikallio et al., 2015; Echaniz-Laguna et al., 2017a). Nevertheless, it is well assumed that mutations falling in the ACD might affect dimerization. Alterations in oligomerization and aberrant interaction with other proteins may explain the presence of aggregates of HSPB1 mutants observed in cells expressing different HSPB1 mutants (Evgrafov et al., 2004; Ackerley et al., 2006; James et al., 2008; Echaniz-Laguna et al., 2017a). Aggregation of HSPB1 mutants has a double consequence on cell homeostasis: from one side, HSPB1 mutants can sequester the HSPB1 WT, acting in a dominant negative manner and resulting in a loss of protective activity of the HSPB1 protein; from the other side, protein aggregates per se alter several cellular functions, e.g., proteostatic mechanisms, cytoskeletal architecture maintenance and axonal transport. Despite HSPB1 self-aggregation, which has not been observed for all HSPB1 mutations, the above-mentioned functions have been found altered in several cell models expressing HSPB1 mutants. For instance, while the HSPB1 WT promotes autophagy, HSPB1 mutations associate with a decreased autophagic flux (Amornvit et al., 2017; Haidar et al., 2019). Regarding cytoskeletal architecture maintenance, HSPB 1 mutants were described to alter both intermediate filaments and microtubule network. The effects of HSPB1 mutants on neurofilaments (NF) assembly and organization are variable, from a slight increase in NF phosphorylation to a severe coaggregation with the HSPB1 mutants (Zhai et al., 2007; Holmgren et al., 2013; Echaniz-Laguna et al., 2017a). Loss of the typical filamentous network of NF was observed in cells expressing the HSPB1 S135F mutant, which co-aggregated with NF at the perinuclear region (Evgrafov et al., 2004). Similarly, a disrupted and co-aggregating NF network was observed in primary neurons expressing the HSPB1 P182L mutation (Ackerley et al., 2006). Alterations of microtubule network resulted in a disrupted or defective axonal transport of organelles, another hallmark of axonal neuropathies (Ackerley et al., 2006; Kalmar et al., 2017). Given the multiple roles of HSPB1 in cell homeostasis, it is not surprising that increased cytotoxicity and decreased resistance against stressors were observed in cells expressing HSPB1 mutants (Evgrafov et al., 2004; Ylikallio et al., 2015; Kalmar et al., 2017). Truncation and frameshift mutations in HSPB1 have been identified. Experimental findings suggest that these mutated HSPB1 variants are still expressed but affected by protein instability. Analyses on cells overexpressing the HSPB1 frameshift mutants L58Afs ${ }^{\star} 105$ and A61Rfs ${ }^{\star} 100$ revealed that these proteins are less stable than the HSPB1 WT and rapidly degraded through the proteasome (DiVincenzo et al., 2014; Echaniz-Laguna et al., 2017a). Instead, the HSPB1 M169Cfs ${ }^{\star} 4$ mutation, which results in the production of a protein lacking almost the entire CTD, is still expressed in patient fibroblasts. While the mutant HSPB1 M169Cfs ${ }^{\star} 4$ distribution seemed unaffected, functional analyses revealed that patient-derived fibroblasts are less tolerant to stress stimuli, and subjected to an increase in misfolded protein load in respect to control cells (Ylikallio et al., 2015). Similar findings have been reported for the HSPB1 A204Gfs ${ }^{*} 6$, a rare variant described in ALS patients. HSPB1 A204Gfs ${ }^{\star} 6$ is less stable than the HSPB1 WT but it still dimerizes sequestering the HSPB1 WT. This causes an impairment in HSPB1-mediated clearance of misfolded substrates (Capponi et al., 2016). Overall, these observations suggest that, even if HSPB1 protein stability 
might be affected by truncating and frameshift mutations, their expression might result in a dominant negative action on the HSPB1 WT, which correlates with a defective cytoprotective activity. Interestingly, HSPB1 deficiency in mice is not linked to a neurological phenotype: in a HSPB1 Knock-out (KO) mouse model neither association to a neuromuscular phenotype nor developmental defects were observed (Huang et al., 2007); while in a second HSPB1 KO mouse, muscular impairments were observed in absence of neurological signs. Overall, these HSPB1 KO mice showed neither developmental defects nor alteration during aging, but a slight decrease in body weight. Ultrastructural studies revealed defects in the structural organization of muscle fibres, consisting in increased intermyofibrillar spaces and alterations in myofibrillar arrangement (Kammoun et al., 2016). Skeletal muscle targeting by HSPB1 is not surprising since HSPB1 mutations (e.g., D129E and R140G) have been described in patients showing myopathy features (Lewis-Smith et al., 2016; Bugiardini et al., 2017). Some HSPB1 mutations have been extensively studied in animal models. Two TG mouse models expressing the HSPB1 S135F mutant have been developed: these mice were vital at birth and manifested motor defects. One of the two mouse models expressed the HSPB1 S135F mutation selectively in neuronal tissue and at 6 months began to manifest progressive motor impairments and signs of sensory defects. Electrophysiological changes, but not demyelination, were observed, revealing an axonal neuropathy. Isolated dorsal root ganglion neurons displayed an impaired mitochondrial axonal transport and reduced acetylated tubulin, suggesting a destabilization of the microtubule network. Noteworthily, HDAC6 inhibitors, by counteracting the deacetylation of tubulin and therefore stabilizing the microtubule network, enhanced motor performance of these mice (d'Ydewalle et al., 2011). The other TG mouse model expressing the human HSPB1 S135F showed reduced motor function at 5 months, correlating with alteration in nerve conduction, a reduction in myelinated axons and fatty acid replacement in muscle. Analyses on sciatic nerves highlighted a reduction in tubulin acetylation and increased levels of phosphorylated NFs (Lee et al., 2015). The TG fly (Drosophila melanogaster) expressing the human HSPB1 S135F mutant in neurons or specifically in MNs did not show developmental defects or decreased life span, but a deeper analysis revealed motor defects, which were reverted by HDAC6 downregulation (Kang et al., 2020). Another TG mouse model expressing human HSPB1 R136W in neurons did not show an evident motor phenotype, but electrophysiological and histological analyses revealed signs of neuropathy (Srivastava et al., 2012). TG mice expressing the HSPB1 P182L mutation in the nervous system developed normally until 6 months of age, when they began manifesting motor impairments, axon loss and denervation (d'Ydewalle et al., 2011). Conversely, other TG mouse models did not recapitulate the neuropathy phenotype, an outcome likely related to a low transgene expression. For instance, mouse models expressing HSPB1 R127W and P182L mutants at levels comparable to the physiological ones did not show motor impairment nor signs of axonal damage (Bouhy et al., 2016).

\section{HSPB2}

HSPB2 has a MW of $20 \mathrm{kDa}$. HSPB2 gene locates near the HSPB5 gene, but in the opposite direction in the $5^{\prime}$ flanking region. Given this unique feature, it has been speculated that HSPB2 gene derives from an ancestral gene duplication (Iwaki et al., 1997). HSPB2 was identified by two independent groups that named it HSPB2 or Myotonic dystrophy protein Kinase Binding Protein (MKBP) (Iwaki et al., 1997; Suzuki et al., 1998). The MKBP name was given since HSPB2 was described as an interactor and activator of DMPK, a kinase that physiologically acts in muscle structure maintenance and can be deregulated in myotonic dystrophy. Indeed, HSPB2 has been observed upregulated in myotonic dystrophy patients (Suzuki et al., 1998). Both groups observed that, even if ubiquitously expressed, HSPB2 is particularly elevated in skeletal and cardiac muscle (Iwaki et al., 1997; Suzuki et al., 1998). For instance, HSPB2 increases its expression in $\mathrm{C} 2 \mathrm{C} 12$ myoblasts during differentiation into myotubes, likely under the control of the myogenic factor MyoD (Sugiyama et al., 2000; Nakagawa et al., 2001). HSPB2 is not heat-inducible, but heat shock itself reduces HSPB2 solubility (Iwaki et al., 1997; Suzuki et al., 1998). As seen for the other HSPBs, HSPB2 overexpression increases cell survival after heat stress (Nakagawa et al., 2001). Other stressors or pathological conditions may induce HSPB2 upregulation and/ or redistribution as a part of the intracellular protective mechanism against stress. Proteasome impairment induces HSPB2 delocalization to actin fibres and, similarly, ischemiamediated stress and oxidative stress induce HSPB2 translocation to Z-lines and intercalated discs in cardiomyocytes (Shama et al., 1999; Yoshida et al., 1999; Verschuure et al., 2002). In skeletal muscle of symptomatic mouse models of Spinal and Bulbar Muscular Atrophy (SBMA), HSPB2 is upregulated (Rusmini et al., 2015). In the nervous system, HSPB2 has been detected in extracellular plaques and cerebral amyloid angiopathy in Alzheimer's disease (AD) patients (Wilhelmus et al., 2006c). In cells, HSPB2 localization was observed in nuclei, where it tends to form droplets in a concentration-dependent manner through a liquid-liquid phase separation (LLPS) process (Morelli et al., 2017b). The CTD of HSPB2 drives its LLPS since its deletion prevents the formation of HSPB2 nuclear foci. The enhancement of this process, which might be a consequence of HSPB2 overexpression but also of the loss of regulatory activity of HSPB2-partner HSPB3, results in the deregulation of chromatin distribution and in the loss of nuclear integrity (Morelli et al., 2017b). HSPB2 forms a 3:1 complex with HSPB3, which represents the building block for further selfinteractions (den Engelsman et al., 2009; Clark et al., 2018). HSPB3, by interacting with HSPB2, regulates its activities and interactions with other partners (Morelli et al., 2017a). Also, HSPB2 has been described to interact with HSPB6 (den Engelsman et al., 2009). Results on HSPB2 chaperone activity are controversial: in some studies HSPB2/HSPB3 complex was reported to exert no or mild anti-aggregation activity against substrates prone to fibrillization such as Amyloid $\beta$ (A $\beta)$ or mutated SNCA both in vitro and in cells (Wilhelmus et al., 2006b; Bruinsma et al., 2011), while other studies on HSPB2 
alone reported an effective chaperone activity (Prabhu et al., 2012; Minoia et al., 2014). Although this discrepancy might be related to the differences in the assays utilized, another explanation is that HSPB2 activity might be dependent on its oligomerization state with HSPB3 (Clark et al., 2018).

HSPB2 mutations have not been identified so far. Interestingly, by developing an HSPB5 $\mathrm{KO}$ mouse, given the proximity of the two genes, double $\mathrm{KO}$ (DKO) mice for HSPB5 and HSPB2 have been generated. These mice did not show developmental defects or alterations related to HSPB5 specific functions in eyes and HSPB2/HSPB5 activities in heart. Instead, muscle degeneration, loss of body weight, and severe postural defects were observed in these DKO aging mice (Brady et al., 2001). Subsequent studies revealed that, even if cardiac functions and development were unaffected, HSPB2/HSPB5 DKO mouse hearts showed increased cell death and defective recovery upon Ischemia/Reperfusion ( $\mathrm{I} / \mathrm{R})$ tests, likely related to the loss of protective function of the two HSPBs towards cytoskeletal contractile elements (Morrison et al., 2004; Golenhofen et al., 2006). Unfortunately, in these initial studies, it was not possible to discriminate if the phenotype observed was related to one or the other HSPBs, since both HSPBs are relevant in the maintenance of skeletal muscle. However, subsequent studies were able to dissect the different roles of the two neighbour genes in heart. Indeed, by comparing DKO mice with DKO animals that were genetically modified to re-express HSPB5, alterations in cardiac energetics have been observed and related to HSPB2 absence (Pinz et al., 2008). These alterations consisted in a faster rate of ATP loss during ischemia, a decreased energy recovery during reperfusion and an inefficient coupling of ATP hydrolysisderived free energy and work (Pinz et al., 2008). On the other hand, HSPB2 overexpression in cardiac tissue in mice associated with a reduction in the size of infarcted tissues after I/R (Grose et al., 2015). The involvement of HSPB2 in metabolism and mitochondrial energetics was additionally proven in a cardiacspecific HSPB2 KO mouse (Ishiwata et al., 2012). In support to the HSPB2 role in energetics, HSPB2 mitochondrial localization was reported to be enhanced after heat shock and cardiac-specific HSPB2 KO mouse model revealed an altered mitochondrial activity in response to stress (Nakagawa et al., 2001; Ishiwata et al., 2012).

\section{HSPB3}

HSPB3 gene was initially identified from a human heart cDNA library (Lam et al., 1996). The correct sequence of HSPB3 was subsequently defined by Boelens et al. (1998), who described the presence of the HSPB3 transcript in smooth muscle, heart and several foetal tissues. HSPB3, with a $\mathrm{MW}$ of $17 \mathrm{kDa}$, is the smallest HSPB. In vitro, HSPB3 is found either in trimers or in tetramers (Asthana et al., 2012). In cells, HSPB3 oligomerizes with HSPB2 forming a 1:3 stoichiometric complex (Sugiyama et al., 2000; den Engelsman et al., 2009). Notably, HSPB3 chaperone-like activity is moderate in vitro, and most of its functions concern its regulatory activity on HSPB2. For instance, HSPB3 oligomerization with HSPB2 negatively regulates HSPB2 interaction with BAG3 (Morelli et al., 2017a). HSPB3 also inhibits HSPB2 recruitment into nuclear foci (Morelli et al., 2017b). HSPB3 is mainly expressed in cardiac and skeletal muscle, but also in smooth muscle and nervous system. In $\mathrm{C} 2 \mathrm{C} 12$ myoblasts, like HSPB2, HSPB3 is expressed with differentiation (Sugiyama et al., 2000). Indeed, HSPB3 gene presents a MyoDresponsive region and $\mathrm{HSPB} 3$ overexpression induces myoblasts differentiation (Tiago et al., 2021). Instead, HSPB3 expression in the nervous system is moderate and varies during development. HSPB3 is found in glial cells, in MNs and in sensory neurons ( $\mathrm{La}$ Padula et al., 2016). HSPB3 localizes in the cytoplasm and associates to cytoskeletal components, e.g., actin bundles and NFs, but also mitochondrial membrane and nuclear envelope (La Padula et al., 2016; Tiago et al., 2021). HSPB3 is upregulated upon proteotoxic stress but not upon thermal stress. For instance, as HSPB2, HSPB3 is upregulated in skeletal muscle of a symptomatic mouse model of SBMA, supporting the specific role of these two HSPBs in muscle maintenance upon proteotoxicity (Rusmini et al., 2015).

HSPB3 mutations have been linked to neuropathies and myopathies. The first reported mutation consists in the substitution R7S identified in dHMNII (Kolb et al., 2010; Laššuthová et al., 2016). The HSPB3 R7 residue is well conserved among the HSPB3 orthologues but not among HSPBs, suggesting a functional role of the residue in HSPB3 activity (Kolb et al., 2010; Benndorf et al., 2014). However, the HSPB3 R7S mutation does not alter the HSPB2-HSPB3 heterodimerization, it has a mild impact on oligomerization and functional defects have not been described, yet (La Padula et al., 2016; Clark et al., 2018). Mutations located in the ACD of HSPB3 are the substitutions R116P and Y118H (Morelli et al., 2017b; Nam et al., 2018). The HSPB3 R116P mutation has been reported in a patient affected by myopathy with axonal neuropathy and in her father affected by mild neuromuscular symptoms (Morelli et al., 2017b). Analyses of the HSPB3 R116P patient muscle biopsies revealed a severe myofibrillar disorganization affecting the Z-disc, abnormal sarcoplasmic reticulum morphology, pluri-segmented nuclei, and intermyofibrillar glycogen accumulation (Morelli et al., 2017b). The HSPB3 R116 residue is conserved among HSPB3 orthologues and it has been postulated that it is topologically equivalent to the R140 residue in HSPB1 (Morelli et al., 2017b; Clark et al., 2018). In cells, the HSPB3 R116P mutant, by losing the ability to bind HSPB2, is not able to regulate the typical HSPB2 nucleuscytoplasm distribution and thus, associates to the abnormal HSPB2 nuclear LLPS (Morelli et al., 2017b). Another HSPB3 $\mathrm{R} 116 \mathrm{P}$ pathogenic mechanism relies on its intranuclear aggregation, which results in HSPB3 WT sequestration and deregulation of transcription processes (Morelli et al., 2017b; Tiago et al., 2021). Instead, the HSPB3 Y118H mutation has been described in one CMT patient with a family history of disease. Analysis of HSPB3 orthologues indicates that the Y118 residue has been conserved during evolution (Nam et al., 2018). Similar to R116P, also HSPB3 Y118H mutation is located at the dimerization surface of the ACD and might determine the loss of interaction with the HSPB2 partner (Morelli et al., 2017b; Nam et al., 2018). However, biochemical and functional studies on 
HSPB3 Y118H homo- and hetero-oligomerization and activity are still missing. The HSPB3 A33AfsX50 (L34Ffs ${ }^{\star 50}$ ) frameshift mutation has been identified in a 70-years-old patient affected by myopathy (Morelli et al., 2017b). Studies in cells revealed that this frameshift mutant, which causes a truncation of the HSPB3 protein, is unstable and rapidly subjected to proteasomal degradation. This results in the loss of regulatory activity on HSPB2, which eventually causes aberrant nuclear foci formation (Morelli et al., 2017b). Finally, from the analysis of a small cohort of CMT/dHMN patients, a novel variant of unknown significance, the HSPB3 L6F, has been recently identified in a patient affected by dHMNII (Yalcintepe et al., 2021). To our knowledge, animal models of HSPB3 mutants have not been developed.

\section{HSPB4 AND HSPB5}

HSPB4 and HSPB5 are highly expressed in lenses. Lens fibres are post-mitotic cells characterized by the absence of most of the light-scattering intracellular organelles, such as nuclei and mitochondria, to guarantee the lens transparency (Bassnett, 2009). The most abundant proteins in lens are $\alpha^{-}, \beta-, \gamma-$ crystallins and form the liquid-like structures of lenses. To maintain lens transparency, the a-crystallins HSPB4 and HSPB5, which represent one-third of total soluble proteins in lens, exert an anti-aggregating activity against proteins that could be damaged during aging (Horwitz, 1992; Andley, 2007). In lenses, HSPB4 and HSPB5 interact with cytoskeletal components: they prevent incorrect interactions of intermediate filaments, avoiding gel formation; they protect actin fibres against stress and participate in actin dynamics in lamellipodia in lens epithelial cells; they stabilize the microtubule network (Del Vecchio et al., 1984; Maddala and Rao, 2005; Xi et al., 2006). Also, HSPB4 and HSPB5 exert a pro-survival activity upon thermal and oxidative stresses or UV-light damage (Andley et al., 1998; Christopher et al., 2014). Indeed, HSPB4 and HSPB5 both abrogate UVA-induced apoptosis by activating the AKT pathway and suppressing the RAF-MEK-ERK pathway, respectively (Liu et al., 2004). Moreover, both HSPB4 and HSPB5 inhibit the pro-apoptotic proteins Bax, Bcl-Xs and caspase-3 (Andley, 2007). Interestingly, HSPB4 expression is confined in lenses and the protein is synthesized later in respect to HSPB5 during cell differentiation (Robinson and Overbeek, 1996). Instead, HSPB5 is also expressed in skeletal and cardiac muscle cells. In cardiac muscle, HSPB5 assures the correct folding of titin, a structural protein involved in muscle fibres integrity, and HSPB5 overexpression associates with less cardiac damage and better contractile functions (Golenhofen et al., 1999; Bullard et al., 2004). In skeletal muscle, HSPB5 expression increases with aging (Doran et al., 2007). HSPB5 is also expressed in the central nervous system and its expression increases during life. HSPB5 exerts an anti-aggregation activity toward different misfolded substrates, such as mutated SNCA, SOD1, and A $\beta$ (Waudby et al., 2010; Shammas et al., 2011; Yerbury et al., 2013; Cox and Ecroyd, 2017). HSPB5 neuroprotective function seems to be mediated by glial-related mechanisms (Bajramović et al., 2000; Ousman et al., 2007; Hagemann et al., 2009; Oliveira et al., 2016; Gorter et al., 2019; Hampton et al., 2020).

Mutations in HSPB4 and HSPB5 have been related to cataracts, myopathies, and cardiomyopathies, based on their tissue expression profile. Most of the mutations are autosomal dominant. As mentioned above, HSPB4 mutations strictly impact eye functions, ranging from more severe phenotypes affecting subjects at birth to less severe and late onset conditions. A rare example of HSPB4 mutation characterized by recessive inheritance is the nonsense mutation HSPB4 W9X, causing congenital cataracts. Indeed, the phenotype manifests only in homozygosis, suggesting that the WT allele is sufficient to compensate the loss of the mutated allele (Pras et al., 2000). HSPB4-deficient models partially resemble this phenotype. Indeed, HSPB4 KO mice do not manifest an obvious phenotype at birth, but, with aging, progressive lens opacity and the presence of inclusion bodies in lenses are observed. Interestingly, the full depletion of the HSPB4 protein associates with poor solubility of the HSPB5 partner and of other "crystallin" proteins, a feature not observed in the heterozygous mouse (Brady et al., 1997). Several HSPB4 mutations result in substitutions of arginine residues throughout the protein sequence. Similarly to HSPB1, most of HSPB4 missense mutations affect oligomerization, solubility, and aggregation properties (Mackay et al., 2003; Santhiya et al., 2006; Andley et al., 2008; Sun et al., 2011; Laurie et al., 2013; Yang et al., 2013; Khoshaman et al., 2017; Song et al., 2018). Of interest, a peculiar behaviour has been related to arginine-to-cysteine substitutions: indeed, in vitro biochemical studies demonstrated that HSPB4 R12C and R54C assemble into high MW oligomers or aggregates through the formation of disulphide bonds between monomers (Khoshaman et al., 2015; Khoshaman et al., 2017). Other HSPB4 mutations cluster at residues 116-119 (Clark et al., 2011). Even in this case, most of these HSPB4 mutants associate with an impairment in oligomerization and aggregation propensity (Litt et al., 1998; Li et al., 2010; Pang et al., 2010; Zhang et al., 2011). Interestingly, not only missense substitutions but also in-frame deletions of these hot-spot AA determine HSPB4 aggregation (Li et al., 2017). As a consequence of HSPB4 aggregation, activation of stress signalling pathways is observed. For instance, activation of the unfolded protein response (UPR) signalling in response to misfolded protein overload, autophagy impairments, and endoplasmic reticulum (ER) stress, were observed and correlated to an increased occurrence of apoptotic events (Andley et al., 2002; Li et al., 2017). Mouse models carrying HSPB4 mutations recapitulate well the human phenotype. For instance, HSPB4 decreased solubility and aggregation were observed in a Knock-in (KI) mouse model expressing the HSPB4 R49C mutation (Xi et al., 2008). Noteworthily, both the heterozygous and the homozygous mouse models showed lens opacity, more severe for the latter. Homozygous mice showed also severe microphthalmia, with halved lens weight. The pathogenic phenotype of the homozygous mice, unlike the heterozygous ones, was present at birth and might result from early defects during lens development at embryonic stages (Andley and Goldman, 
2016). Indeed, analyses on homozygous mouse lenses at embryonic stages and at birth showed severe morphological alteration, characterized by lens fibre cells disorganization, defective cell-cell interactions, and vacuoles formation (Xi et al., 2008; Andley and Goldman, 2016). Further investigations in mice carrying the HSPB4 R49C mutation revealed an impairment of the autophagic pathway, as shown by sequestosome1/p62 (SQSTM1/p62) accumulation and defective autophagosomes, and UPR pathway activation (Watson and Andley, 2010; Andley and Goldman, 2016). The HSPB4 R54H and R54C substitutions have been also detected in mice strains showing recessive congenital cataract (Chang et al., 1996; Chang et al., 1999; Xia et al., 2006). Another mutation, the HSPB4 Y118D substitution, has been obtained in two mouse models (Xia et al., 2006; Jia et al., 2021). Both HSPB4 Y118D mouse models recapitulate the phenotype and the biochemical and functional observations reported, which are the increased protein insolubility and UPR pathway activation in response to ER stress (Xia et al., 2006; Li et al., 2017; Jia et al., 2021). Mutations causing substantial modification of the CTD include the HSPB4 Q147Rfs ${ }^{\star} 48$ frameshift mutation or point mutations at the stop codon (Javadiyan et al., 2017; Marakhonov et al., 2020). The latter are the HSPB $4{ }^{\star} 174$ Qext $^{\star} 41$ and ${ }^{\star} 174$ Sext ${ }^{\star} 41$ de novo mutations, reported in patients suffering from congenital aphakia, a developmental condition characterized by lens absence, microphthalmia, microcornea, and iris hypoplasia/aniridia (Marakhonov et al., 2020). These two mutations, falling in the stop codon of the HSPB4 gene, cause the abrogation of the translation termination and the production of an elongated protein. The pathogenic mechanisms at the basis of these mutations have not been investigated, but it has been suggested that the presence of the aberrant C-terminal extensions impact on HSPB4 solubility and chaperone function, abolishing its cytoprotective activities (Marakhonov et al., 2020). Given the role of HSPB4 in lenses, HSPB4 polymorphisms have been identified at the promoter or untranslated regions of the HSPB4 gene in association with milder pathogenic conditions such as age-related cataract and macular degeneration, but the pathogenicity remains uncertain (Ma et al., 2016; Xu et al., 2019; Hongtao Yu et al., 2021).

Similarly to HSPB4, several mutations of HSPB5 have been identified in congenital cataracts and most of these mutations associate with increased aggregation propensity (Li et al., 2008; Raju and Abraham, 2013; Ghahramani et al., 2020). As observed for HSPB4, several of these HSPB5 mutations consist in arginine substitutions, which affect HSPB5 homo- and heterooligomerization and chaperone activity (Raju and Abraham, 2013; Ghahramani et al., 2020; Muranova et al., 2020). Aggregation is also a feature of HSPB5 mutants linked to myopathies, cardiomyopathies or more severe multisystem disorders (Vicart et al., 1998; Inagaki et al., 2006; Reilich et al., 2010; Brodehl et al., 2017; Fichna et al., 2017). Aggregation has been also observed in HSPB5 mutations at residues R120 and D109, which are considered to mediate HSPB dimerization, by forming a salt bridge (Simon et al., 2007b; Michiel et al., 2009; Clark et al., 2011). HSPB5 R120G substitution was the first HSPB mutation to be linked to a neuromuscular disease and thus it has been deeply characterized (Vicart et al., 1998). Indeed, HSPB5 R120G cytoplasmic aggregates have been detected in several cell models, localizing at the perinuclear region in aggresomal structures positive for amyloid oligomers (Vicart et al., 1998; Chávez Zobel et al., 2003; Sanbe et al., 2004; Inagaki et al., 2006; Nivon et al., 2016; Brodehl et al., 2017). TG mice overexpressing the HSPB5 R120G mutation specifically in heart showed a 100\% mortality at adult age due to cardiac hypertrophy and dysfunction. In agreement with cell studies, the HSPB5 R120G has been found in aggregates together with desmin, a musclespecific intermediate filament, in mouse hearts (Wang et al., 2001). Beside HSPB5 R120G effect on structural proteins, other functional alterations were observed, including aberrant mitochondrial activity, ER stress, calcium homeostasis dysregulation, and apoptosis, likely related to HSPB5 aggregation-mediated proteotoxicity (Maloyan et al., 2005; Jiao et al., 2014; Alam et al., 2020). Indeed, proteostasis impairment characterized both TG mice and cells overexpressing the HSPB5 R120G mutant, as supported by an increase in ubiquitinated proteins and defective delivery of substrates to the UPS (Chen et al., 2005). Interestingly, an increase of the autophagic flux was also described, which might represent a compensatory mechanism to counteract the misfolded protein overload (Tannous et al., 2008). Indeed, autophagic inhibition both in cells and in vivo resulted in a worsening of HSPB5 R120G phenotype, while its potentiation favoured HSPB5 aggregates removal (Tannous et al., 2008; Pattison et al., 2011). Conversely, HSPB5 deficiency or complete loss of function associate to multisystem disorders in which eye lenses and skeletal and heart muscles might also be affected. This is the case of homozygous HSPB5 M1X and S21Afs ${ }^{\star} 24$ mutations, linked to infantile hypertonic myofibrillar myopathy (MFM), a severe and rare form of myopathy, often accompanied by cardiomyopathy and cataracts (Del Bigio et al., 2011; Ma et al., 2019; Lu et al., 2021). The HSPB5 M1X mutation determines the loss of the ATG starting codon and it likely associates with loss of HSPB5 protein. As mentioned, HSPB5/ HSPB2 DKO mice are vital and do not display lens or cardiac alterations (Brady et al., 2001). The HSPB5 S21Afs ${ }^{\star} 24$ mutation is predicted to cause the production of a short protein product, carrying only the first 21 AA of HSPB5 NTD, while a completely different C-terminus of 44 AA. This HSPB5 frameshift mutant seems to be still expressed, although it is thought that mRNA decay affects its expression. Indeed, HSPB5 frameshift mutant immunoreactivity has been observed in inclusions positive for myosin, myoglobin, and desmin in patients muscle specimens (Del Bigio et al., 2011). Very similar observations have been made for the HSPB5 S115Pfs ${ }^{\star} 14$ frameshift mutant identified in infantile MFM (Forrest et al., 2011). Also in this case, HSPB5 mutant abnormal distribution was observed in the patient muscle biopsies, although its protein levels were decreased in respect to the HSPB5 WT in samples from a healthy subject (Forrest et al., 2011). The molecular mechanism underlying HSPB5 S115Pfs ${ }^{\star} 14$ mutant pathogenicity was deeply investigated using patientderived induced Pluripotent Stem Cells (iPSCs), showing that iPSC-derived skeletal myotubes and cardiomyocytes are devoid of the mutated HSPB5 protein product, despite the presence of its 
related mRNA transcript (Mitzelfelt et al., 2016). Interestingly, the lack of the HSPB5 mutant protein apparently was not the result of miRNA targeting, defective translation, or disposal through the degradative systems, while, when the HSPB5 S115Pfs ${ }^{\star} 14$ mutant was overexpressed, its aggregation was observed (Mitzelfelt et al., 2016). Similarly, other truncated or frameshift mutants of HSPB5 have been found in the insoluble protein fractions and were prone to aggregate when overexpressed in cell models (Berry et al., 2001; Selcen and Engel, 2003; Simon et al., 2007a; Hayes et al., 2008; Zhang et al., 2010; Bortolani et al., 2020). Finally, falling at the very CTD end, mutations causing the abrogation of the stop codon with the formation of an elongated C-terminus have been described. These include the HSPB5 A172Pfs ${ }^{\star} 14$, linked to a multisystem syndrome, consisting of congenital cataract, hypotonia and a slight delay in motor skills acquisition without cognitive impairments, and HSPB5 X176Wext ${ }^{\star} 19$, linked to cataracts and DCM (Marcos et al., 2020; Yinhui Yu et al., 2021). It is not yet known which are the functional consequences of the HSPB5 A172Pfs ${ }^{\star} 14$ CTD modification, but, the presence of non-polar $\mathrm{AA}$ and the absence of the charged ones suggest a strong impact on protein solubility and functionality (Marcos et al., 2020). Similarly, the elongated tract at the CTD of HSPB5 X176Wext ${ }^{\star} 19$ has been predicted to cause HSPB5 CTD folding in a new $\alpha$-helix and random-coil structure and its aggregation has been observed in cardiomyocytes from patients-explanted heart (van der Smagt et al., 2014; Yinhui Yu et al., 2021).

\section{HSPB6}

HSPB6 is a cytoplasmic protein of $17 \mathrm{kDa}$ constitutively expressed in a wide variety of tissues, but predominantly in smooth, cardiac and skeletal muscle (Kato et al., 1994; Brophy et al., 1999; Fan and Kranias, 2011). HSPB6 mainly forms homodimers and tetramers in solution (van de Klundert et al., 1998; Bukach et al., 2004; Weeks et al., 2014; Delbecq et al., 2015). In vitro, HSPB6 has been found to interact with HSPB5, HSPB1 and HSPB7 (Bukach et al., 2009; Heirbaut et al., 2016; Heirbaut et al., 2017; Mymrikov et al., 2020; Shatov et al., 2020; Muranova et al., 2021). HSPB6 can also bind the co-chaperone BAG3 (Fuchs et al., 2009; Shemetov and Gusev, 2011; Morelli et al., 2017a; Rauch et al., 2017). HSPB6 possesses a RRXS motif in its NTD, which represents a consensus motif for the protein kinases PKA, PKG and PKD1. Indeed, HSPB6 serine-16 (S16) phosphorylation modulates protein-protein interaction and enhances its activity (Beall et al., 1999; Rembold et al., 2000; Sin and Baillie, 2015). For instance, it has been shown that phosphorylation promotes HSPB6 oligomers disassembly (Brophy et al., 1999), increases its interaction with $A \beta$, thus reducing or preventing $A \beta$-related toxicity (Cameron et al., 2014), and potentiates its antiapoptotic activity (Edwards et al., 2012). However, the major role of phosphorylated HSPB6 is related to cytoskeletal dynamics during muscle relaxation. Additionally, HSPB6 can undergo acetylation at lysine residues of its CTD (e.g., Lys160), which is reversed by KDAC8/HDAC8 activity (Chen et al., 2013). Both phosphorylation and acetylation are thought to mediate smooth muscle relaxation, as reported in studies conducted in airway and myometrial smooth muscles cells (Komalavilas et al., 2008; Tyson et al., 2008; Ba et al., 2009; Karolczak-Bayatti et al., 2011; Chen et al., 2013). It has been shown that HSPB6 acetylation and phosphorylation can occur together in response to increased PKA activity (Karolczak-Bayatti et al., 2011). Upon phosphorylation, HSPB6 is able to interact with the 14-3-3 protein, releasing the actin-binding protein cofilin, which, once dephosphorylated, favours actin depolymerization, thus muscle cells relaxation (Karolczak-Bayatti et al., 2011). However, given the weak interaction between 14-3-3 protein and cofilin, it is likely that other factors participate in cofilin dephosphorylation and depolymerizing activity (Sudnitsyna et al., 2012). Other mechanisms hypothesized to mediate muscle cell relaxation suggest that phosphorylated HSPB6 can directly inhibit myosin binding to actin filaments, as supported by the presence of a short motif highly homologous to troponin I inhibitory region in HSPB6 sequence (Rembold et al., 2000; Ba et al., 2009). However, in vitro analyses demonstrated that HSPB6 is unable to directly bind actin fibres (Bukach et al., 2005). Beside its role in smooth muscle relaxation, an HSPB6 protective activity is observed in cardiac cells. For instance, HSPB6 overexpression in rat cardiomyocytes determined an increase in cell viability and HSPB6 cardiac-specific TG mice showed an enhanced functional recovery and attenuated cardiac damage after I/R (Fan et al., 2005; Islamovic et al., 2007). Cardioprotection seems to rely on HSPB6 antiapoptotic activity in inhibiting pro-apoptotic factor Bax translocation to mitochondria and subsequent caspase- 3 activation (Fan et al., 2005). Also in this case, phosphorylation promotes HSPB6 activity, since a phosphomimic HSPB6 mutant (S16D) increases the protection against apoptosis, while the phospho-null S16A mutant shows an attenuated protective activity (Fan et al., 2004; Qian et al., 2009). HSPB6 displays another cardiovascular protective activity, that relies on its secretion from cells. Indeed, plasma HSPB6, secreted within exosomes by cardiomyocytes and artery walls, can inhibit thrombin-mediated platelet aggregation by blocking calcium influx and favours angiogenesis (Niwa et al., 2000; Kozawa et al., 2002; McLemore et al., 2004; Zhang et al., 2012). The role of HSPB6 in the nervous system has also been investigated. HSPB6 mRNA and protein have been detected in the nervous system, and HSPB6 expression increases both during development and upon oxidative or hyperosmotic stress (Verschuure et al., 2003; Bartelt-Kirbach and Golenhofen, 2014). Similarly to other HSPBs, HSPB6 exerts an antiaggregant activity towards several misfolded and aggregating proteins, such as SNCA and $A \beta$, and it is found associated to AD plaques (Lee et al., 2005; Wilhelmus et al., 2006b; Bruinsma et al., 2011; Cameron et al., 2014). HSPB6 has been found in astrocytes of preactive and active lesions in autoptic samples from patients affected by X-linked adrenoleukodystrophy (Görtz et al., 2018) and in active lesion of subjects affected by Multiple Sclerosis (Peferoen et al., 2015). Of note, HSPB6 immunoreactivity has been described specifically in astrocytes surrounding areas of tissue damage in the lateral tracts of ALS patients, while no differences in HSPB6 staining 
were observed in neuronal cells of the spinal cord between patients and healthy subjects (Gorter et al., 2019). Although these observations suggest that HSPB6 exerts a role in the nervous system, such as the other HSPBs, its activity in neuronal cells is not well defined. In vitro studies evidenced its ability to interact with NF and to inhibit their oligomerization, but with a weaker activity in respect to other HSPBs (Nefedova et al., 2017). Neuroprotection was also investigated in epilepsy: upon pharmacologically induced seizures, rats showed HSPB6 upregulation and phosphorylation in the hippocampal neurons in concert with PKA pathway activation, while abrogation of PKA pathway resulted in increased apoptosis and pro-inflammatory factors (Qi et al., 2019).

Two mutations in HSPB6 have been reported in patients affected by DCM (Nicolaou et al., 2008; Liu et al., 2018a). HSPB6 P20L substitution has been described as a rare variant both in cardiomyopathy patients and in healthy subjects (Nicolaou et al., 2008). Nevertheless, rat cardiomyocytes overexpressing the HSPB6 WT or the P20L variant showed neither differences in HSPB6 protein levels nor variations in apoptosis in physiological conditions. However, when cells were challenged through I/R simulated conditions, the antiapoptotic activity of HSPB6 was completely abolished (Nicolaou et al., 2008). The S10F HSPB6 mutant has been extensively studied in a cardiac-selective TG mouse model (Liu et al., 2018b); these mice, with aging, displayed a pathologic phenotype with deterioration of cardiac functionality, progressive cardiac dilation and fibrosis, resulting in a halved life span. TG HSPB6 S10F mice cardiomyocytes displayed increased apoptotic events correlated to increased caspase-3 activation. Of note, TG HSPB6 S10F mice cardiomyocytes were characterized by a decreased autophagic flux, as demonstrated by a lesser conversion of the autophagic adaptor LC3-I to II and diminished levels of the autophagy regulator beclin-1. Notably, while HSPB6 WT can interact with beclin-1, displacing the beclin-1 suppressor Bcl-2, thus promoting autophagy, the HSPB6 S10F mutant loses this ability and favours beclin-1 ubiquitination and proteasomal degradation. In TG mice, beclin-1 instability ultimately resulted in loss of autophagic power and increased apoptosis, while its exogenous overexpression reverted the phenotype (Liu et al., 2018b). Noteworthily, cardiac phenotypes and molecular alterations have been observed only in TG HSPB6 S10F male mice, while minor changes affected the females under unstressed conditions, suggesting that HSPB6 S10F pathogenicity is subjected to gender differences (Liu et al., 2018a). Additional studies revealed that female TG HSPB6 S10F mice were unable to cope with pregnancy-associated cardiac stress. This resulted in cardiac dysfunction and remodelling and decreased survival after pregnancy, suggesting that HSPB6 S10F mutation carriers might be subjected to develop peripartum cardiomyopathy (Liu et al., 2018a). Structural analyses conducted in vitro showed that the HSPB6 P20L substitution affects the structure of HSPB6, by decreasing the $\beta$-sheet content toward an increase in $\alpha$-helical or unordered structures (Nicolaou et al., 2008). Both HSPB6 P20L and S10F mutants were less resistant to heat-induced denaturation and aggregation, and more prone to oligomerization under crowded environment compared to the
HSPB6 WT (Shatov and Gusev, 2020). Instead, no differences in HSPB6 hetero-oligomerization with HSPB1 and HSPB5 were observed (Shatov and Gusev, 2020). Finally, while the S10F mutant did not show variation in phosphorylation typical of the HSPB6 WT, the P20L mutant was characterized by an increased phosphorylation rate (Shatov and Gusev, 2020).

\section{HSPB7}

HSPB7 is a $19 \mathrm{kDa}$ protein also known as cardiovascular HSP (cvHSP) (Krief et al., 1999). Three isoforms have been described as a result of mRNA alternative splicing: isoforms 1 and 2 correspond to two proteins of 170 and $175 \mathrm{AA}$, respectively, which differ for the presence of a AHPTA pentapeptide in the NTD; isoform 3 corresponds to a 68 AA-long protein (Krief et al., 1999). Beside the ACD, HSPB7 possesses a serine-rich stretch at position 17-29 in the NTD (Wu et al., 2019). Studies on HSPB7 homo- and hetero-interactions are conflicting (Golenhofen et al., 2004; Vos et al., 2010; Yang et al., 2011; Lin et al., 2014; Mymrikov et al., 2017). More recent in vitro evidence showed that HSPB7 forms mainly $600 \mathrm{kDa}$ large oligomers and a small fraction of $36 \mathrm{kDa}$ oligomers, and that the equilibrium between the two oligomeric states can be influenced by oxidation (Muranova et al., 2021). Indeed, HSPB7, like HSPB1, possesses a cysteine residue (C126) in the ACD, responsible of disulphide-crosslinked dimers formation and shifting of the oligomeric state towards large oligomers formation, upon mild oxidative conditions (Muranova et al., 2021). HSPB7 oligomerization is also affected by the NTD, since its deletion associates with smallsize oligomers (Muranova et al., 2021). HSPB7 heterooligomerization has been described with HSPB6 and HSPB8 (Sun et al., 2004; Muranova et al., 2021). The interaction of HSPB7 with BAG3 is still controversial, but most studies support that HSPB7 is not a BAG3 partner and that its activities are BAG3-independent (Vos et al., 2010; Morelli et al., 2017a; Esslinger et al., 2017; Fang et al., 2019). Interestingly, the NTD of HSPB7 drives its localization into SC35 nuclear speckles (nuclear structures enriched in pre-mRNA and factors involved in splicing) where it appears to be a resident protein, but with unknown functions rather than substrates chaperoning (Vos et al., 2009). Moreover, the HSPB7 NTD mediates the HSPB7 anti-aggregating and pro-degradative activities against misfolded proteins involved in neurodegenerative diseases (NDs) via autophagy (Vos et al., 2010; Minoia et al., 2014; Wu et al., 2019). However, HSPB7 function seems not to be fundamental in NDs since its expression in the nervous system is physiologically low. Notably, even if HSPB7 mRNA has been detected in most tissues, HSPB7 protein has been observed only in myogenic tissues, such as in heart where its mRNA accounts for the $0.3 \%$ of total mRNA, but also in skeletal muscle and adipose tissue (Krief et al., 1999). In myogenic tissues, HSPB7 exerts a surveillance function on the cytoskeleton, by interacting with structural components, such as actin, filamin C and titin (Juo et al., 2016; Liao et al., 2017; Wu et al., 2017; Mercer et al., 2018). It has been postulated that HSPB7 might be considered a pathobiochemical indicator of muscle damage in dystrophinopathy. 
Indeed, mouse models of X-linked muscular dystrophy show higher levels of HSPB7 in respect to controls, which increase with aging, correlating with muscle degeneration. The increase of HSPB7 is thought to be a protective response to muscle fibres disintegration, in order to counteract the accumulation of damaged substrates and favour cytoskeletal repair (Doran et al., 2006; Doran et al., 2009; Lewis et al., 2009). HSPB7 upregulation, together with other HSPBs, has been also observed in skeletal muscle fibres of aging rats, in respect to young controls, supporting again a physiological role of HSPB7 in muscle structural maintenance and suggesting that strategies to induce its expression might be relevant to counteract agingassociated sarcopenia (Doran et al., 2007). HSPB7 has been also indicated as a candidate gene involved in heart development and cardiac failure (Villard et al., 2011; Aung et al., 2019). GWAS and EWAS defined HSPB7 gene locus as a risk factor to develop DCM or heart failure (Cappola et al., 2010; Stark et al., 2010; Villard et al., 2011; Garnier et al., 2015; Wang et al., 2016; Esslinger et al., 2017; Garnier et al., 2021). HSPB7 has also been detected in plasma, with HSPB7 plasmatic concentrations apparently higher in subjects and mouse models of myocardial infarction from 3 up to $24 \mathrm{~h}$ after the onset of symptoms (Chiu et al., 2012). HSPB7 plasma levels increase has been also described in early stages of heart failure in mouse models, suggesting that HSPB7 could be an early biomarker of heart damage (Rüdebusch et al., 2017). Also, HSPB7 variants have been found in sporadic cardiomyopathy (Matkovich et al., 2010). Recently, a single nucleotide polymorphism has been associated with obesity and higher fat intake, suggesting other mechanisms through which HSPB7 might be involved in cardiovascular disorders (Pavlová et al., 2018). Nevertheless, all the variants identified so far in humans are single nucleotide polymorphisms located in non-coding regions of the HSPB7 gene or are synonym mutations, causing no changes in the HSPB7 protein sequence, thus into its structure (Matkovich et al., 2010). Although HSPB7 mutations have not yet been identified in humans, a missense mutation has been recently described in cattle and associated with heat tolerance, whereas animal models mimicking HSPB7 deficiency have been generated to rule out the functions of HSPB7 in development and tissues maintenance (Zeng et al., 2019). These studies unravelled a dual role of HSPB7 in muscle development and maintenance, which agrees with the dynamic changes in HSPB7 localization in cells, mainly in mice cardiomyocytes, from early stages of embryonic life through adulthood (Liao et al., 2017; Wu et al., 2017). For instance, HSPB7 Knock-down (KD) in Zebrafish impacts on the development of left-right asymmetry of the heart, leading to morphologic defects (Lahvic et al., 2013; Rosenfeld et al., 2013). Consistent with the role of HSPB7 in development, both global and cardiac-selective $\mathrm{KO}$ in mice are lethal at the embryonic stage, with embryos characterized by smaller hearts, thinner left ventricular walls and features indicative of heart failure. Analyses of cardiomyocytes in HSPB7 KO mice revealed sarcomere disorganization, with longer thin filaments and the formation of abnormal actin filaments bundles containing Z-line components, such as $\alpha$-actinin, but devoid of contractile components (Liao et al., 2017; Wu et al., 2017; Mercer et al.,
2018). On the other hand, animal models from other studies allowed to investigate the role of HSPB7 in adult cells. Indeed, a HSPB7 KD Zebrafish model did not show severe developmental defects, but adult fish were affected by mild cardiac pathology with cardiomegaly and a higher rate of mortality upon exercise (Mercer et al., 2018). Consistently, HSPB7 conditional KO in mice determined cardiomyopathy and sudden death from arrythmia, which seem related to intercalated discs disruption, sarcomeres defective organization and filamin C aggregates observed in cardiac tissue (Liao et al., 2017). Filamin C aggregation has been observed in skeletal muscle-specific $\mathrm{KO}$ mice which developed a progressive myopathy phenotype, with loss of muscle fibres, defects in muscle morphology and increased mortality (Juo et al., 2016). Conversely, HSPB7 depletion in skeletal muscle cells indicated that HSPB7 is apparently not required during embryonic development (Juo et al., 2016). Finally, HSPB7 is expressed in adipocytes where it may have a role during differentiation (Imran et al., 2017; Jin et al., 2020; Rahman and Kim, 2020).

\section{HSPB8}

HSPB8 is a $22 \mathrm{kDa}$ protein ubiquitously expressed, especially in cardiac and skeletal muscles. Although HSPB8 interaction with the others HSPBs has been reported, it is found mainly as a monomer and homodimer, interacting with the co-chaperone BAG3, with whom it forms a 2:1 stoichiometric complex through two BAG3 Isoleucine-Proline-Valine (IPV) domains (Kim et al., 2004; Sun et al., 2004; Fontaine et al., 2005; Fuchs et al., 2009; Shatov et al., 2021). The dependency of HSPB8 on BAG3 is supported not only by the fact that HSPB8 stability depends on BAG3 interaction, but also because HSPB8 has the highest affinity to BAG3 in respect to other BAG3-binding HSPBs (Carra et al., 2008a; Morelli et al., 2017a). In concert with BAG3, HSPB8 takes part in the Chaperone-Assisted Selective Autophagy (CASA), a selective autophagy pathway that mediates the removal of damaged and misfolded substrates (Carra et al., 2008b; Arndt et al., 2010). The CASA is mediated by a heteromeric complex formed by the associated proteins HSPB8 and BAG3 bound to the chaperone HSP70/HSPA and the E3 ubiquitin ligase carboxyterminus of HSC70 interacting protein (CHIP/STUB1). HSPB8 activity consists in the recognition of substrates, and, by contacting BAG3, it helps in the HSP70/HSPA-driven refolding process of the substrate or in its degradation through autophagy (Gamerdinger et al., 2009; Gamerdinger et al., 2011; Rusmini et al., 2017). The role of BAG3 and HSPB8 interaction in the removal of misfolded proteins through autophagy was firstly observed in cells overexpressing proteins with elongated polyQ tracts, such as polyQ-HTT (Carra et al., 2008a). However, the first description of CASA complex composition and activity was reported in skeletal muscle cells by Arndt et al. (2010), who demonstrated the importance of the CASA complex in favouring the disposal of damaged components of the Z-disc structures, such as filamin, in response to its tension-induced unfolding upon mechanical stress (Ulbricht et al., 2013). CASA activity has been also demonstrated to be very efficient against mutated or 
aberrant protein products prone to misfold and found in inclusions in several NDs (Carra et al., 2005; Wilhelmus et al., 2006a; Carra et al., 2008a; Carra et al., 2008b; Crippa et al., 2010; Rusmini et al., 2013; Crippa et al., 2016; Cao et al., 2017; Cicardi et al., 2018; Cristofani et al., 2018; Cicardi et al., 2019). HSPB8 roles in cell homeostasis also comprise granulostasis, which is the process of stress granules (SGs) quality control in their composition and dynamics. In this context, HSPB8 is recruited to SGs where it acts as holdase, by preventing the irreversible aggregation of misfolded substrates and defective ribosomal products into SGs, and recruits BAG3-HSP70/HSPA machinery, for subsequent substrates disposal (Ganassi et al., 2016; Mateju et al., 2017). Also, HSPB8 promotes eukaryotic initiation factor-2a (eIF2 $\alpha$ ) phosphorylation to shut down translation of unnecessary proteins upon proteotoxicity (Carra et al., 2009). Recently, it has been shown that HSPB8 and BAG3 participate in the cytosolic unfolded protein response (cUPR), an integrated stress response pathway that mediates protein translation shutdown and degradation in response to proteotoxicity, acting on eIF2 $\alpha$ kinase heme-regulated inhibitor (HRI) and eIF2a (Abdel-Nour et al., 2019; Mukherjee et al., 2021). HSPB8 is induced by different cell stresses that share the proteostasis-challenging feature, such as degradative systems blockade, but also sodium-arsenite, oxidative and osmotic stresses (Yew et al., 2005; Wilhelmus et al., 2006a; Bartelt-Kirbach and Golenhofen, 2014). Beside proteotoxic stress response, HSPB8 and BAG3 play an active role in cell division, by assuring actin structures homeostasis and dynamics during mitosis and cytokinesis (Fuchs et al., 2015; Varlet et al., 2017).

HSPB8 mutations are causative of dHMNs, CMT2 and myopathies, characterized by high variability in onset and progression. Noteworthily, BAG3 mutations are also associated with similar, even if often more severe, phenotypes (Selcen et al., 2009; Jaffer et al., 2012; Lee et al., 2012; Semmler et al., 2014; Kostera-Pruszczyk et al., 2015; Meister-Broekema et al., 2018; Shy et al., 2018). The most frequent encountered HSPB8 mutation consists in the substitution of the conserved lysine141 residue (K141E/N/T/M) (Irobi et al., 2004; Tang et al., 2005; Nakhro et al., 2013; Echaniz-Laguna et al., 2017a). HSPB8 K141 mutations have been mainly described in patients suffering from neuropathy, but myopathy with neurogenic involvement has been also linked to K141E mutation (Ghaoui et al., 2016). This conserved residue falls in the ACD, suggesting a role in dimerization. Noteworthily, HSPB8 K141E/N are not only still able to dimerize but also show an increased interaction with the HSPB8 WT (Fontaine et al., 2006). Instead, data on HSPB8 K141 mutants interaction with BAG3 are controversial, with some reports showing no changes in interaction, while others a decreased or increased interaction (Crippa et al., 2010; Shemetov and Gusev, 2011; Echaniz-Laguna et al., 2017a). Nevertheless, functional analyses in vitro and in cells showed a loss of chaperone activity and pro-degradative function of HSPB8 $\mathrm{K} 141 \mathrm{E} / \mathrm{N}$ toward certain protein models and misfolded substrates of CASA complex (Carra et al., 2005; Kim et al., 2006; Crippa et al., 2010). HSPB8 K141E/N loss of activity might be related to its own aggregation (Irobi et al., 2004; Irobi et al., 2012; Sanbe et al., 2013; Yang et al., 2017). HSPB8 K141E/N mutations have been extensively studied in patient biopsies, cells, and animal models. A first observation is that MNs are the primary target of HSPB8 K141E/N mutations as only primary MNs and N2a cell models show important neurite degeneration, while primary sensory neurons are only mildly affected and primary cortical neurons do not show signs of neurodegeneration (Irobi et al., 2010). Animal models recapitulate quite well the human phenotype. For instance, homozygous KI mice overexpressing HSPB8 K141N mutant showed MN pathology with progressive axonal degeneration and muscle atrophy, abnormal and degenerating organelles and accumulating mitochondria, which suggest an impaired autophagic flux. Indeed, sciatic nerve of presymptomatic mice showed low autophagy potential while postsymptomatic mice displayed HSPB8 aggregation. Moreover, homozygous KI mice manifested MFM signs with Z-disc disorganization, likely independent from the neuronal pathology, and characterized by aggregating HSPB8, HSPB5, desmin, and by the presence of rimmed vacuoles. Instead, the heterozygous model did not display signs of $\mathrm{MNs}$ or muscle dysfunction, but accumulating abnormal mitochondria were observed in muscle (Bouhy et al., 2018). Fly models overexpressing the HSPB8 ortholog Hsp67Bc carrying the $\mathrm{R} 126 \mathrm{E}$ or R126N mutations, which correspond to human HSPB8 K141E or K141N mutants, showed normal muscle performance, but had histopathological hallmarks of muscle dysfunction, such as myofibrillar disorganization (Carra et al., 2010; Jabłońska et al., 2018). Mitochondria abnormalities observed in mice, fly models and patient fibroblasts, suggest that these organelles are a target of HSPB8 mutant-mediated cytotoxicity (Irobi et al., 2012). Of note, HSPB8 exerts a protective activity upon oxidative stress by inhibiting ROS formation and mitochondrial apoptotic pathway, while HSPB8 K141N mutant expression associates with higher ROS levels and reduced response to oxidative stress (Jo et al., 2017; Yang et al., 2017; Yu et al., 2019). In addition, HSPB8-BAG3 complex regulates the antioxidant axis of Kelch-like ECH-associated protein 1-nuclear factor (erythroid-derived 2)-like 2, Keap1-Nrf2. For instance, cells expressing HSPB8 K141N mutant showed impaired Nrf2 nuclear translocation which was reverted by antioxidants, and similar alterations have been observed in cells expressing the myopathy-related BAG3 P209L mutant (Yang et al., 2017; Guilbert et al., 2018). HSPB8 is also involved in RNA metabolism: HSPB8 can bind the RNA helicase DDX20, which is a component of Survival Motor Neuron (SMN) and small nuclear ribonucleoproteins (snRNP) complexes, and HSPB8 K141 mutants show alteration of DDX20 binding (Sun et al., 2010). Moreover, a deregulation in the RNA binding protein (RBP) TDP-43 activity has been observed in dHMN and MFM patients carrying the K141E mutation; in particular, alteration of splicing of TDP-43 target genes and decreased mRNA levels of TDP-43 correlating to HSPB8 aggregation were observed in patients muscles (Cortese et al., 2018). In summary, mutations in HSPB8 K141 hotspot are characterized both by a loss of protective function, and by a likely gain of toxic function. Recently, four different frameshift mutations have been linked to autosomal dominant myopathies: the HSPB8 P173Sfs ${ }^{\star} 43$, T176Wfs ${ }^{\star} 38, \mathrm{Q} 170 G f s^{\star} 45$ and $\mathrm{T}^{2}$ 194Sfs ${ }^{\star} 23$ (Echaniz-Laguna 
et al., 2017b; Al-Tahan et al., 2019; Nicolau et al., 2020; InoueShibui et al., 2021). Although these mutations are often causative of primary myopathies, neurogenic involvement can be observed (Ghaoui et al., 2016). Histopathological features associated with the Q170Gfs ${ }^{\star} 45$ mutation consist in signs of MFM with protein aggregates formed by structural components such as desmin, dystrophin, myotilin and members of the proteostasis network, such as HSPB8 itself, BAG3, HSPB5, ubiquitin, but also TDP-43, and rimmed vacuoles (Echaniz-Laguna et al., 2017b). Similar histopathological signs were observed in T194Sfs ${ }^{\star} 23$ mutation carriers, with myofibrillar aggregates and rimmed vacuoles (Nicolau et al., 2020). Strikingly, all these frameshift mutations fall in the CTD of HSPB8 and cause the production of HSPB8 proteins with a variably modified CTD and a common extended C-terminal tail, resulting from the use of an alternative downstream stop codon. Evaluation of the extended C-terminal tail by in silico tools revealed a decreased solubility and an increased aggregation propensity of a tract corresponding to the ILV tripeptide, which resembles the I/V-X-I/V domain shared by several HSPBs, but not present in HSPB8 (Inoue-Shibui et al., 2021). Interestingly, previous biochemical studies investigating $\mathrm{HSPBs}$ interaction with BAG3 showed that the introduction of the CTD of HSPB1, which presents a I/V-X-I/ $\mathrm{V}$ motif, into HSPB8, decreased HSPB8 solubility, suggesting a deleterious effect of $\mathrm{I} / \mathrm{V}-\mathrm{X}-\mathrm{I} / \mathrm{V}$ motif-like sequence on HSPB8 dynamics (Fuchs et al., 2009). In addition, I/V-X-I/V motif mutations in HSPB1, and similarly in BAG3, are linked to neuromyopathies, strengthening the idea of a role of the new ILV motif in HSPB8 frameshift mutants-related diseases (Selcen et al., 2009; Jaffer et al., 2012; Semmler et al., 2014; Shy et al., 2018; Adriaenssens et al., 2020). However, the effects of the novel HSPB8 frameshift mutations are not yet clear. It has been suggested that HSPB8 frameshift mutations cause HSPB8 haploinsufficiency, since no extended HSPB8 species have been detected and halved HSPB8 protein levels were observed; this is likely related to a rapid degradation of mutant HSPB8, which has been reported in muscle and fibroblast cells (EchanizLaguna et al., 2017b). Noteworthily, HSPB8 KO mice do not manifest any myopathic phenotype, suggesting that a simple loss of function of HSPB8 frameshift mutants is not sufficient to induce muscle diseases (Bouhy et al., 2018). Indeed, it is likely that HSPB8 frameshift mutants cause an impairment in CASA pathway which determines an insufficient clearance of aggregates, as suggested by the accumulation of the autophagic markers LC3 and SQSTM1/p62 in patient fibroblasts; alternatively, it is possible that HSPB8 mutants are prone to form aggregates themselves (Al-Tahan et al., 2019). Moreover, impairments of RNA metabolism and SGs formation are suggested as other pathological mechanisms of HSPB8 frameshift mutations. Indeed, HSPB8 T194Sfs ${ }^{\star} 23$ mutation was associated with abnormal punctate distribution of TIA-1, a component of SGs (Nicolau et al., 2020). Interestingly, HSPB8 mutations have not been correlated with cardiomyopathies, unlike BAG3 substitutions. However, TG mice overexpressing HSPB8 K141N in cardiac tissue show aggregating HSPB8 and mitochondrial dysfunction in cardiomyocytes and develop signs of cardiomyopathy at the age of 6 months (Sanbe et al., 2013), while KO mice show cardiac defects with aging (Wu et al., 2021). HSPB8 variants have been also described in cancer (e.g., W51C and P173H (Gober et al., 2003; Smith et al., 2011)), in which HSPB8 role has been recently extensively reviewed (Cristofani et al., 2021).

\section{HSPB9 AND HSPB10}

Little is known about HSPB9 and HSPB10, which are testisspecific HSPBs. HSPB9 has a MW of $17.5 \mathrm{kDa}$ and, among the orthologous HSPBs, its protein sequence is the most divergent between mouse and human (Kappé et al., 2001). HSPB9 expression is confined in testis germ cells and varies during spermatogenesis. HSPB9 has been also detected in tumors, suggesting HSPB9 as a candidate Cancer/Testis Antigen (de Wit et al., 2004). Studies on HSPB9 oligomerization are missing, but yeast two-hybrid screening revealed its interaction through the CTD with the t-complex testis expressed protein-1, a light chain subunit of dynein, which also follows a similar expression pattern in testis and cancers (de Wit et al., 2004). To our knowledge, the roles of HSPB9 have not yet been investigated neither in testis nor in tumorigenesis and mutations have not been identified. HSPB10 association with HSPBs dates to 2003, when two independent groups identified the Outer Dense Fibre protein 1 (ODF1) as the last member of HSPBs family (Fontaine et al., 2003; Kappé et al., 2003). HSPB10 protein is the largest member of the family, with a MW of $28.4 \mathrm{kDa}$ and a highly extended NTD. HSPB10 expression is confined to testis, especially in spermatids, where it takes part in the formation of the Outer Dense Fibres (ODF), cytoskeletal accessory structures of sperm tails fundamental for elastic recoil (Baltz et al., 1990; Gastmann et al., 1993; Burmester and Hoyer-Fender, 1996). Recently, HSPB10 protein has been detected also in kidney collecting ducts, suggesting that HSPB10 might play a structural role in specialized structures, such as cilia and flagella (Cabrillana et al., 2019). Beside the ACD, HSPB10 structure is characterized by the presence of several C-X-P repeats in the CTD and a putative leucine-zipper domain in the NTD (Shao and van der Hoorn, 1996). Yeast two-hybrid screening studies revealed that HSPB10 might self-interact through its putative leucine-zipper domain and that it multimerizes in vitro at high concentrations (Shao and van der Hoorn, 1996). Also, the leucine-zipper motif of HSPB10 has been found to mediate interactions with other constituents of the ODF structure, such as ODF2, the sperm-associated antigens SPAG4, an axoneme-binding protein, and SPAG5, a component of the mitotic spindle, and the kinesin light chain 3 (Petersen et al., 1999; Shao et al., 1999; Shao et al., 2001; Bhullar et al., 2003; Fitzgerald et al., 2006). Instead, the C-X-P rich domain was found to mediate HSPB10 interaction with ODF1-interacting protein (OIP1), a member of the Really Interesting New Gene finger family and a putative E3 ubiquitin protein ligase (Zarsky et al., 2003). It has been hypothesized that this interaction, which is stronger when HSPB10 is phosphorylated at serine (S196), might favour HSPB10 degradation, thus promoting ODF complex disassembly and sperm tail detachment after fertilization 
(Rosales et al., 2007). Notably, a high content of cysteines characterizes the HSPB10 protein sequence, and it has been proposed that thiol groups redox status changes during spermatozoa maturation and its alteration impacts on spermatozoa motility (Kappé et al., 2003; Dias et al., 2014; Cabrillana et al., 2017). HSPB10 role in diseases has been strictly investigated in the field of male fertility, even if no HSPB10 pathogenic mutation has yet been identified in humans. Indeed, only one homozygous variant, consisting in a 27-bp deletion in the C-X-P repeat-rich CTD, has been reported in literature so far, but it resulted not being associated to any pathogenic phenotype (Hofferbert et al., 1993). On the other hand, a reduction of HSPB10 levels has been observed within the gametes in a small cohort of infertile idiopathic male patients in respect to fertile donors, suggesting HSPB10 as fertility biomarker (Hetherington et al., 2016). Interestingly, spermatozoa of infertile subjects resulted vulnerable to decapitation after freeze-thawing stress induction (Hetherington et al., 2016). Mice showed a similar phenotype when HSPB10 was depleted (Kappé et al., 2003; Yang et al., 2012; Yang et al., 2014). Indeed, homozygous HSPB10-deficient mice, which are infertile, are characterized by defects in head-to-tail linkage in sperm, with decapitated spermatozoa displaying mitochondrial disorganization (Yang et al., 2012). Notably, heterozygous male mice, which showed halved levels of HSPB10, were fertile or subfertile, but still characterized by a weakening of the sperm head-to-tail coupling and decreased sperm motility (Yang et al., 2014). HSPB10 ectopic expression has also been found in some cancers, suggesting that, as HSPB9, it should be evaluated as a cancer biomarker (Ghafouri-Fard et al., 2010; Li et al., 2021).

\section{DISCUSSION}

HSPBs are a subset of chaperones playing multiple roles aimed at maintaining cell homeostasis. HSPBs main roles are exploited through pathways related to the protein quality control (PQC) system and consist in recognition of damaged and misfolded proteins, protein aggregation prevention, cooperation with other chaperones and the degradative systems for protein substrates refolding or disposal.

Interestingly, the expression of some HSPBs is confined to specific tissues, while others are broadly expressed. However, although many HSPBs are ubiquitously expressed, some tissues strictly rely on HSPBs for the accomplishment of different physiological activities. For instance, both skeletal and cardiac muscle require structural integrity of the cytoskeletal components for cell contraction; neuronal cells cytoskeletal architecture must be preserved for axonal transport and communication with target cells; eye lenses fibres need to prevent crystallin proteins damage and aggregation to assure lens transparency. Overall, these cell types are characterized by an absent or low cell turnover (postmitotic or with low mitotic index cells), which suggests that the maintenance of a healthy proteome is essential from early ages and during aging. Besides proteostasis, HSPBs modulate cell death. The redundance of HSPBs functions suggests that those tissues expressing several HSPBs might be able to obviate the absence of one HSPB through its replacement with another one. On the other hand, several studies suggest that HSPBs activities diverged to specialized functions that cannot be accomplished by the other members of the family. To mention few examples, it has been shown that HSPB2 plays a role in cells energetics and nuclear integrity; HSPB6 in cell muscle relaxation, HSPB8 in cell division, protein translation and SGs dynamics.

On these bases, it is expected that mutations in HSPBs affect those tissues in which HSPBs themselves are predominantly or exclusively expressed, giving rise to a clear clinical phenotype in affected patients. However, mutations in HSPBs with a pleiotropic activity might be related to different or multiple phenotypes. For instance, HSPB5 mutations have been linked to cataracts or cardiomyopathy or myopathy, but also to multiple system diseases in which all these pathological conditions are observed. Similarly, HSPB1 or HSPB8 have been described in neuropathies and/or myopathies. Moreover, different phenotypes can be linked to the same mutation, suggesting that other genetics, epigenetics, or exogenous factors have a role in predisposition to a certain disease. Importantly, most of the HSPBs mutations are dominantly inherited.

Of note, mutations in HSPBs have been identified along the whole structure. Mutations include missense, nonsense, and frameshift mutations that might affect HSPBs protein expression and stability, PTMs, dynamics in oligomerization and interaction with target proteins, thus altering HSPBs activity. While some HSPBs mutations have been deeply investigated in vitro and in vivo, others have not been subjected to a deep characterization and the number of mutations is still growing. Thus, the mechanisms of action of several mutants are not defined, yet.

Instead, other pathogenic mechanisms are quite well defined. One of the mechanisms at the basis of HSPBs-related diseases includes their complete deficiency. This is the case of nonsense or frameshift mutations that cause the complete loss of protein production or, as in the case of mutations falling in the NTD or ACD, severe modification of the protein itself. Several mutations that are associated with a complete loss of the HSPBs protein products cause the disease only in homozygosis, while heterozygous carriers are unaffected, suggesting that the WT allele is sufficient to accomplish its functions. Instead, haploinsufficiency mechanisms have been hypothesized in the case of frameshift mutations affecting HSPBs protein sequence to a lesser extent (e.g., mutations falling at the CTD). In this case, it has been suggested that decreased levels of a HSPB might be sufficient for disease manifestation. However, several studies also report that several HSPBs frameshift mutants, when expressed in cell models, are prone to aggregate. Indeed, HSPBs aggregation is observed for several HSPBs mutations, including also missense mutations, and represents another mechanism of pathogenicity. Protein aggregation is a hallmark of muscle and neuron diseases and associates with several intracellular alterations. Indeed, aberrant oligomeric structures and aggregates may impair the PQC system, by overwhelming it or by sequestering not only the other HSPBs, but also key factors involved in proteostasis. In addition, these toxic species directly affect cytoskeletal structures and, in the case of HSPBs mutants, co-segregate with structural components. Finally, other intracellular structures and organelles might be damaged by these toxic species. Overall, these 
alterations increase the vulnerability to cell death. Therapeutic strategies to counteract the onset or progression of HSPBs-related diseases should be developed based on the pathogenic mechanism (e.g., HSPB deficiency or aggregation) and on the cell types affected. For example, boosting the expression of other HSPBs has been hypothesized to be a possible therapeutic approach to replace a dysfunctional and mutated HSPB and to favour its disposal, in the case of its aggregation. Alternatively, strategies to revert the intracellular alterations caused by HSPBs mutations might be beneficial. For instance, drugs or approaches to counteract oxidative stress, cytoskeletal modifications or stressresponse pathways that might lead to cell death have been also tested. Thus, mutations in HSPBs determine a loss of their functional activity, which can be accompanied by a gain of toxic functions and/or by a dominant action on the WT allele, underlying that mutated HSPBs pathogenicity manifests through multiple ways.

\section{AUTHOR CONTRIBUTIONS}

BT and AP designed and wrote the manuscript and critically discussed all sections of the review. In addition, BT and RC prepared the figures. RC, VF, MCo, PR, EC, MCh, FM, MG, $\mathrm{MP}$, and VC critically revised the manuscript and the figures. All Authors have provided final approval of the version to be published.

\section{REFERENCES}

Abdel-Nour, M., Carneiro, L. A. M., Downey, J., Tsalikis, J., Outlioua, A., Prescott, D., et al. (2019). The Heme-Regulated Inhibitor Is a Cytosolic Sensor of Protein Misfolding that Controls Innate Immune Signaling. Science 365, eaaw4144. doi:10.1126/science.aaw4144

Ackerley, S., James, P. A., Kalli, A., French, S., Davies, K. E., and Talbot, K. (2006). A Mutation in the Small Heat-Shock Protein HSPB1 Leading to Distal Hereditary Motor Neuronopathy Disrupts Neurofilament Assembly and the Axonal Transport of Specific Cellular Cargoes. Hum. Mol. Genet. 15, 347-354. doi:10.1093/hmg/ddi452

Acunzo, J., Katsogiannou, M., and Rocchi, P. (2012). Small Heat Shock Proteins HSP27 (HspB1), aB-crystallin (HspB5) and HSP22 (HspB8) as Regulators of Cell Death. Int. J. Biochem. Cel Biol. 44, 1622-1631. doi:10.1016/j.biocel.2012. 04.002

Adriaenssens, E., Tedesco, B., Mediani, L., Asselbergh, B., Crippa, V., Antoniani, F., et al. (2020). BAG3 Pro209 Mutants Associated with Myopathy and Neuropathy Relocate Chaperones of the CASA-Complex to Aggresomes. Sci. Rep. 10, 8755. doi:10.1038/s41598-020-65664-z

Alam, S., Abdullah, C. S., Aishwarya, R., Morshed, M., Nitu, S. S., Miriyala, S., et al. (2020). Dysfunctional Mitochondrial Dynamic and Oxidative Phosphorylation Precedes Cardiac Dysfunction in R120G-aB-CrystallinInduced Desmin-Related Cardiomyopathy. Jaha 9, e017195. doi:10.1161/ JAHA.120.017195

Alderson, T. R., Roche, J., Gastall, H. Y., Dias, D. M., Pritišanac, I., Ying, J., et al. (2019). Local Unfolding of the HSP27 Monomer Regulates Chaperone Activity. Nat. Commun. 10, 1068. doi:10.1038/s41467-019-08557-8

Alderson, T. R., Adriaenssens, E., Asselbergh, B., Pritišanac, I., Van Lent, J., Gastall, H. Y., et al. (2021). A Weakened Interface in the P182L Variant of HSP27 Associated with Severe Charcot-Marie-Tooth Neuropathy Causes Aberrant Binding to Interacting Proteins. EMBO J. 40, e103811. doi:10.15252/embj. 2019103811

Almeida-Souza, L., Goethals, S., de Winter, V., Dierick, I., Gallardo, R., Van Durme, J., et al. (2010). Increased Monomerization of Mutant HSPB1 Leads to

\section{FUNDING}

This research was funded by: Fondazione Telethon, Italy (n. GGP19128 to AP); Kennedy's disease association (2018 grant to RC; 2020 grant to MG); Fondazione Cariplo, Italy (n. 2017_0747 to VC and n. 2021-1544 to RC); Fondazione AriSLA, Italy (n. MLOpathy to AP; Target-RAN to AP); Association Française contre les Myopathies, France (AFM Telethon n. 23236 to AP); Bando Straordinario per Progetti Interdipartimentali (Bando SEED 2019: \#TDP-43-iPSC to VC; and \#Gender-ALS to MG); Italian Ministry of University and Research (MIUR), PRIN_Progetti di ricerca di interesse nazionale (n. 2017F2A2C5 to AP; n. 2020PBS5MJ to VC); Fondo per il Finanziamento delle Attività Base di Ricerca (FFABR) (MIUR, to MG, and PR); Agenzia Italiana del Farmaco (AIFA) (Co_ALS to AP); Fondazione Regionale per la Ricerca Biomedica (FRRB) (Regione Lombardia, TRANS_ALS, project nr. 2015-0023, to AP); Italian Ministry of University and Research (Progetto Dipartimenti di Eccellenza).

\section{SUPPLEMENTARY MATERIAL}

The Supplementary Material for this article can be found online at: https://www.frontiersin.org/articles/10.3389/fmolb.2022.842149/ full\#supplementary-material

Protein Hyperactivity in Charcot-Marie-Tooth Neuropathy. J. Biol. Chem. 285, 12778-12786. doi:10.1074/jbc.M109.082644

Al-Tahan, S., Weiss, L., Yu, H., Tang, S., Saporta, M., Vihola, A., et al. (2019). New Family with HSPB8-Associated Autosomal Dominant Rimmed Vacuolar Myopathy. Neurol. Genet. 5, e349. doi:10.1212/NXG.0000000000000349

Amornvit, J., Yalvac, M. E., Chen, L., and Sahenk, Z. (2017). A Novel p.T139M Mutation in HSPB1 Highlighting the Phenotypic Spectrum in a Family. Brain Behav. 7, e00774. doi:10.1002/brb3.774

An, J.-J., Lee, Y.-P., Kim, D.-W., Sohn, E.-J., Jeong, H.-J., Kang, H.-W., et al. (2009). Transduced HSP27 Protein Protects Neuronal Cell Death by Enhancing FALSAssociated SOD1 Mutant Activity. BMB Rep. 42, 136-141. doi:10.5483/bmbrep. 2009.42.3.136

Andley, U. P., and Goldman, J. W. (2016). Autophagy and UPR in AlphaCrystallin Mutant Knock-In Mouse Models of Hereditary Cataracts. Biochim. Biophys. Acta (Bba) - Gen. Subjects 1860, 234-239. doi:10.1016/j.bbagen. 2015.06.001

Andley, U. P., Song, Z., Wawrousek, E. F., and Bassnett, S. (1998). The Molecular Chaperone aA-Crystallin Enhances Lens Epithelial Cell Growth and Resistance to UVA Stress. J. Biol. Chem. 273, 31252-31261. doi:10.1074/jbc.273.47.31252

Andley, U. P., Patel, H. C., and Xi, J.-H. (2002). The R116C Mutation in aAcrystallin Diminishes its Protective Ability against Stress-Induced Lens Epithelial Cell Apoptosis. J. Biol. Chem. 277, 10178-10186. doi:10.1074/jbc. M109211200

Andley, U. P., Hamilton, P. D., and Ravi, N. (2008). Mechanism of Insolubilization by a Single-Point Mutation in aA-Crystallin Linked with Hereditary Human Cataracts. Biochemistry 47, 9697-9706. doi:10.1021/bi800594t

Andley, U. P. (2007). Crystallins in the Eye: Function and Pathology. Prog. Retin. Eye Res. 26, 78-98. doi:10.1016/j.preteyeres.2006.10.003

Arndt, V., Dick, N., Tawo, R., Dreiseidler, M., Wenzel, D., Hesse, M., et al. (2010). Chaperone-assisted Selective Autophagy Is Essential for Muscle Maintenance. Curr. Biol. 20, 143-148. doi:10.1016/j.cub.2009.11.022

Arrigo, A. P., and Welch, W. J. (1987). Characterization and Purification of the Small 28,000-dalton Mammalian Heat Shock Protein. J. Biol. Chem. 262, 15359-15369. Available at: http://www.ncbi.nlm.nih.gov/pubmed/3680201. doi:10.1016/s0021-9258(18)47733-2 
Arrigo, A.-P. (2007). The Cellular "Networking" of Mammalian Hsp27 and its Functions in the Control of Protein Folding, Redox State and Apoptosis. Adv. Exp. Med. Biol. 594, 14-26. doi:10.1007/978-0-387-39975-1_2

Arrigo, A.-P. (2017). Mammalian HspB1 (Hsp27) Is a Molecular Sensor Linked to the Physiology and Environment of the Cell. Cell Stress Chaperones 22, 517-529. doi:10.1007/s12192-017-0765-1

Asthana, A., Raman, B., Ramakrishna, T., and Rao, C. M. (2012). Structural Aspects and Chaperone Activity of Human HspB3: Role of the "C-Terminal Extension". Cell Biochem. Biophys. 64, 61-72. doi:10.1007/s12013-012-9366-x

Aung, N., Vargas, J. D., Yang, C., Cabrera, C. P., Warren, H. R., Fung, K., et al. (2019). Genome-Wide Analysis of Left Ventricular Image-Derived Phenotypes Identifies Fourteen Loci Associated with Cardiac Morphogenesis and Heart Failure Development. Circulation 140, 1318-1330. doi:10.1161/ CIRCULATIONAHA.119.041161

Ba, A., Singer, C., Tyagi, M., Brophy, C., Baker, J., Cremo, C., et al. (2009). HSP20 Phosphorylation and Airway Smooth Muscle Relaxation. Cell Health Cytoskelet 1, 27-42. doi:10.2147/chc.s5783

Bajramović, J. J., Plomp, A. C., Goes, A. v. d., Koevoets, C., Newcombe, J., Cuzner, M. L., et al. (2000). Presentation of aB-Crystallin to T Cells in Active Multiple Sclerosis Lesions: An Early Event Following Inflammatory Demyelination. J. Immunol. 164, 4359-4366. doi:10.4049/jimmunol.164.8.4359

Baltz, J. M., Oneeka Williams, P., and Cone, R. A. (1990). Dense Fibers Protect Mammalian Sperm against Damage. Biol. Reprod. 43, 485-491. doi:10.1095/ biolreprod43.3.485

Baranova, E. V., Weeks, S. D., Beelen, S., BukachGusev, O. V. N. B., Gusev, N. B., and Strelkov, S. V. (2011). Three-Dimensional Structure of $\alpha$-Crystallin Domain Dimers of Human Small Heat Shock Proteins HSPB1 and HSPB6. J. Mol. Biol. 411, 110-122. doi:10.1016/j.jmb.2011.05.024

Bartelt-Kirbach, B., and Golenhofen, N. (2014). Reaction of Small Heat-Shock Proteins to Different Kinds of Cellular Stress in Cultured Rat Hippocampal Neurons. Cell Stress Chaperones 19, 145-153. doi:10.1007/s12192-013-0452-9

Basha, E., O'Neill, H., and Vierling, E. (2012). Small Heat Shock Proteins and $\alpha-$ crystallins: Dynamic Proteins with Flexible Functions. Trends Biochem. Sci. 37, 106-117. doi:10.1016/j.tibs.2011.11.005

Bassnett, S. (2009). On the Mechanism of Organelle Degradation in the Vertebrate Lens. Exp. Eye Res. 88, 133-139. doi:10.1016/j.exer.2008.08.017

Beall, A., Bagwell, D., Woodrum, D., Stoming, T. A., Kato, K., Suzuki, A., et al. (1999). The Small Heat Shock-Related Protein, HSP20, Is Phosphorylated on Serine 16 during Cyclic Nucleotide-dependent Relaxation. J. Biol. Chem. 274, 11344-11351. doi:10.1074/jbc.274.16.11344

Benndorf, R., Martin, J. L., Kosakovsky Pond, S. L., and Wertheim, J. O. (2014). Neuropathy- and Myopathy-Associated Mutations in Human Small Heat Shock Proteins: Characteristics and Evolutionary History of the Mutation Sites. Mutat. Res./Rev. Mutat. Res. 761, 15-30. doi:10.1016/j.mrrev.2014.02.004

Berry, V., Francis, P., Reddy, M. A., Collyer, D., Vithana, E., MacKay, I., et al. (2001). Alpha-B Crystallin Gene (CRYAB) Mutation Causes Dominant Congenital Posterior Polar Cataract in Humans. Am. J. Hum. Genet. 69, 1141-1145. doi:10.1086/324158

Bhullar, B., Zhang, Y., Junco, A., Oko, R., and van der Hoorn, F. A. (2003). Association of Kinesin Light Chain with Outer Dense Fibers in a Microtubuleindependent Fashion. J. Biol. Chem. 278, 16159-16168. doi:10.1074/jbc. M213126200

Boelens, W. C., Van Boekel, M. A. M., and De Jong, W. W. (1998). HspB3, the Most Deviating of the Six Known Human Small Heat Shock Proteins. Biochim. Biophys. Acta (Bba) - Protein Struct. Mol. Enzymol. 1388, 513-516. doi:10.1016/ s0167-4838(98)00215-5

Boelens, W. C. (2020). Structural Aspects of the Human Small Heat Shock Proteins Related to Their Functional Activities. Cell Stress Chaperones 25, 581-591. doi:10.1007/s12192-020-01093-1

Bortolani, S., Fattori, F., Monforte, M., Ricci, E., and Tasca, G. (2020). Peculiar Muscle Imaging Findings in a Patient with alphaBCrystallinopathy and Axial Myopathy. J. Neurol. Sci. 416, 116999. doi:10.1016/j.jns.2020.116999

Bouhy, D., Geuens, T., De Winter, V., Almeida-Souza, L., Katona, I., Weis, J., et al. (2016). Characterization of New Transgenic Mouse Models for Two CharcotMarie-Tooth-Causing HspB1 Mutations Using the Rosa26 Locus. Ind 3, 183-200. doi:10.3233/JND-150144
Bouhy, D., Juneja, M., Katona, I., Holmgren, A., Asselbergh, B., De Winter, V., et al. (2018). A Knock-In/knock-Out Mouse Model of HSPB8-Associated Distal Hereditary Motor Neuropathy and Myopathy Reveals Toxic Gain-Of-Function of Mutant Hspb8. Acta Neuropathol. 135, 131-148. doi:10.1007/s00401-017$1756-0$

Brady, J. P., Garland, D., Duglas-Tabor, Y., Robison, W. G., Groome, A., and Wawrousek, E. F. (1997). Targeted Disruption of the Mouse A-Crystallin Gene Induces Cataract and Cytoplasmic Inclusion Bodies Containing the Small Heat Shock Protein B-Crystallin. Proc. Natl. Acad. Sci. 94, 884-889. doi:10.1073/ pnas.94.3.884

Brady, J. P., Garland, D. L., Green, D. E., Tamm, E. R., Giblin, F. J., and Wawrousek, E. F. (2001). AlphaB-Crystallin in Lens Development and Muscle Integrity: a Gene Knockout Approach. Invest. Ophthalmol. Vis. Sci. 42, 2924-2934. Available at: http://www.ncbi.nlm.nih.gov/pubmed/11687538.

Brodehl, A., Gaertner-Rommel, A., Klauke, B., Grewe, S. A., Schirmer, I., Peterschröder, A., et al. (2017). The Novel aB-crystallin ( CRYAB ) Mutation p.D109G Causes Restrictive Cardiomyopathy. Hum. Mutat. 38, 947-952. doi:10.1002/humu.23248

Brophy, C. M., Dickinson, M., and Woodrum, D. (1999). Phosphorylation of the Small Heat Shock-Related Protein, HSP20, in Vascular Smooth Muscles Is Associated with Changes in the Macromolecular Associations of HSP20. J. Biol. Chem. 274, 6324-6329. doi:10.1074/jbc.274.10.6324

Bruey, J.-M., Ducasse, C., Bonniaud, P., Ravagnan, L., Susin, S. A., Diaz-Latoud, C., et al. (2000). Hsp27 Negatively Regulates Cell Death by Interacting with Cytochrome C. Nat. Cel. Biol. 2, 645-652. doi:10.1038/35023595

Bruinsma, I. B., Bruggink, K. A., Kinast, K., Versleijen, A. A. M., Segers-Nolten, I. M. J., Subramaniam, V., et al. (2011). Inhibition of $\alpha$-Synuclein Aggregation by Small Heat Shock Proteins. Proteins 79, 2956-2967. doi:10.1002/prot. 23152

Bryantsev, A. L., Loktionova, S. A., Ilyinskaya, O. P., Tararak, E. M., Kampinga, H. H., and Kabakov, A. E. (2002). Distribution, Phosphorylation, and Activities of Hsp25 in Heat-Stressed H9c2 Myoblasts: a Functional Link to Cytoprotection. Cell Stress Chaper 7, 146-155. doi:10.1379/1466-1268(2002)007<0146: dpaaoh $>2.0$. co; 2

Bugiardini, E., Rossor, A. M., Lynch, D. S., Swash, M., Pittman, A. M., Blake, J. C., et al. (2017). Homozygous Mutation in HSPB1 Causing Distal Vacuolar Myopathy and Motor Neuropathy. Neurol. Genet. 3, e168. doi:10.1212/ NXG.0000000000000168

Bukach, O. V., Seit-Nebi, A. S., Marston, S. B., and Gusev, N. B. (2004). Some Properties of Human Small Heat Shock Protein Hsp20 (HspB6). Eur. J. Biochem. 271, 291-302. doi:10.1046/j.1432-1033.2003.03928.x

Bukach, O. V., Marston, S. B., and Gusev, N. B. (2005). Small Heat Shock Protein with Apparent Molecular Mass $20 \mathrm{kDa}$ (Hsp20, HspB6) Is Not a Genuine Actin-Binding Protein. J. Muscle Res. Cel Motil. 26, 175-181. doi:10.1007/ s10974-005-9008-7

Bukach, O. V., Glukhova, A. E., Seit-Nebi, A. S., and Gusev, N. B. (2009). Heterooligomeric Complexes Formed by Human Small Heat Shock Proteins HspB1 (Hsp27) and HspB6 (Hsp20). Biochim. Biophys. Acta (Bba) - Proteins Proteomics 1794, 486-495. doi:10.1016/j.bbapap.2008.11.010

Bullard, B., Ferguson, C., Minajeva, A., Leake, M. C., Gautel, M., Labeit, D., et al. (2004). Association of the Chaperone aB-crystallin with Titin in Heart Muscle. J. Biol. Chem. 279, 7917-7924. doi:10.1074/jbc.M307473200

Burmester, S., and Hoyer-Fender, S. (1996). Transcription and Translation of the Outer Dense Fiber Gene (Odf1) during Spermiogenesis in the Rat. A Study by In Situ Analyses and Polysome Fractionation. Mol. Reprod. Dev. 45, 10-20. doi:10.1002/(sici)1098-2795(199609)45:1<10:aid-mrd2>3.0.co;2-v

Cabrillana, M. E., Monclus, M. d. l. Á., Lancellotti, T. E. S., Boarelli, P. V., Vincenti, A. E., Fornés, M. M., et al. (2017). Thiols of Flagellar Proteins Are Essential for Progressive Motility in Human Spermatozoa. Reprod. Fertil. Dev. 29, 1435-1446. doi:10.1071/RD16225

Cabrillana, M. E., Bocanegra, V., Monclus, M. A., Lancellotti, T. S., Simón, L., Funes, A. K., et al. (2019). ODF1, Sperm Flagelar Protein Is Expressed in Kidney Collecting Ducts of Rats. Heliyon 5, e02932. doi:10.1016/j.heliyon.2019.e02932

Cameron, R. T., Quinn, S. D., Cairns, L. S., MacLeod, R., Samuel, I. D. W., Smith, B. O., et al. (2014). The Phosphorylation of Hsp20 Enhances its Association with Amyloid- $\beta$ to Increase protection against Neuronal Cell Death. Mol. Cel. Neurosci. 61, 46-55. doi:10.1016/j.mcn.2014.05.002 
Cao, Y.-L., Yang, Y.-P., Mao, C.-J., Zhang, X.-Q., Wang, C.-T., Yang, J., et al. (2017). A Role of BAG3 in Regulating SNCA/a-synuclein Clearance via Selective Macroautophagy. Neurobiol. Aging 60, 104-115. doi:10.1016/j. neurobiolaging.2017.08.023

Cappola, T. P., Li, M., He, J., Ky, B., Gilmore, J., Qu, L., et al. (2010). Common Variants in HSPB7 and FRMD4B Associated with Advanced Heart Failure. Circ. Cardiovasc. Genet. 3, 147-154. doi:10.1161/CIRCGENETICS.109.898395

Capponi, S., Geuens, T., Geroldi, A., Origone, P., Verdiani, S., Cichero, E., et al. (2016). Molecular Chaperones in the Pathogenesis of Amyotrophic Lateral Sclerosis: The Role of HSPB1. Hum. Mutat. 37, 1202-1208. doi:10.1002/humu. 23062

Carra, S., Sivilotti, M., Chávez Zobel, A. T., Lambert, H., and Landry, J. (2005). HspB8, a Small Heat Shock Protein Mutated in Human Neuromuscular Disorders, Has In Vivo Chaperone Activity in Cultured Cells. Hum. Mol. Genet. 14, 1659-1669. doi:10.1093/hmg/ddil74

Carra, S., Seguin, S. J., Lambert, H., and Landry, J. (2008a). HspB8 Chaperone Activity toward Poly(Q)-Containing Proteins Depends on its Association with Bag3, a Stimulator of Macroautophagy. J. Biol. Chem. 283, 1437-1444. doi:10. 1074/jbc.M706304200

Carra, S., Seguin, S. J., and Landry, J. (2008b). HspB8 and Bag3: a New Chaperone Complex Targeting Misfolded Proteins to Macroautophagy. Autophagy 4, 237-239. doi:10.4161/auto.5407

Carra, S., Brunsting, J. F., Lambert, H., Landry, J., and Kampinga, H. H. (2009). HspB8 Participates in Protein Quality Control by a Non-Chaperone-like Mechanism that Requires eIF2a Phosphorylation. J. Biol. Chem. 284, 5523-5532. doi:10.1074/jbc.M807440200

Carra, S., Boncoraglio, A., Kanon, B., Brunsting, J. F., Minoia, M., Rana, A., et al. (2010). Identification of the Drosophila Ortholog of HSPB8. J. Biol. Chem. 285, 37811-37822. doi:10.1074/jbc.M110.127498

Caspers, G.-J., Leunissen, J. A. M., and de Jong, W. W. (1995). The Expanding Small Heat-Shock Protein Family, and Structure Predictions of the Conserved "a-Crystallin Domain". J. Mol. Evol. 40, 238-248. doi:10.1007/bf00163229

Chavez Zobel, A. T., Loranger, A., Marceau, N., Thériault, J. R., Lambert, H., and Landry, J. (2003). Distinct Chaperone Mechanisms Can Delay the Formation of Aggresomes by the Myopathy-Causing R120G B-Crystallin Mutant. Hum. Mol. Genet. 12, 1609-1620. doi:10.1093/hmg/ddg173

Chalova, A. S., Sudnitsyna, M. V., Semenyuk, P. I., Orlov, V. N., and Gusev, N. B. (2014a). Effect of Disulfide Crosslinking on thermal Transitions and Chaperone-like Activity of Human Small Heat Shock Protein HspB1. Cell Stress Chaperones 19, 963-972. doi:10.1007/s12192-014-0520-9

Chalova, A. S., Sudnitsyna, M. V., Strelkov, S. V., and Gusev, N. B. (2014b). Characterization of Human Small Heat Shock Protein HspB1 that Carries C-Terminal Domain Mutations Associated with Hereditary Motor Neuron Diseases. Biochim. Biophys. Acta (Bba) - Proteins Proteomics 1844, 2116-2126. doi:10.1016/j.bbapap.2014.09.005

Chang, B., Hawes, N. L., Smith, R. S., Heckenlively, J. R., Davisson, M. T., and Roderick, T. H. (1996). Chromosomal Localization of a New Mouse Lens Opacity Gene (Lop18). Genomics 36, 171-173. doi:10.1006/geno.1996.0439

Chang, B., Hawes, N. L., Roderick, T. H., Smith, R. S., Heckenlively, J. R., Horwitz, J., et al. (1999). Identification of a Missense Mutation in the alphaA-Crystallin Gene of the Lop18 Mouse. Mol. Vis. 5, 21. Available at: http://www.ncbi.nlm. nih.gov/pubmed/10493778.

Chen, Q., Liu, J.-B., Horak, K. M., Zheng, H., Kumarapeli, A. R. K., Li, J., et al. (2005). Intrasarcoplasmic Amyloidosis Impairs Proteolytic Function of Proteasomes in Cardiomyocytes by Compromising Substrate Uptake. Circ. Res. 97, 1018-1026. doi:10.1161/01.RES.0000189262.92896.0b

Chen, A., Karolczak-Bayatti, M., Sweeney, M., Treumann, A., Morrissey, K., Ulrich, S. M., et al. (2013). Lysine Deacetylase Inhibition Promotes Relaxation of Arterial Tone and C-Terminal Acetylation of HSPB6 (Hsp20) in Vascular Smooth Muscle Cells. Physiol. Rep. 1, e00127. doi:10.1002/phy2.127

Chiu, T.-F., Li, C.-H., Chen, C.-C., Chen, C.-H., Cheng, C.-J., Yan, Y.-T., et al. (2012). Association of Plasma Concentration of Small Heat Shock Protein B7 with Acute Coronary Syndrome. Circ. J. 76, 2226-2233. doi:10.1253/circj.cj-120238

Christopher, K. L., Pedler, M. G., Shieh, B., Ammar, D. A., Petrash, J. M., and Mueller, N. H. (2014). Alpha-crystallin-mediated protection of Lens Cells against Heat and Oxidative Stress-Induced Cell Death. Biochim. Biophys. Acta (Bba) - Mol. Cel. Res. 1843, 309-315. doi:10.1016/j.bbamcr.2013.11.010
Cicardi, M. E., Cristofani, R., Rusmini, P., Meroni, M., Ferrari, V., Vezzoli, G., et al. (2018). Tdp-25 Routing to Autophagy and Proteasome Ameliorates its Aggregation in Amyotrophic Lateral Sclerosis Target Cells. Sci. Rep. 8, 12390. doi:10.1038/s41598-018-29658-2

Cicardi, M. E., Cristofani, R., Crippa, V., Ferrari, V., Tedesco, B., Casarotto, E., et al. (2019). Autophagic and Proteasomal Mediated Removal of Mutant Androgen Receptor in Muscle Models of Spinal and Bulbar Muscular Atrophy. Front. Endocrinol. 10, 569. doi:10.3389/fendo.2019.00569

Clark, A. R., Naylor, C. E., Bagnéris, C., Keep, N. H., and Slingsby, C. (2011). Crystal Structure of R120G Disease Mutant of Human aB-Crystallin Domain Dimer Shows Closure of a Groove. J. Mol. Biol. 408, 118-134. doi:10.1016/j.jmb. 2011.02.020

Clark, A. R., Vree Egberts, W., Kondrat, F. D. L., Hilton, G. R., Ray, N. J., Cole, A. R., et al. (2018). Terminal Regions Confer Plasticity to the Tetrameric Assembly of Human HspB2 and HspB3. J. Mol. Biol. 430, 3297-3310. doi:10.1016/j.jmb. 2018.06.047

Collier, M. P., Alderson, T. R., de Villiers, C. P., Nicholls, D., Gastall, H. Y., Allison, T. M., et al. (2019). HspB1 Phosphorylation Regulates its Intramolecular Dynamics and Mechanosensitive Molecular Chaperone Interaction with Filamin C. Sci. Adv. 5, eaav8421. doi:10.1126/sciadv.aav8421

Cortese, A., Laurà, M., Casali, C., Nishino, I., Hayashi, Y. K., Magri, S., et al. (2018). Altered TDP-43-dependent Splicing in HSPB8 -related Distal Hereditary Motor Neuropathy and Myofibrillar Myopathy. Eur. J. Neurol. 25, 154-163. doi:10.1111/ene.13478

Cox, D., and Ecroyd, H. (2017). The Small Heat Shock Proteins aB-Crystallin (HSPB5) and Hsp27 (HSPB1) Inhibit the Intracellular Aggregation of asynuclein. Cell Stress Chaperones 22, 589-600. doi:10.1007/s12192-017-0785-x

Crippa, V., Sau, D., Rusmini, P., Boncoraglio, A., Onesto, E., Bolzoni, E., et al. (2010). The Small Heat Shock Protein B8 (HspB8) Promotes Autophagic Removal of Misfolded Proteins Involved in Amyotrophic Lateral Sclerosis (ALS). Hum. Mol. Genet. 19, 3440-3456. doi:10.1093/hmg/ddq257

Crippa, V., D’Agostino, V. G., Cristofani, R., Rusmini, P., Cicardi, M. E., Messi, E., et al. (2016). Transcriptional Induction of the Heat Shock Protein B8 Mediates the Clearance of Misfolded Proteins Responsible for Motor Neuron Diseases. Sci. Rep. 6, 22827. doi:10.1038/srep22827

Cristofani, R., Crippa, V., Vezzoli, G., Rusmini, P., Galbiati, M., Cicardi, M. E., et al. (2018). The Small Heat Shock Protein B8 (HSPB8) Efficiently Removes Aggregating Species of Dipeptides Produced in C9ORF72-Related Neurodegenerative Diseases. Cell Stress Chaperones 23, 1-12. doi:10.1007/ s12192-017-0806-9

Cristofani, R., Piccolella, M., Crippa, V., Tedesco, B., Montagnani Marelli, M., Poletti, A., et al. (2021). The Role of HSPB8, a Component of the Chaperone-Assisted Selective Autophagy Machinery, in Cancer. Cells 10, 335. doi:10.3390/cells10020335

d'Ydewalle, C., Krishnan, J., Chiheb, D. M., Van Damme, P., Irobi, J., Kozikowski, A. P., et al. (2011). HDAC6 Inhibitors Reverse Axonal Loss in a Mouse Model of Mutant HSPB1-Induced Charcot-Marie-Tooth Disease. Nat. Med. 17, 968-974. doi: $10.1038 / \mathrm{nm} .2396$

de Wit, N. J. W., Verschuure, P., Kappé, G., King, S. M., de Jong, W. W., van Muijen, G. N. P., et al. (2004). Testis-specific Human Small Heat Shock Protein HSPB9 Is a Cancer/testis Antigen, and Potentially Interacts with the Dynein Subunit TCTEL1. Eur. J. Cel. Biol. 83, 337-345. doi:10.1078/0171-9335-00396

Del Bigio, M. R., Chudley, A. E., Sarnat, H. B., Campbell, C., Goobie, S., Chodirker, B. N., et al. (2011). Infantile Muscular Dystrophy in Canadian Aboriginals Is an aB-Crystallinopathy. Ann. Neurol. 69, 866-871. doi:10.1002/ana.22331

Del Vecchio, P. J., MacElroy, K. S., Rosser, M. P., and Church, R. L. (1984). Association of a-crystallin with Actin in Cultured Lens Cells. Curr. Eye Res. 3, 1213-1219. doi:10.3109/02713688409000824

Delbecq, S. P., Rosenbaum, J. C., and Klevit, R. E. (2015). A Mechanism of Subunit Recruitment in Human Small Heat Shock Protein Oligomers. Biochemistry 54, 4276-4284. doi:10.1021/acs.biochem.5b00490

den Engelsman, J., Boros, S., Dankers, P. Y. W., Kamps, B., Vree Egberts, W. T., Böde, C. S., et al. (2009). The Small Heat-Shock Proteins HSPB2 and HSPB3 Form Well-Defined Heterooligomers in a Unique 3 to 1 Subunit Ratio. J. Mol. Biol. 393, 1022-1032. doi:10.1016/j.jmb.2009.08.052

Dias, G. M., López, M. L., Ferreira, A. T. S., Chapeaurouge, D. A., Rodrigues, A., Perales, J., et al. (2014). Thiol-Disulfide Proteins of Stallion Epididymal Spermatozoa. Anim. Reprod. Sci. 145, 29-39. doi:10.1016/j.anireprosci.2013. 12.007 
Diaz-Latoud, C., Buache, E., Javouhey, E., and Arrigo, A.-P. (2005). Substitution of the Unique Cysteine Residue of Murine Hsp25 Interferes with the Protective Activity of This Stress Protein through Inhibition of Dimer Formation. Antioxid. Redox Signal. 7, 436-445. doi:10.1089/ars.2005.7.436

DiVincenzo, C., Elzinga, C. D., Medeiros, A. C., Karbassi, I., Jones, J. R., Evans, M. C., et al. (2014). The Allelic Spectrum of Charcot-Marie-Tooth Disease in over 17,000 Individuals with Neuropathy. Mol. Genet. Genomic Med. 2, 522-529. doi:10.1002/mgg3.106

Doran, P., Martin, G., Dowling, P., Jockusch, H., and Ohlendieck, K. (2006). Proteome Analysis of the Dystrophin-Deficient MDX Diaphragm Reveals a Drastic Increase in the Heat Shock Protein cvHSP. Proteomics 6, 4610-4621. doi:10.1002/pmic.200600082

Doran, P., Gannon, J., O'Connell, K., and Ohlendieck, K. (2007). Aging Skeletal Muscle Shows a Drastic Increase in the Small Heat Shock Proteins aBcrystallin/HspB5 and cvHsp/HspB7. Eur. J. Cel Biol. 86, 629-640. doi:10. 1016/j.jcb.2007.07.003

Doran, P., Wilton, S. D., Fletcher, S., and Ohlendieck, K. (2009). Proteomic Profiling of Antisense-Induced Exon Skipping Reveals Reversal of Pathobiochemical Abnormalities in Dystrophic Mdx Diaphragm. Proteomics 9, 671-685. doi:10.1002/pmic.200800441

Echaniz-Laguna, A., Geuens, T., Petiot, P., Péréon, Y., Adriaenssens, E., Haidar, M., et al. (2017a). Axonal Neuropathies Due to Mutations in Small Heat Shock Proteins: Clinical, Genetic, and Functional Insights into Novel Mutations. Hum. Mutat. 38, 556-568. doi:10.1002/humu.23189

Echaniz-Laguna, A., Lornage, X., Lannes, B., Schneider, R., Bierry, G., Dondaine, N., et al. (2017b). HSPB8 Haploinsufficiency Causes Dominant Adult-Onset Axial and Distal Myopathy. Acta Neuropathol. 134, 163-165. doi:10.1007/ s00401-017-1724-8

Edwards, H. V., Scott, J. D., and Baillie, G. S. (2012). PKA Phosphorylation of the Small Heat-Shock Protein Hsp20 Enhances its Cardioprotective Effects. Biochem. Soc. Trans. 40, 210-214. doi:10.1042/BST20110673

Esslinger, U., Garnier, S., Korniat, A., Proust, C., Kararigas, G., Müller-Nurasyid, M., et al. (2017). Exome-wide Association Study Reveals Novel Susceptibility Genes to Sporadic Dilated Cardiomyopathy. PLoS One 12, e0172995. doi:10. 1371/journal.pone.0172995

Evgrafov, O. V., Mersiyanova, I., Irobi, J., Van Den Bosch, L., Dierick, I., Leung, C. L., et al. (2004). Mutant Small Heat-Shock Protein 27 Causes Axonal CharcotMarie-Tooth Disease and Distal Hereditary Motor Neuropathy. Nat. Genet. 36, 602-606. doi:10.1038/ng1354

Fan, G.-C., and Kranias, E. G. (2011). Small Heat Shock Protein 20 (HspB6) in Cardiac Hypertrophy and Failure. J. Mol. Cel. Cardiol. 51, 574-577. doi:10. 1016/j.yjmcc.2010.09.013

Fan, G.-C., Chu, G., Mitton, B., Song, Q., Yuan, Q., and Kranias, E. G. (2004). Small Heat-Shock Protein Hsp20 Phosphorylation Inhibits $\beta$-Agonist-Induced Cardiac Apoptosis. Circ. Res. 94, 1474-1482. doi:10.1161/01.RES. 0000129179.66631 .00

Fan, G.-C., Ren, X., Qian, J., Yuan, Q., Nicolaou, P., Wang, Y., et al. (2005). Novel Cardioprotective Role of a Small Heat-Shock Protein, Hsp20, against Ischemia/ reperfusion Injury. Circulation 111, 1792-1799. doi:10.1161/01.CIR. 0000160851.41872.C6

Fang, X., Bogomolovas, J., Trexler, C., and Chen, J. (2019). The BAG3-Dependent and -independent Roles of Cardiac Small Heat Shock Proteins. JCI Insight 4, e126464. doi:10.1172/jci.insight.126464

Fichna, J. P., Potulska-Chromik, A., Miszta, P., Redowicz, M. J., Kaminska, A. M., Zekanowski, C., et al. (2017). A Novel Dominant D109A CRYAB Mutation in a Family with Myofibrillar Myopathy Affects aB-Crystallin Structure. BBA Clin. 7, 1-7. doi:10.1016/j.bbacli.2016.11.004

Fitzgerald, C. J., Oko, R. J., and van der Hoorn, F. A. (2006). Rat Spag5 Associates in Somatic Cells with Endoplasmic Reticulum and Microtubules but in Spermatozoa with Outer Dense Fibers. Mol. Reprod. Dev. 73, 92-100. doi:10.1002/mrd.20388

Fontaine, J.-M., Rest, J. S., Welsh, M. J., and Benndorf, R. (2003). The Sperm Outer Dense Fiber Protein Is the 10th Member of the Superfamily of Mammalian Small Stress Proteins. Cell Stress Chaper 8, 62-69. doi:10.1379/1466-1268(2003) $8<62$ :tsodfp $>2.0$. co $; 2$

Fontaine, J.-M., Sun, X., Benndorf, R., and Welsh, M. J. (2005). Interactions of HSP22 (HSPB8) with HSP20, aB-crystallin, and HSPB3. Biochem. Biophys. Res. Commun. 337, 1006-1011. doi:10.1016/j.bbrc.2005.09.148
Fontaine, J. M., Sun, X., Hoppe, A. D., Simon, S., Vicart, P., Welsh, M. J., et al. (2006). Abnormal Small Heat Shock Protein Interactions Involving Neuropathy-associated HSP22 (HSPB8) Mutants. FASEB j. 20, 2168-2170. doi:10.1096/fj.06-5911fje

Forrest, K. M. L., Al-Sarraj, S., Sewry, C., Buk, S., Tan, S. V., Pitt, M., et al. (2011). Infantile Onset Myofibrillar Myopathy Due to Recessive CRYAB Mutations. Neuromuscul. Disord. 21, 37-40. doi:10.1016/j.nmd.2010.11.003

Fuchs, M., Poirier, D. J., Seguin, S. J., Lambert, H., Carra, S., Charette, S. J., et al. (2009). Identification of the Key Structural Motifs Involved in HspB8/HspB6Bag3 Interaction. Biochem. J. 425, 245-257. doi:10.1042/BJ20090907

Fuchs, M., Luthold, C., Guilbert, S. M., Varlet, A. A., Lambert, H., Jetté, A., et al. (2015). A Role for the Chaperone Complex BAG3-HSPB8 in Actin Dynamics, Spindle Orientation and Proper Chromosome Segregation during Mitosis. Plos Genet. 11, e1005582. doi:10.1371/journal.pgen.1005582

Gamerdinger, M., Hajieva, P., Kaya, A. M., Wolfrum, U., Hartl, F. U., and Behl, C. (2009). Protein Quality Control during Aging Involves Recruitment of the Macroautophagy Pathway by BAG3. EMBO J. 28, 889-901. doi:10.1038/emboj. 2009.29

Gamerdinger, M., Kaya, A. M., Wolfrum, U., Clement, A. M., and Behl, C. (2011). BAG3 Mediates Chaperone-based Aggresome-targeting and Selective Autophagy of Misfolded Proteins. EMBO Rep. 12, 149-156. doi:10.1038/ embor.2010.203

Ganassi, M., Mateju, D., Bigi, I., Mediani, L., Poser, I., Lee, H. O., et al. (2016). A Surveillance Function of the HSPB8-BAG3-HSP70 Chaperone Complex Ensures Stress Granule Integrity and Dynamism. Mol. Cel. 63, 796-810. doi:10.1016/j.molcel.2016.07.021

Garnier, S., Hengstenberg, C., Lamblin, N., Dubourg, O., De Groote, P., Fauchier, L., et al. (2015). Involvement of BAG3 and HSPB7 Loci in Various Etiologies of Systolic Heart Failure: Results of a European Collaboration Assembling More Than 2000 Patients. Int. J. Cardiol. 189, 105-107. doi:10.1016/j.ijcard.2015. 04.003

Garnier, S., Harakalova, M., Weiss, S., Mokry, M., Regitz-Zagrosek, V., Hengstenberg, C., et al. (2021). Genome-wide Association Analysis in Dilated Cardiomyopathy Reveals Two New Players in Systolic Heart Failure on Chromosomes 3p25.1 and 22q11.23. Eur. Heart J. 42, 2000-2011. doi:10. 1093/eurheartj/ehab030

Garrido, C., Paul, C., Seigneuric, R., and Kampinga, H. H. (2012). The Small Heat Shock Proteins Family: the Long Forgotten Chaperones. Int. J. Biochem. Cel Biol. 44, 1588-1592. doi:10.1016/j.biocel.2012.02.022

Gastmann, O., Burfeind, P., Güunther, E., Hameister, H., Szpirer, C., and HoyerFender, S. (1993). Sequence, Expression, and Chromosomal Assignment of a Human Sperm Outer Dense Fiber Gene. Mol. Reprod. Dev. 36, 407-418. doi:10. 1002/mrd.1080360402

Ghafouri-Fard, S., Ousati Ashtiani, Z., Sabah Golian, B., Hasheminasab, S.-M., and Modarressi, M. H. (2010). Expression of Two Testis-specific Genes, SPATA19 and LEMD1, in Prostate Cancer. Arch. Med. Res. 41, 195-200. doi:10.1016/j. arcmed.2010.04.003

Ghahramani, M., Yousefi, R., Krivandin, A., Muranov, K., Kurganov, B., and Moosavi-Movahedi, A. A. (2020). Structural and Functional Characterization of $\mathrm{D} 109 \mathrm{H}$ and R69C Mutant Versions of Human aB-Crystallin: The Biochemical Pathomechanism Underlying Cataract and Myopathy Development. Int. J. Biol. Macromol. 146, 1142-1160. doi:10.1016/j.ijbiomac. 2019.09.239

Ghaoui, R., Palmio, J., Brewer, J., Lek, M., Needham, M., Evilä, A., et al. (2016). Mutations inHSPB8causing a New Phenotype of Distal Myopathy and Motor Neuropathy. Neurology 86, 391-398. doi:10.1212/WNL. 0000000000002324

Görtz, A. L., Peferoen, L. A. N., Gerritsen, W. H., van Noort, J. M., Bugiani, M., and Amor, S. (2018). Heat Shock Protein Expression in Cerebral X-Linked Adrenoleukodystrophy Reveals Astrocyte Stress Prior to Myelin Loss. Neuropathol. Appl. Neurobiol. 44, 363-376. doi:10.1111/nan.12399

Gober, M. D., Smith, C. C., Ueda, K., Toretsky, J. A., and Aurelian, L. (2003). Forced Expression of the H11 Heat Shock Protein Can Be Regulated by DNA Methylation and Trigger Apoptosis in Human Cells. J. Biol. Chem. 278, 37600-37609. doi:10.1074/jbc.M303834200

Golenhofen, N., Htun, P., Ness, W., Koob, R., Schaper, W., and Drenckhahn, D. (1999). Binding of the Stress ProteinaB-Crystallin to Cardiac Myofibrils Correlates with the Degree of Myocardial Damage during Ischemia/ 
Reperfusionin Vivo. J. Mol. Cell Cardiol. 31, 569-580. doi:10.1006/jmcc.1998. 0892

Golenhofen, N., Perng, M. D., Quinlan, R. A., and Drenckhahn, D. (2004). Comparison of the Small Heat Shock Proteins ?B-Crystallin, MKBP, HSP25, HSP20, and cvHSP in Heart and Skeletal Muscle. Histochem. Cel Biol. 122, 415-425. doi:10.1007/s00418-004-0711-z

Golenhofen, N., Redel, A., Wawrousek, E. F., and Drenckhahn, D. (2006). Ischemia-induced Increase of Stiffness of aB-Crystallin/HSPB2-deficient Myocardium. Pflugers Arch. - Eur. J. Physiol. 451, 518-525. doi:10.1007/ s00424-005-1488-1

Gonçalves, C. C., Sharon, I., Schmeing, T. M., Ramos, C. H. I., and Young, J. C. (2021). The Chaperone HSPB1 Prepares Protein Aggregates for Resolubilization by HSP70. Sci. Rep. 11, 17139. doi:10.1038/s41598-02196518-x

Gorter, R. P., Stephenson, J., Nutma, E., Anink, J., de Jonge, J. C., Baron, W., et al. (2019). Rapidly Progressive Amyotrophic Lateral Sclerosis Is Associated with Microglial Reactivity and Small Heat Shock Protein Expression in Reactive Astrocytes. Neuropathol. Appl. Neurobiol. 45, 459-475. doi:10.1111/nan. 12525

Grose, J. H., Langston, K., Wang, X., Squires, S., Mustafi, S. B., Hayes, W., et al. (2015). Characterization of the Cardiac Overexpression of HSPB2 Reveals Mitochondrial and Myogenic Roles Supported by a Cardiac HspB2 Interactome. PLoS One 10, e0133994. doi:10.1371/journal.pone.0133994

Guilbert, S. M., Lambert, H., Rodrigue, M. A., Fuchs, M., Landry, J., and Lavoie, J. N. (2018). HSPB8 and BAG3 Cooperate to Promote Spatial Sequestration of Ubiquitinated Proteins and Coordinate the Cellular Adaptive Response to Proteasome Insufficiency. FASEB j. 32, 3518-3535. doi:10.1096/fj. 201700558RR

Hagemann, T. L., Boelens, W. C., Wawrousek, E. F., and Messing, A. (2009). Suppression of GFAP Toxicity by aB-crystallin in Mouse Models of Alexander Disease. Hum. Mol. Genet. 18, 1190-1199. doi:10.1093/hmg/ddp013

Haidar, M., Asselbergh, B., Adriaenssens, E., De Winter, V., Timmermans, J.-P., Auer-Grumbach, M., et al. (2019). Neuropathy-causing Mutations in HSPB1 Impair Autophagy by Disturbing the Formation of SQSTM1/p62 Bodies. Autophagy 15, 1051-1068. doi:10.1080/15548627.2019.1569930

Hampton, D. W., Amor, S., Story, D., Torvell, M., Bsibsi, M., van Noort, J. M., et al. (2020). HspB5 Activates a Neuroprotective Glial Cell Response in Experimental Tauopathy. Front. Neurosci. 14, 574. doi:10.3389/fnins.2020.00574

Hayes, V. H., Devlin, G., and Quinlan, R. A. (2008). Truncation of aB-Crystallin by the Myopathy-Causing Q151X Mutation Significantly Destabilizes the Protein Leading to Aggregate Formation in Transfected Cells. J. Biol. Chem. 283, 10500-10512. doi:10.1074/jbc.M706453200

Heilman, P. L., Song, S., Miranda, C. J., Meyer, K., Srivastava, A. K., Knapp, A., et al. (2017). HSPB1 Mutations Causing Hereditary Neuropathy in Humans Disrupt Non-cell Autonomous protection of Motor Neurons. Exp. Neurol. 297, 101-109. doi:10.1016/j.expneurol.2017.08.002

Heirbaut, M., Lermyte, F., Martin, E. M., Beelen, S., Verschueren, T., Sobott, F., et al. (2016). The Preferential Heterodimerization of Human Small Heat Shock Proteins HSPB1 and HSPB6 Is Dictated by the N-Terminal Domain. Arch. Biochem. Biophys. 610, 41-50. doi:10.1016/j.abb.2016.10.002

Heirbaut, M., Lermyte, F., Martin, E. M., Beelen, S., Sobott, F., Strelkov, S. V., et al. (2017). Specific Sequences in the N-Terminal Domain of Human Small HeatShock Protein HSPB6 Dictate Preferential Hetero-Oligomerization with the Orthologue HSPB1. J. Biol. Chem. 292, 9944-9957. doi:10.1074/jbc.M116. 773515

Hetherington, L., Schneider, E. K., Scott, C., DeKretser, D., Muller, C. H., Hondermarck, H., et al. (2016). Deficiency in Outer Dense Fiber 1 Is a Marker and Potential Driver of Idiopathic Male Infertility. Mol. Cell Proteomics 15, 3685-3693. doi:10.1074/mcp.M116.060343

Hofferbert, S., Burfeind, P., Hoyer-Fender, S., Lange, R., Haldl, G., and Engel, W. (1993). A Homozygous Deletion of 27 Basepairs in the Coding Region of the Human Outer Dense Fiber Protein Gene Does Not Result in a Pathologic Phenotype. Hum. Mol. Genet. 2, 2167-2170. doi:10.1093/hmg/2.12.2167

Holmgren, A., Bouhy, D., De Winter, V., Asselbergh, B., Timmermans, J.-P., Irobi, J., et al. (2013). Charcot-Marie-Tooth Causing HSPB1 Mutations Increase Cdk5-Mediated Phosphorylation of Neurofilaments. Acta Neuropathol. 126, 93-108. doi:10.1007/s00401-013-1133-6
Horwitz, J. (1992). Alpha-crystallin Can Function as a Molecular Chaperone. Proc. Natl. Acad. Sci. 89, 10449-10453. doi:10.1073/pnas.89.21.10449

Huang, L., Min, J.-N., Masters, S., Mivechi, N. F., and Moskophidis, D. (2007). Insights into Function and Regulation of Small Heat Shock Protein 25 (HSPB1) in a Mouse Model with Targeted Gene Disruption. Genesis 45, 487-501. doi:10. 1002/dvg.20319

Imran, K. M., Rahman, N., Yoon, D., Jeon, M., Lee, B.-T., and Kim, Y.-S. (2017). Cryptotanshinone Promotes Commitment to the Brown Adipocyte Lineage and Mitochondrial Biogenesis in C3H10T1/2 Mesenchymal Stem Cells via AMPK and P38-MAPK Signaling. Biochim. Biophys. Acta (Bba) - Mol. Cel Biol. Lipids 1862, 1110-1120. doi:10.1016/j.bbalip.2017.08.001

Inagaki, N., Hayashi, T., Arimura, T., Koga, Y., Takahashi, M., Shibata, H., et al. (2006). aB-crystallin Mutation in Dilated Cardiomyopathy. Biochem. Biophys. Res. Commun. 342, 379-386. doi:10.1016/j.bbrc.2006.01.154

Inoue-Shibui, A., Niihori, T., Kobayashi, M., Suzuki, N., Izumi, R., Warita, H., et al. (2021). A Novel Deletion in the C-Terminal Region of HSPB8 in a Family with Rimmed Vacuolar Myopathy. J. Hum. Genet. 66, 965-972. doi:10.1038/s10038021-00916-y

Irobi, J., Impe, K. V., Seeman, P., Jordanova, A., Dierick, I., Verpoorten, N., et al. (2004). Hot-spot Residue in Small Heat-Shock Protein 22 Causes Distal Motor Neuropathy. Nat. Genet. 36, 597-601. doi:10.1038/ng1328

Irobi, J., Almeida-Souza, L., Asselbergh, B., De Winter, V., Goethals, S., Dierick, I., et al. (2010). Mutant HSPB8 Causes Motor Neuron-specific Neurite Degeneration. Hum. Mol. Genet. 19, 3254-3265. doi:10.1093/hmg/ddq234

Irobi, J., Holmgren, A., Winter, V. D., Asselbergh, B., Gettemans, J., Adriaensen, D., et al. (2012). Mutant HSPB8 Causes Protein Aggregates and a Reduced Mitochondrial Membrane Potential in Dermal Fibroblasts from Distal Hereditary Motor Neuropathy Patients. Neuromuscul. Disord. 22, 699-711. doi:10.1016/j.nmd.2012.04.005

Ishiwata, T., Orosz, A., Wang, X., Mustafi, S. B., Pratt, G. W., Christians, E. S., et al. (2012). HSPB2 Is Dispensable for the Cardiac Hypertrophic Response but Reduces Mitochondrial Energetics Following Pressure Overload in Mice. PLoS One 7, e42118. doi:10.1371/journal.pone.0042118

Islamovic, E., Duncan, A., Bers, D. M., Gerthoffer, W. T., and Mestril, R. (2007). Importance of Small Heat Shock Protein 20 (Hsp20) C-Terminal Extension in Cardioprotection. J. Mol. Cel. Cardiol. 42, 862-869. doi:10.1016/j.yjmcc.2007. 01.002

Iwaki, A., Nagano, T., Nakagawa, M., Iwaki, T., and Fukumaki, Y. (1997). Identification and Characterization of the Gene Encoding a New Member of the $a$-Crystallin/Small Hsp Family, Closely Linked to the aB-Crystallin Gene in a Head-To-Head Manner. Genomics 45, 386-394. doi:10.1006/geno.1997. 4956

Jabłońska, J., Dubińska-Magiera, M., Jagla, T., Jagla, K., and Daczewska, M. (2018). Drosophila Hsp67Bc Hot-Spot Variants Alter Muscle Structure and Function. Cell. Mol. Life Sci. 75, 4341-4356. doi:10.1007/s00018-018-2875-z

Jaffer, F., Murphy, S. M., Scoto, M., Healy, E., Rossor, A. M., Brandner, S., et al. (2012). BAG3 Mutations: Another Cause of Giant Axonal Neuropathy. J. Peripher. Nerv Syst. 17, 210-216. doi:10.1111/j.1529-8027.2012.00409.x

Jakob, U., Gaestel, M., Engel, K., and Buchner, J. (1993). Small Heat Shock Proteins Are Molecular Chaperones. J. Biol. Chem. 268, 1517-1520. Available at: http:// www.ncbi.nlm.nih.gov/pubmed/8093612. doi:10.1016/s0021-9258(18)53882-5

James, P. A., Rankin, J., and Talbot, K. (2008). Asymmetrical Late Onset Motor Neuropathy Associated with a Novel Mutation in the Small Heat Shock Protein HSPB1 (HSP27). J. Neurol. Neurosurg. Psychiatry 79, 461-463. doi:10.1136/ jnnp.2007.125179

Javadiyan, S., Craig, J. E., Souzeau, E., Sharma, S., Lower, K. M., Mackey, D. A., et al. (2017). High-Throughput Genetic Screening of 51 Pediatric Cataract Genes Identifies Causative Mutations in Inherited Pediatric Cataract in South Eastern Australia. G3 (Bethesda) 7, 3257-3268. doi:10.1534/g3.117.300109

Jia, Z.-K., Fu, C.-X., Wang, A.-L., Fu, C.-X., Wang, A.-L., Yao, K., et al. (2021). Cataract-causing Allele in CRYAA (Y118D) Proceeds through Endoplasmic Reticulum Stress in Mouse Model. Zool. Res. 42, 300-309. doi:10.24272/j.issn. 2095-8137.2020.354

Jiao, Q., Sanbe, A., Zhang, X., Liu, J.-P., and Minamisawa, S. (2014). aB-Crystallin R120G Variant Causes Cardiac Arrhythmias and Alterations in the Expression of Ca2+-Handling Proteins and Endoplasmic Reticulum Stress in Mice. Clin. Exp. Pharmacol. Physiol. 41, 589-599. doi:10.1111/1440-1681.12253 
Jin, C., Shuai, T., and Tang, Z. (2020). HSPB7 Regulates Osteogenic Differentiation of Human Adipose Derived Stem Cells via ERK Signaling Pathway. Stem Cel. Res. Ther. 11, 450. doi:10.1186/s13287-020-01965-4

Jo, H. S., Kim, D. W., Shin, M. J., Cho, S. B., Park, J. H., Lee, C. H., et al. (2017). TatHSP22 Inhibits Oxidative Stress-Induced Hippocampal Neuronal Cell Death by Regulation of the Mitochondrial Pathway. Mol. Brain 10, 1. doi:10.1186/ s13041-016-0281-8

Juo, L.-Y., Liao, W.-C., Shih, Y.-L., Yang, B.-Y., Liu, A.-B., and Yan, Y.-T. (2016). HSPB7 Interacts with Dimerized FLNC and its Absence Results in Progressive Myopathy in Skeletal Muscles. J. Cel. Sci. 129, 1661-1670. doi:10.1242/jcs. 179887

Kalmar, B., Innes, A., Wanisch, K., Kolaszynska, A. K., Pandraud, A., Kelly, G., et al. (2017). Mitochondrial Deficits and Abnormal Mitochondrial Retrograde Axonal Transport Play a Role in the Pathogenesis of Mutant Hsp27-Induced Charcot Marie Tooth Disease. Hum. Mol. Genet. 26, 3313-3326. doi:10.1093/ $\mathrm{hmg} / \mathrm{dd} \times 216$

Kammoun, M., Picard, B., Astruc, T., Gagaoua, M., Aubert, D., Bonnet, M., et al. (2016). The Invalidation of HspB1 Gene in Mouse Alters the Ultrastructural Phenotype of Muscles. PLoS One 11, e0158644. doi:10.1371/journal.pone. 0158644

Kang, K.-H., Han, J. E., Hong, Y. B., Nam, S. H., Choi, B.-O., and Koh, H. (2020). Human HSPB1 Mutation Recapitulates Features of Distal Hereditary Motor Neuropathy (dHMN) in Drosophila. Biochem. Biophys. Res. Commun. 521, 220-226. doi:10.1016/j.bbrc.2019.10.110

Kappé, G., Verschuure, P., Philipsen, R. L., Staalduinen, A. A., Van de Boogaart, P., Boelens, W. C., et al. (2001). Characterization of Two Novel Human Small Heat Shock Proteins: Protein Kinase-Related HspB8 and Testis-specific HspB9. Biochim. Biophys. Acta 1520, 1-6. doi:10.1016/s0167-4781(01)00237-8

Kappé, G., Franck, E., Verschuure, P., Boelens, W. C., Leunissen, J. A., and de Jong, W. W. (2003). The Human Genome Encodes 10 Alpha-Crystallin-Related Small Heat Shock Proteins: HspB1-10. Cell Stress Chaperones 8, 53-61. doi:10. 1379/1466-1268(2003)8<53:thgecs >2.0.co;2

Kappé, G., Boelens, W. C., and de Jong, W. W. (2010). Why Proteins without an $\alpha-$ Crystallin Domain Should Not Be Included in the Human Small Heat Shock Protein Family HSPB. Cell Stress Chaperones 15, 457-461. doi:10.1007/s12192009-0155-4

Karolczak-Bayatti, M., Sweeney, M., Cheng, J., Edey, L., Robson, S. C., Ulrich, S. M., et al. (2011). Acetylation of Heat Shock Protein 20 (Hsp20) Regulates Human Myometrial Activity. J. Biol. Chem. 286, 34346-34355. doi:10.1074/jbc.M111. 278549

Kato, K., Goto, S., Inaguma, Y., Hasegawa, K., Morishita, R., and Asano, T. (1994). Purification and Characterization of a $20-\mathrm{kDa}$ Protein that Is Highly Homologous to Alpha B Crystallin. J. Biol. Chem. 269, 15302-15309. Available at: https://www.ncbi.nlm.nih.gov/pubmed/8195168. doi:10.1016/ s0021-9258(17)36606-1

Khoshaman, K., Yousefi, R., Tamaddon, A. M., Saso, L., and Moosavi-Movahedi, A. A. (2015). The Impact of Hydrogen Peroxide on Structure, Stability and Functional Properties of Human R12C Mutant aA-Crystallin: The Imperative Insights into Pathomechanism of the Associated Congenital Cataract Incidence. Free Radic. Biol. Med. 89, 819-830. doi:10.1016/j. freeradbiomed.2015.09.013

Khoshaman, K., Yousefi, R., Tamaddon, A. M., Abolmaali, S. S., Oryan, A., Moosavi-Movahedi, A. A., et al. (2017). The Impact of Different Mutations at Arg54 on Structure, Chaperone-like Activity and Oligomerization State of Human aA-Crystallin: The Pathomechanism Underlying Congenital CataractCausing Mutations R54L, R54P and R54C. Biochim. Biophys. Acta (Bba) Proteins Proteomics 1865, 604-618. doi:10.1016/j.bbapap.2017.02.003

Kim, M. V., Seit-Nebi, A. S., Marston, S. B., and Gusev, N. B. (2004). Some Properties of Human Small Heat Shock Protein Hsp22 (H11 or HspB8). Biochem. Biophys. Res. Commun. 315, 796-801. doi:10.1016/j.bbrc.2004.01.130

Kim, M. V., Kasakov, A. S., Seit-Nebi, A. S., Marston, S. B., and Gusev, N. B. (2006). Structure and Properties of K141E Mutant of Small Heat Shock Protein HSP22 (HspB8, H11) that Is Expressed in Human Neuromuscular Disorders. Arch. Biochem. Biophys. 454, 32-41. doi:10.1016/j.abb.2006.07.014

Kolb, S. J., Snyder, P. J., Poi, E. J., Renard, E. A., Bartlett, A., Gu, S., et al. (2010). Mutant Small Heat Shock Protein B3 Causes Motor Neuropathy: Utility of a Candidate Gene Approach. Neurology 74, 502-506. doi:10.1212/WNL. ob013e3181cef84a
Komalavilas, P., Penn, R. B., Flynn, C. R., Thresher, J., Lopes, L. B., Furnish, E. J., et al. (2008). The Small Heat Shock-Related Protein, HSP20, Is a cAMPdependent Protein Kinase Substrate that Is Involved in Airway Smooth Muscle Relaxation. Am. J. Physiol.-Lung Cell Mol. Physiol. 294, L69-L78. doi:10.1152/ ajplung.00235.2007

Kostera-Pruszczyk, A., Suszek, M., Płoski, R., Franaszczyk, M., Potulska-Chromik, A., Pruszczyk, P., et al. (2015). BAG3-related Myopathy, Polyneuropathy and Cardiomyopathy with Long QT Syndrome. J. Muscle Res. Cel. Motil. 36, 423-432. doi:10.1007/s10974-015-9431-3

Kozawa, O., Matsuno, H., Niwa, M., Hatakeyama, D., Oiso, Y., Kato, K., et al. (2002). HSP20, Low-Molecular-Weight Heat Shock-Related Protein, Acts Extracellularly as a Regulator of Platelet Functions :a Novel Defense Mechanism. Life Sci. 72, 113-124. doi:10.1016/s0024-3205(02) 02144-6

Krief, S., Faivre, J.-F., Robert, P., Le Douarin, B., Brument-Larignon, N., Lefrère, I., et al. (1999). Identification and Characterization of cvHsp. J. Biol. Chem. 274, 36592-36600. doi:10.1074/jbc.274.51.36592

Kriehuber, T., Rattei, T., Weinmaier, T., Bepperling, A., Haslbeck, M., and Buchner, J. (2010). Independent Evolution of the Core Domain and its Flanking Sequences in Small Heat Shock Proteins. FASEB j. 24, 3633-3642. doi:10.1096/fj.10-156992

La Padula, V., Staszewski, O., Nestel, S., Busch, H., Boerries, M., Roussa, E., et al. (2016). HSPB3 Protein Is Expressed in Motoneurons and Induces Their Survival after Lesion-Induced Degeneration. Exp. Neurol. 286, 40-49. doi:10. 1016/j.expneurol.2016.08.014

Lahvic, J. L., Ji, Y., Marin, P., Zuflacht, J. P., Springel, M. W., Wosen, J. E., et al. (2013). Small Heat Shock Proteins Are Necessary for Heart Migration and Laterality Determination in Zebrafish. Dev. Biol. 384, 166-180. doi:10.1016/j. ydbio.2013.10.009

Lam, W. Y., Tsui, S. K. W., Law, P. T. W., Luk, S. C. W., Fung, K. P., Lee, C. Y., et al. (1996). Isolation and Characterization of a Human Heart cDNA Encoding a New Member of the Small Heat Shock Protein Family - HSPL27. Biochim. Biophys. Acta (Bba) - Mol. Cel Res. 1314, 120-124. doi:10.1016/s0167-4889(96) 00121-8

Laššuthová, P., Šafka Brožková, D., Krůtová, M., Neupauerová, J., Haberlová, J., Mazanec, R., et al. (2016). Improving Diagnosis of Inherited Peripheral Neuropathies through Gene Panel Analysis. Orphanet J. Rare Dis. 11, 118. doi:10.1186/s13023-016-0500-5

Laurie, K. J., Dave, A., Straga, T., Souzeau, E., Chataway, T., Sykes, M. J., et al. (2013). Identification of a Novel Oligomerization Disrupting Mutation inCRYAAAssociated with Congenital Cataract in a South Australian Family. Hum. Mutat. 34, 435-438. doi:10.1002/humu.22260

Lavoie, J. N., Lambert, H., Hickey, E., Weber, L. A., and Landry, J. (1995). Modulation of Cellular Thermoresistance and Actin Filament Stability Accompanies Phosphorylation-Induced Changes in the Oligomeric Structure of Heat Shock Protein 27. Mol. Cel. Biol. 15, 505-516. doi:10.1128/MCB.15. 1.505

Lee, S., Carson, K., Rice-Ficht, A., and Good, T. (2005). Hsp20, a Novel -crystallin, Prevents A Fibril Formation and Toxicity. Protein Sci. 14, 593-601. doi:10.1110/ ps. 041020705

Lee, H., Cherk, S., Chan, S., Wong, S., Tong, T., Ho, W., et al. (2012). BAG3-related Myofibrillar Myopathy in a Chinese Family. Clin. Genet. 81, 394-398. doi:10. 1111/j.1399-0004.2011.01659.x

Lee, J., Jung, S.-C., Joo, J., Choi, Y.-R., Moon, H. W., Kwak, G., et al. (2015). Overexpression of Mutant HSP27 Causes Axonal Neuropathy in Mice. J. Biomed. Sci. 22, 43. doi:10.1186/s12929-015-0154-y

Leroux, M. R., Melki, R., Gordon, B., Batelier, G., and Candido, E. P. M. (1997). Structure-function Studies on Small Heat Shock Protein Oligomeric Assembly and Interaction with Unfolded Polypeptides. J. Biol. Chem. 272, 24646-24656. doi:10.1074/jbc.272.39.24646

Lewis, C., Carberry, S., and Ohlendieck, K. (2009). Proteomic Profiling of X-Linked Muscular Dystrophy. J. Muscle Res. Cel Motil. 30, 267-279. doi:10.1007/s10974009-9197-6

Lewis-Smith, D. J., Duff, J., Pyle, A., Griffin, H., Polvikoski, T., Birchall, D., et al. (2016). NovelHSPB1mutation Causes Both Motor Neuronopathy and Distal Myopathy. Neurol. Genet. 2, e110. doi:10.1212/NXG.0000000000000110

Li, H., Li, C., Lu, Q., Su, T., Ke, T., Li, D. W.-C., et al. (2008). Cataract Mutation P20S of $\alpha$ B-crystallin Impairs Chaperone Activity of $\alpha \mathrm{A}$-crystallin and Induces 
Apoptosis of Human Lens Epithelial Cells. Biochim. Biophys. Acta (Bba) - Mol. Basis Dis. 1782, 303-309. doi:10.1016/j.bbadis.2008.01.011

Li, F.-F., Yang, M., Ma, X., Zhang, Q., Zhang, M., Wang, S.-Z., et al. (2010). Autosomal Dominant Congenital Nuclear Cataracts Caused by a CRYAA Gene Mutation. Curr. Eye Res. 35, 492-498. doi:10.3109/02713681003624901

Li, L., Fan, D.-B., Zhao, Y.-T., Li, Y., Kong, D.-Q., Cai, F.-F., et al. (2017). Two Novel Mutations Identified in ADCC Families Impair Crystallin Protein Distribution and Induce Apoptosis in Human Lens Epithelial Cells. Sci. Rep. 7, 17848. doi:10.1038/s41598-017-18222-z

Li, B., Li, X., Mao, R., Liu, M., Fu, L., Shi, L., et al. (2021). Overexpression of ODF1 in Gastrointestinal Tract Neuroendocrine Neoplasms: a Novel Potential Immunohistochemical Biomarker for Well-Differentiated Neuroendocrine Tumors. Endocr. Pathol. 32, 301-308. doi:10.1007/ s12022-020-09649-8

Liao, W.-C., Juo, L.-Y., Shih, Y.-L., Chen, Y.-H., and Yan, Y.-T. (2017). HSPB7 Prevents Cardiac Conduction System Defect through Maintaining Intercalated Disc Integrity. Plos Genet. 13, e1006984. doi:10.1371/journal.pgen.1006984

Lin, W., Yang, Z., Lu, Y., and Zhao, X. (2014). Refined Purification of Large Amounts of Rat cvHsp/HspB7 and Partial Biological Characterization In Vitro. Ppl 21, 503-510. doi:10.2174/092986652105140218121109

Litt, M., Kramer, P., LaMorticella, D. M., Murphey, W., Lovrien, E. W., and Weleber, R. G. (1998). Autosomal Dominant Congenital Cataract Associated with a Missense Mutation in the Human Alpha Crystallin Gene CRYAA. Hum. Mol. Genet. 7, 471-474. doi:10.1093/hmg/7.3.471

Liu, J.-P., Schlosser, R., Ma, W.-Y., Dong, Z., Feng, H., Liu, L., et al. (2004). Human $\alpha \mathrm{A}$ - and $\alpha \mathrm{B}$-crystallins Prevent UVA-Induced Apoptosis through Regulation of PKCa, RAF/MEK/ERK and AKT Signaling Pathways. Exp. Eye Res. 79, 393-403. Available at: http://www.ncbi.nlm.nih.gov/pubmed/15669141. doi:10.1016/j.exer.2004.06.015

Liu, G. S., Gardner, G., Adly, G., Jiang, M., Cai, W. F., Lam, C. K., et al. (2018a). A Novel Human S10F-Hsp20 Mutation Induces Lethal Peripartum Cardiomyopathy. J. Cell. Mol. Med. 22, 3911-3919. doi:10.1111/jcmm.13665

Liu, G.-S., Zhu, H., Cai, W.-F., Wang, X., Jiang, M., Essandoh, K., et al. (2018b). Regulation of BECN1-Mediated Autophagy by HSPB6: Insights from a Human HSPB6S10F Mutant. Autophagy 14, 80-97. doi:10.1080/15548627.2017. 1392420

Lu, X.-G., Yu, U., Han, C.-X., Mai, J.-H., Liao, J.-X., and Hou, Y.-Q. (2021). c.3G>A Mutation in the CRYAB Gene that Causes Fatal Infantile Hypertonic Myofibrillar Myopathy in the Chinese Population. J. Integr. Neurosci. 20, 143-151. doi:10.31083/j.jin.2021.01.267

Ma, X., Jiao, X., Ma, Z., and Hejtmancik, J. F. (2016). Polymorphism Rs7278468 Is Associated with Age-Related Cataract through Decreasing Transcriptional Activity of the CRYAA Promoter. Sci. Rep. 6, 23206. doi:10.1038/srep23206

Ma, K., Luo, D., Tian, T., Li, N., He, X., Rao, C., et al. (2019). A Novel Homozygous Initiation Codon Variant Associated with Infantile Alpha-Bcrystallinopathy in a Chinese Family. Mol. Genet. Genomic Med. 7, e825. doi:10.1002/mgg3.825

Maaroufi, H., and Tanguay, R. M. (2013). Analysis and Phylogeny of Small Heat Shock Proteins from marine Viruses and Their Cyanobacteria Host. PLoS One 8, e81207. doi:10.1371/journal.pone.0081207

Mackay, D. S., Andley, U. P., and Shiels, A. (2003). Cell Death Triggered by a Novel Mutation in the alphaA-Crystallin Gene Underlies Autosomal Dominant Cataract Linked to Chromosome 21q. Eur. J. Hum. Genet. 11, 784-793. doi:10.1038/sj.ejhg.5201046

Maddala, R., and Rao, V. P. (2005). a-Crystallin Localizes to the Leading Edges of Migrating Lens Epithelial Cells. Exp. Cel. Res. 306, 203-215. doi:10.1016/j.yexcr. 2005.01.026

Maloyan, A., Sanbe, A., Osinska, H., Westfall, M., Robinson, D., Imahashi, K.-i., et al. (2005). Mitochondrial Dysfunction and Apoptosis Underlie the Pathogenic Process in a-B-Crystallin Desmin-Related Cardiomyopathy. Circulation 112, 3451-3461. doi:10.1161/CIRCULATIONAHA.105.572552

Marakhonov, A. V., Voskresenskaya, A. A., Ballesta, M. J., Konovalov, F. A., Vasilyeva, T. A., Blanco-Kelly, F., et al. (2020). Expanding the Phenotype of CRYAA Nucleotide Variants to a Complex Presentation of Anterior Segment Dysgenesis. Orphanet J. Rare Dis. 15, 207. doi:10.1186/s13023-020-01484-8

Marcos, A. T., Amorós, D., Muñoz-Cabello, B., Galán, F., Rivas Infante, E., AlcarazMas, L., et al. (2020). A Novel Dominant Mutation inCRYABgene Leading to a Severe Phenotype with Childhood Onset. Mol. Genet. Genomic Med. 8, e1290. doi:10.1002/mgg3.1290
Mateju, D., Franzmann, T. M., Patel, A., Kopach, A., Boczek, E. E., Maharana, S., et al. (2017). An Aberrant Phase Transition of Stress Granules Triggered by Misfolded Protein and Prevented by Chaperone Function. EMBO J. 36, 1669-1687. doi:10.15252/embj.201695957

Matkovich, S. J., Van Booven, D. J., Hindes, A., Kang, M. Y., Druley, T. E., Vallania, F. L. M., et al. (2010). Cardiac Signaling Genes Exhibit Unexpected Sequence Diversity in Sporadic Cardiomyopathy, Revealing HSPB7 Polymorphisms Associated with Disease. J. Clin. Invest. 120, 280-289. doi:10.1172/JCI39085

McLemore, E. C., Tessier, D. J., Flynn, C. R., Furnish, E. J., Komalavilas, P., Thresher, J. S., et al. (2004). Transducible Recombinant Small Heat ShockRelated Protein, HSP20, Inhibits Vasospasm and Platelet Aggregation. Surgery 136, 573-578. doi:10.1016/j.surg.2004.04.024

Meister-Broekema, M., Freilich, R., Jagadeesan, C., Rauch, J. N., Bengoechea, R., Motley, W. W., et al. (2018). Myopathy Associated BAG3 Mutations lead to Protein Aggregation by Stalling Hsp70 Networks. Nat. Commun. 9, 5342. doi:10.1038/s41467-018-07718-5

Mercer, E. J., Lin, Y.-F., Cohen-Gould, L., and Evans, T. (2018). Hspb7 Is a Cardioprotective Chaperone Facilitating Sarcomeric Proteostasis. Dev. Biol. 435, 41-55. doi:10.1016/j.ydbio.2018.01.005

Michiel, M., Skouri-Panet, F., Duprat, E., Simon, S., Férard, C., Tardieu, A., et al. (2009). Abnormal Assemblies and Subunit Exchange of aB-Crystallin R120 Mutants Could Be Associated with Destabilization of the Dimeric Substructure. Biochemistry 48, 442-453. doi:10.1021/bi8014967

Minoia, M., Grit, C., and Kampinga, H. H. (2014). HSPA1A-independent Suppression of PARK2 C289G Protein Aggregation by Human Small Heat Shock Proteins. Mol. Cell Biol. 34, 3570-3578. doi:10.1128/MCB.00698-14

Miron, T., Vancompernolle, K., Vandekerckhove, J., Wilchek, M., and Geiger, B. (1991). A 25-kD Inhibitor of Actin Polymerization Is a Low Molecular Mass Heat Shock Protein. J. Cel Biol 114, 255-261. doi:10.1083/jcb.114.2.255

Mitzelfelt, K. A., Limphong, P., Choi, M. J., Kondrat, F. D. L., Lai, S., Kolander, K. D., et al. (2016). The Human 343delT HSPB5 Chaperone Associated with EarlyOnset Skeletal Myopathy Causes Defects in Protein Solubility. J. Biol. Chem. 291, 14939-14953. doi:10.1074/jbc.M116.730481

Morelli, F. F., Mediani, L., Heldens, L., Bertacchini, J., Bigi, I., Carrà, A. D., et al. (2017a). An Interaction Study in Mammalian Cells Demonstrates Weak Binding of HSPB2 to BAG3, Which Is Regulated by HSPB3 and Abrogated by HSPB8. Cell Stress Chaperones 22, 531-540. doi:10.1007/s12192-017-0769-x

Morelli, F. F., Verbeek, D. S., Bertacchini, J., Vinet, J., Mediani, L., Marmiroli, S., et al. (2017b). Aberrant Compartment Formation by HSPB2 Mislocalizes Lamin A and Compromises Nuclear Integrity and Function. Cel. Rep. 20, 2100-2115. doi:10.1016/j.celrep.2017.08.018

Morrison, L. E., Whittaker, R. J., Klepper, R. E., Wawrousek, E. F., and Glembotski, C. C. (2004). Roles for aB-crystallin and HSPB2 in Protecting the Myocardium from Ischemia-Reperfusion-Induced Damage in a KO Mouse Model. Am. J. Physiol.Heart Circ. Physiol. 286, H847-H855. doi:10.1152/ajpheart.00715.2003

Mukherjee, T., Ramaglia, V., Abdel-Nour, M., Bianchi, A. A., Tsalikis, J., Chau, H. N., et al. (2021). The eIF2 $\alpha$ Kinase HRI Triggers the Autophagic Clearance of Cytosolic Protein Aggregates. J. Biol. Chem. 296, 100050. doi:10.1074/jbc. RA120.014415

Muranova, L. K., Weeks, S. D., Strelkov, S. V., and Gusev, N. B. (2015). Characterization of Mutants of Human Small Heat Shock Protein HspB1 Carrying Replacements in the N-Terminal Domain and Associated with Hereditary Motor Neuron Diseases. PLoS One 10, e0126248. doi:10.1371/ journal.pone.0126248

Muranova, L. K., Strelkov, S. V., and Gusev, N. B. (2020). Effect of CataractAssociated Mutations in the N-Terminal Domain of aB-crystallin (HspB5). Exp. Eye Res. 197, 108091. doi:10.1016/j.exer.2020.108091

Muranova, L. K., Shatov, V. M., Slushchev, A. V., and Gusev, N. B. (2021). Quaternary Structure and Hetero-Oligomerization of Recombinant Human Small Heat Shock Protein HspB7 (cvHsp). Ijms 22, 7777. doi:10.3390/ ijms 22157777

Mymrikov, E. V., Bukach, O. V., Seit-Nebi, A. S., and Gusev, N. B. (2010). The Pivotal Role of the $\beta 7$ Strand in the Intersubunit Contacts of Different Human Small Heat Shock Proteins. Cell Stress Chaperones 15, 365-377. doi:10.1007/ s12192-009-0151-8

Mymrikov, E. V., Daake, M., Richter, B., Haslbeck, M., and Buchner, J. (2017). The Chaperone Activity and Substrate Spectrum of Human Small Heat Shock Proteins. J. Biol. Chem. 292, 672-684. doi:10.1074/jbc.M116.760413 
Mymrikov, E. V., Riedl, M., Peters, C., Weinkauf, S., Haslbeck, M., and Buchner, J. (2020). Regulation of Small Heat-Shock Proteins by Hetero-Oligomer Formation. J. Biol. Chem. 295, 158-169. doi:10.1074/jbc.RA119.011143

Nakagawa, M., Tsujimoto, N., Nakagawa, H., Iwaki, T., Fukumaki, Y., and Iwaki, A. (2001). Association of HSPB2, a Member of the Small Heat Shock Protein Family, with Mitochondria. Exp. Cel Res. 271, 161-168. doi:10.1006/excr.2001. 5362

Nakhro, K., Park, J.-M., Kim, Y. J., Yoon, B. R., Yoo, J. H., Koo, H., et al. (2013). A Novel Lys141Thr Mutation in Small Heat Shock Protein 22 (HSPB8) Gene in Charcot-Marie-Tooth Disease Type 2L. Neuromuscul. Disord. 23, 656-663. doi:10.1016/j.nmd.2013.05.009

Nam, D. E., Nam, S. H., Lee, A. J., Hong, Y. B., Choi, B.-O., and Chung, K. W. (2018). Small Heat Shock Protein B3 (HSPB3) Mutation in an Axonal CharcotMarie-Tooth Disease Family. J. Peripher. Nerv Syst. 23, 60-66. doi:10.1111/jns. 12249

Nefedova, V. V., Datskevich, P. N., Sudnitsyna, M. V., Strelkov, S. V., and Gusev, N. B. (2013a). Physico-chemical Properties of R140G and K141Q Mutants of Human Small Heat Shock Protein HspB1 Associated with Hereditary Peripheral Neuropathies. Biochimie 95, 1582-1592. doi:10.1016/j.biochi.2013. 04.014

Nefedova, V. V., Sudnitsyna, M. V., Strelkov, S. V., and Gusev, N. B. (2013b). Structure and Properties of G84R and L99M Mutants of Human Small Heat Shock Protein HspB1 Correlating with Motor Neuropathy. Arch. Biochem. Biophys. 538, 16-24. doi:10.1016/j.abb.2013.07.028

Nefedova, V. V., Sudnitsyna, M. V., and Gusev, N. B. (2017). Interaction of Small Heat Shock Proteins with Light Component of Neurofilaments (NFL). Cell Stress Chaperones 22, 467-479. doi:10.1007/s12192-016-0757-6

Nicolaou, P., Knöll, R., Haghighi, K., Fan, G.-C., Dorn, G. W., Hasenfuß, G., et al. (2008). Human Mutation in the Anti-apoptotic Heat Shock Protein 20 Abrogates its Cardioprotective Effects. J. Biol. Chem. 283, 33465-33471. doi:10.1074/jbc.M802307200

Nicolau, S., Liewluck, T., Elliott, J. L., Engel, A. G., and Milone, M. (2020). A Novel Heterozygous Mutation in the C-Terminal Region of HSPB8 Leads to LimbGirdle Rimmed Vacuolar Myopathy. Neuromuscul. Disord. 30, 236-240. doi:10. 1016/j.nmd.2020.02.005

Nivon, M., Fort, L., Muller, P., Richet, E., Simon, S., Guey, B., et al. (2016). NFkB Is a central Regulator of Protein Quality Control in Response to Protein Aggregation Stresses via Autophagy Modulation. MBoC 27, 1712-1727. doi:10.1091/mbc.E15-12-0835

Niwa, M., Kozawa, O., Matsuno, H., Kato, K., and Uematsu, T. (2000). Small Molecular Weight Heat Shock-Related Protein, HSP20, Exhibits an Antiplatelet Activity by Inhibiting Receptor-Mediated Calcium Influx. Life Sci. 66, PL7-12. doi:10.1016/s0024-3205(99)00566-4

Oliveira, A. O., Osmand, A., Outeiro, T. F., Muchowski, P. J., and Finkbeiner, S. (2016). aB-Crystallin Overexpression in Astrocytes Modulates the Phenotype of the BACHD Mouse Model of Huntington's Disease. Hum. Mol. Genet. 25, 1677-1689. doi:10.1093/hmg/ddw028

Ousman, S. S., Tomooka, B. H., van Noort, J. M., Wawrousek, E. F., O'Conner, K., Hafler, D. A., et al. (2007). Protective and Therapeutic Role for aB-crystallin in Autoimmune Demyelination. Nature 448, 474-479. doi:10.1038/nature05935

Pandey, P., Farber, R., Nakazawa, A., Kumar, S., Bharti, A., Nalin, C., et al. (2000). Hsp27 Functions as a Negative Regulator of Cytochrome C-Dependent Activation of Procaspase-3. Oncogene 19, 1975-1981. doi:10.1038/sj.onc. 1203531

Pang, M., Su, J.-T., Feng, S., Tang, Z.-W., Gu, F., Zhang, M., et al. (2010). Effects of Congenital Cataract Mutation R116H on aA-crystallin Structure, Function and Stability. Biochim. Biophys. Acta (Bba) - Proteins Proteomics 1804, 948-956. doi:10.1016/j.bbapap.2010.01.001

Parcellier, A., Brunet, M., Schmitt, E., Col, E., Didelot, C., Hammann, A., et al. (2006). HSP27 Favors Ubiquitination and Proteasomal Degradation of P27 Kip1 and Helps S-phase Re-entry in Stressed Cells. FASEB j. 20, 1179-1181. doi:10.1096/fj.05-4184fje

Pasta, S. Y., Raman, B., Ramakrishna, T., and Rao, C. M. (2003). Role of the Conserved SRLFDQFFG Region of a-Crystallin, a Small Heat Shock Protein. J. Biol. Chem. 278, 51159-51166. doi:10.1074/jbc.M307523200

Pattison, J. S., Osinska, H., and Robbins, J. (2011). Atg7 Induces Basal Autophagy and Rescues Autophagic Deficiency in CryAB R120G Cardiomyocytes. Circ. Res. 109, 151-160. doi:10.1161/CIRCRESAHA.110.237339
Paul, C., Simon, S., Gibert, B., Virot, S., Manero, F., and Arrigo, A.-P. (2010). Dynamic Processes that Reflect Anti-apoptotic Strategies Set up by HspB1 (Hsp27). Exp. Cel Res. 316, 1535-1552. doi:10.1016/j.yexcr.2010.03.006

Pavlová, T., Novák, J., Zlámal, F., and Bienertová-Vašků, J. (2018). HSPB7 Gene Polymorphism Associated with Anthropometric Parameters of Obesity and Fat Intake in a Central European Population. Cent. Eur. J. Public Health 26, 272-277. doi:10.21101/cejph.a4921

Peferoen, L. A. N., Gerritsen, W. H., Breur, M., Ummenthum, K. M. D., PeferoenBaert, R. M. B., van der Valk, P., et al. (2015). Small Heat Shock Proteins Are Induced during Multiple Sclerosis Lesion Development in white but Not Grey Matter. Acta Neuropathol. Commun. 3, 87. doi:10.1186/s40478-015-0267-2

Perng, M. D., Cairns, L., van den IJssel, P., Prescott, A., Hutcheson, A. M., and Quinlan, R. A. (1999). Intermediate Filament Interactions Can Be Altered by HSP27 and alphaB-Crystallin. J. Cel Sci 112 (Pt 13), 2099-2112. Available at: https://www.ncbi.nlm.nih.gov/pubmed/10362540. doi:10.1242/jcs.112.13.2099

Petersen, C., Füzesi, L., and Hoyer-Fender, S. (1999). Outer Dense Fibre Proteins from Human Sperm Tail: Molecular Cloning and Expression Analyses of Two cDNA Transcripts Encoding Proteins of $70 \mathrm{kDa}$. Mol. Hum. Reprod. 5, 627-635. doi:10.1093/molehr/5.7.627

Pinz, I., Robbins, J., Rajasekaran, N. S., Benjamin, I. J., and Ingwall, J. S. (2008). Unmasking Different Mechanical and Energetic Roles for the Small Heat Shock Proteins CryAB and HSPB2 Using Genetically Modified Mouse Hearts. FASEB j. 22, 84-92. doi:10.1096/fj.07-8130com

Poulain, P., Gelly, J.-C., and Flatters, D. (2010). Detection and Architecture of Small Heat Shock Protein Monomers. PLoS One 5, e9990. doi:10.1371/journal. pone.0009990

Prabhu, S., Raman, B., Ramakrishna, T., and Rao, C. M. (2012). HspB2/myotonic Dystrophy Protein Kinase Binding Protein (MKBP) as a Novel Molecular Chaperone: Structural and Functional Aspects. PLoS One 7, e29810. doi:10. 1371/journal.pone.0029810

Pras, E., Frydman, M., Levy-Nissenbaum, E., Bakhan, T., Raz, J., Assia, E. I., et al. (2000). A Nonsense Mutation (W9X) in CRYAA Causes Autosomal Recessive Cataract in an Inbred Jewish Persian Family. Invest. Ophthalmol. Vis. Sci. 41, 3511-3515. Available at: https://www.ncbi.nlm.nih.gov/pubmed/11006246.

Qi, A.-Q., Zhang, Y.-H., Qi, Q.-D., Liu, Y.-H., and Zhu, J.-L. (2019). Overexpressed HspB6 Underlines a Novel Inhibitory Role in Kainic Acid-Induced Epileptic Seizure in Rats by Activating the cAMP-PKA Pathway. Cell. Mol. Neurobiol. 39, 111-122. doi:10.1007/s10571-018-0637-y

Qian, J., Ren, X., Wang, X., Zhang, P., Jones, W. K., Molkentin, J. D., et al. (2009). Blockade of Hsp20 Phosphorylation Exacerbates Cardiac Ischemia/reperfusion Injury by Suppressed Autophagy and Increased Cell Death. Circ. Res. 105, 1223-1231. doi:10.1161/CIRCRESAHA.109.200378

Rahman, M. S., and Kim, Y.-S. (2020). PINK1-PRKN Mitophagy Suppression by Mangiferin Promotes a Brown-Fat-Phenotype via PKA-P38 MAPK Signalling in Murine C3H10T1/2 Mesenchymal Stem Cells. Metabolism 107, 154228. doi:10.1016/j.metabol.2020.154228

Rajagopal, P., Liu, Y., Shi, L., Clouser, A. F., and Klevit, R. E. (2015). Structure of the a-crystallin Domain from the Redox-Sensitive Chaperone, HSPB1. J. Biomol. NMR 63, 223-228. doi:10.1007/s10858-015-9973-0

Raju, I., and Abraham, E. C. (2013). Mutants of Human aB-crystallin Cause Enhanced Protein Aggregation and Apoptosis in Mammalian Cells: Influence of Co-expression of HspB1. Biochem. Biophysical Res. Commun. 430, 107-112. doi:10.1016/j.bbrc.2012.11.051

Rauch, J. N., Tse, E., Freilich, R., Mok, S.-A., Makley, L. N., Southworth, D. R., et al. (2017). BAG3 Is a Modular, Scaffolding Protein that Physically Links Heat Shock Protein 70 (Hsp70) to the Small Heat Shock Proteins. J. Mol. Biol. 429, 128-141. doi:10.1016/j.jmb.2016.11.013

Reilich, P., Schoser, B., Schramm, N., Krause, S., Schessl, J., Kress, W., et al. (2010). The p.G154S Mutation of the Alpha-B Crystallin Gene (CRYAB) Causes LateOnset Distal Myopathy. Neuromuscul. Disord. 20, 255-259. doi:10.1016/j.nmd. 2010.01.012

Rembold, C. M., Foster, D. B., Strauss, J. D., Wingard, C. J., and Eyk, J. E. (2000). cGMP-mediated Phosphorylation of Heat Shock Protein 20 May Cause Smooth Muscle Relaxation without Myosin Light Chain Dephosphorylation in Swine Carotid Artery. J. Physiol. 524 (Pt 3), 865-878. doi:10.1111/j.1469-7793.2000. 00865.x

Robinson, M. L., and Overbeek, P. A. (1996). Differential Expression of Alpha Aand Alpha B-Crystallin during Murine Ocular Development. Invest. 
Ophthalmol. Vis. Sci. 37, 2276-2284. Available at: http://www.ncbi.nlm.nih. gov/pubmed/8843924.

Rosales, J., Sarker, K., Ho, N., Broniewska, M., Wong, P., Cheng, M., et al. (2007). ODF1 Phosphorylation by Cdk5/p35 Enhances ODF1-OIP1 Interaction. Cell. Physiol. Biochem. 20, 311-318. doi:10.1159/000107517

Rosenfeld, G. E., Mercer, E. J., Mason, C. E., and Evans, T. (2013). Small Heat Shock Proteins Hspb7 and Hspb12 Regulate Early Steps of Cardiac Morphogenesis. Dev. Biol. 381, 389-400. doi:10.1016/j.ydbio.2013.06.025

Rüdebusch, J., Benkner, A., Poesch, A., Dörr, M., Völker, U., Grube, K., et al. (2017). Dynamic Adaptation of Myocardial Proteome during Heart Failure Development. PLoS One 12, e0185915. doi:10.1371/journal. pone. 0185915

Rusmini, P., Crippa, V., Giorgetti, E., Boncoraglio, A., Cristofani, R., Carra, S., et al. (2013). Clearance of the Mutant Androgen Receptor in Motoneuronal Models of Spinal and Bulbar Muscular Atrophy. Neurobiol. Aging 34, 2585-2603. doi:10.1016/j.neurobiolaging.2013.05.026

Rusmini, P., Polanco, M. J., Cristofani, R., Cicardi, M. E., Meroni, M., Galbiati, M., et al. (2015). Aberrant Autophagic Response in the Muscle of A Knock-In Mouse Model of Spinal and Bulbar Muscular Atrophy. Sci. Rep. 5, 15174. doi:10. 1038/srep15174

Rusmini, P., Cristofani, R., Galbiati, M., Cicardi, M. E., Meroni, M., Ferrari, V., et al. (2017). The Role of the Heat Shock Protein B8 (HSPB8) in Motoneuron Diseases. Front. Mol. Neurosci. 10, 176. doi:10.3389/fnmol.2017.00176

Sanbe, A., Osinska, H., Saffitz, J. E., Glabe, C. G., Kayed, R., Maloyan, A., et al. (2004). Desmin-related Cardiomyopathy in Transgenic Mice: a Cardiac Amyloidosis. Proc. Natl. Acad. Sci. 101, 10132-10136. doi:10.1073/pnas. 0401900101

Sanbe, A., Marunouchi, T., Abe, T., Tezuka, Y., Okada, M., Aoki, S., et al. (2013). Phenotype of Cardiomyopathy in Cardiac-specific Heat Shock Protein B8 K141N Transgenic Mouse. J. Biol. Chem. 288, 8910-8921. doi:10.1074/jbc. M112.368324

Santhiya, S. T., Soker, T., Klopp, N., Illig, T., Prakash, M. V., Selvaraj, B., et al. (2006). Identification of a Novel, Putative Cataract-Causing Allele in CRYAA (G98R) in an Indian Family. Mol. Vis. 12, 768-773. Available at: http://www. ncbi.nlm.nih.gov/pubmed/16862070.

Selcen, D., and Engel, A. G. (2003). Myofibrillar Myopathy Caused by Novel Dominant Negative ?B-Crystallin Mutations. Ann. Neurol. 54, 804-810. doi:10. 1002/ana.10767

Selcen, D., Muntoni, F., Burton, B. K., Pegoraro, E., Sewry, C., Bite, A. V., et al. (2009). Mutation in BAG3 Causes Severe Dominant Childhood Muscular Dystrophy. Ann. Neurol. 65, 83-89. doi:10.1002/ana.21553

Semmler, A.-L., Sacconi, S., Bach, J. E., Liebe, C., Bürmann, J., Kley, R. A., et al. (2014). Unusual Multisystemic Involvement and a Novel BAG3 Mutation Revealed by NGS Screening in a Large Cohort of Myofibrillar Myopathies. Orphanet J. Rare Dis. 9, 121. doi:10.1186/s13023-014-0121-9

Shama, K. M., Suzuki, A., Harada, K., Fujitani, N., Kimura, H., Ohno, S., et al. (1999). Transient Up-Regulation of Myotonic Dystrophy Protein KinaseBinding Protein, MKBP, and HSP27 in the Neonatal Myocardium. Cell Struct. Funct. 24, 1-4. doi:10.1247/csf.24.1

Shammas, S. L., Waudby, C. A., Wang, S., Buell, A. K., Knowles, T. P. J., Ecroyd, H., et al. (2011). Binding of the Molecular Chaperone $\alpha B-C r y s t a l l i n$ to A $\beta$ Amyloid Fibrils Inhibits Fibril Elongation. Biophysical J. 101, 1681-1689. doi:10.1016/j. bpj.2011.07.056

Shao, X., and van der Hoorn, F. A. (1996). Self-Interaction of the Major 27Kilodalton Outer Dense Fiber Protein Is in Part Mediated by a Leucine Zipper Domain in the Rat1. Biol. Reprod. 55, 1343-1350. doi:10.1095/biolreprod55.6. 1343

Shao, X., Tarnasky, H. A., Lee, J. P., Oko, R., and van der Hoorn, F. A. (1999). Spag4, a Novel Sperm Protein, Binds Outer Dense-Fiber Protein Odf1 and Localizes to Microtubules of Manchette and Axoneme. Dev. Biol. 211, 109-123. doi:10.1006/dbio.1999.9297

Shao, X., Xue, J., and van der Hoorn, F. A. (2001). Testicular Protein Spag5 Has Similarity to Mitotic Spindle Protein Deepest and Binds Outer Dense Fiber Protein Odf1. Mol. Reprod. Dev. 59, 410-416. doi:10.1002/mrd.1047

Shatov, V. M., and Gusev, N. B. (2020). Physico-Chemical Properties of Two point Mutants of Small Heat Shock Protein HspB6 (Hsp20) with Abrogated Cardioprotection. Biochimie 174, 126-135. doi:10.1016/j.biochi.2020.04.021
Shatov, V. M., Strelkov, S. V., and Gusev, N. B. (2020). The Heterooligomerization of Human Small Heat Shock Proteins Is Controlled by Conserved Motif Located in the N-Terminal Domain. Ijms 21, 124248. doi:10.3390/ijms21124248

Shatov, V. M., Sluchanko, N. N., and Gusev, N. B. (2021). Replacement of Arg in the Conserved N-Terminal RLFDQxFG Motif Affects Physico-Chemical Properties and Chaperone-like Activity of Human Small Heat Shock Protein HspB8 (Hsp22). PLoS One 16, e0253432. doi:10.1371/journal. pone. 0253432

Shemetov, A. A., and Gusev, N. B. (2011). Biochemical Characterization of Small Heat Shock Protein HspB8 (Hsp22)-Bag3 Interaction. Arch. Biochem. Biophys. 513, 1-9. doi:10.1016/j.abb.2011.06.014

Shy, M., Rebelo, A. P., Feely, S. M., Abreu, L. A., Tao, F., Swenson, A., et al. (2018). Mutations in BAG3 Cause Adult-Onset Charcot-Marie-Tooth Disease. J. Neurol. Neurosurg. Psychiatry 89, 313-315. doi:10.1136/jnnp-2017-315929

Simon, S., Fontaine, J.-M., Martin, J. L., Sun, X., Hoppe, A. D., Welsh, M. J., et al. (2007a). Myopathy-Associated aB-Crystallin Mutants: Abnormal Phosphorylation, Intracellular Location, and Interactions With Other Small Heat Shock Proteins. J. Biol. Chem. 282, 34276-34287. doi:10.1074/jbc. M703267200

Simon, S., Michiel, M., Skouri-Panet, F., Lechaire, J. P., Vicart, P., and Tardieu, A. (2007b). Residue R120 Is Essential for the Quaternary Structure and Functional Integrity of Human aB-Crystallin. Biochemistry 46, 9605-9614. doi:10.1021/ bi7003125

Sin, Y. Y., and Baillie, G. S. (2015). Heat Shock Protein 20 (HSP20) Is a Novel Substrate for Protein Kinase D1 (PKD1). Cell Biochem. Funct. 33, 421-426. doi:10.1002/cbf.3147

Smith, C. C., Li, B., Liu, J., Lee, K.-S., and Aurelian, L. (2011). The Levels of H11/ HspB8 DNA Methylation in Human Melanoma Tissues and Xenografts Are a Critical Molecular Marker for 5-Aza-2'-Deoxycytidine Therapy. Cancer Invest. 29, 383-395. doi:10.3109/07357907.2011.584588

Song, Z., Si, N., and Xiao, W. (2018). A Novel Mutation in the CRYAA Gene Associated with Congenital Cataract and Microphthalmia in a Chinese Family. BMC Med. Genet. 19, 190. doi:10.1186/s12881-018-0695-5

Srivastava, A. K., Renusch, S. R., Naiman, N. E., Gu, S., Sneh, A., Arnold, W. D., et al. (2012). Mutant HSPB1 Overexpression in Neurons Is Sufficient to Cause Age-Related Motor Neuronopathy in Mice. Neurobiol. Dis. 47, 163-173. doi:10. 1016/j.nbd.2012.03.035

Stark, K., Esslinger, U. B., Reinhard, W., Petrov, G., Winkler, T., Komajda, M., et al. (2010). Genetic Association Study Identifies HSPB7 as a Risk Gene for Idiopathic Dilated Cardiomyopathy. Plos Genet. 6, e1001167. doi:10.1371/journal.pgen.1001167

Sudnitsyna, M. V., Seit-Nebi, A. S., and Gusev, N. B. (2012). Cofilin Weakly Interacts with 14-3-3 and Therefore Can Only Indirectly Participate in Regulation of Cell Motility by Small Heat Shock Protein HspB6 (Hsp20). Arch. Biochem. Biophys. 521, 62-70. doi:10.1016/j.abb.2012.03.010

Sugiyama, Y., Suzuki, A., Kishikawa, M., Akutsu, R., Hirose, T., Waye, M. M. Y., et al. (2000). Muscle Develops a Specific Form of Small Heat Shock Protein Complex Composed of MKBP/HSPB2 and HSPB3 during Myogenic Differentiation. J. Biol. Chem. 275, 1095-1104. doi:10.1074/jbc.275.2.1095

Sun, X., Fontaine, J.-M., Rest, J. S., Shelden, E. A., Welsh, M. J., and Benndorf, R. (2004). Interaction of Human HSP22 (HSPB8) with Other Small Heat Shock Proteins. J. Biol. Chem. 279, 2394-2402. doi:10.1074/jbc.M311324200

Sun, X., Fontaine, J.-M., Hoppe, A. D., Carra, S., DeGuzman, C., Martin, J. L., et al. (2010). Abnormal Interaction of Motor Neuropathy-Associated Mutant HspB8 (Hsp22) Forms with the RNA Helicase Ddx20 (Gemin3). Cell Stress Chaperones 15, 567-582. doi:10.1007/s12192-010-0169-y

Sun, W., Xiao, X., Li, S., Guo, X., and Zhang, Q. (2011). Mutation Analysis of 12 Genes in Chinese Families with Congenital Cataracts. Mol. Vis. 17, 2197-2206. Available at: http://www.ncbi.nlm.nih.gov/pubmed/21866213.

Suzuki, A., Sugiyama, Y., Hayashi, Y., Nyu-i, N., Yoshida, M., Nonaka, I., et al. (1998). MKBP, a Novel Member of the Small Heat Shock Protein Family, Binds and Activates the Myotonic Dystrophy Protein Kinase. J. Cel. Biol. 140, 1113-1124. doi:10.1083/jcb.140.5.1113

Tang, B.-s., Zhao, G.-h., Luo, W., Xia, K., Cai, F., Pan, Q., et al. (2005). Small HeatShock Protein 22 Mutated in Autosomal Dominant Charcot-Marie-Tooth Disease Type 2L. Hum. Genet. 116, 222-224. doi:10.1007/s00439-004-1218-3

Tannous, P., Zhu, H., Johnstone, J. L., Shelton, J. M., Rajasekaran, N. S., Benjamin, I. J., et al. (2008). Autophagy Is an Adaptive Response in Desmin-Related 
Cardiomyopathy. Proc. Natl. Acad. Sci. 105, 9745-9750. doi:10.1073/pnas. 0706802105

Tiago, T., Hummel, B., Morelli, F. F., Basile, V., Vinet, J., Galli, V., et al. (2021). Small Heat-Shock Protein HSPB3 Promotes Myogenesis by Regulating the Lamin B Receptor. Cell Death Dis 12, 452. doi:10.1038/s41419-021-03737-1

Tyson, E. K., Macintyre, D. A., Smith, R., Chan, E.-C., and Read, M. (2008). Evidence that a Protein Kinase A Substrate, Small Heat-Shock Protein 20, Modulates Myometrial Relaxation in Human Pregnancy. Endocrinology 149, 6157-6165. doi:10.1210/en.2008-0593

Ulbricht, A., Eppler, F. J., Tapia, V. E., van der Ven, P. F. M., Hampe, N., Hersch, N., et al. (2013). Cellular Mechanotransduction Relies on Tension-Induced and Chaperone-Assisted Autophagy. Curr. Biol. 23, 430-435. doi:10.1016/j.cub. 2013.01.064

van de Klundert, F. A. J. M., Smulders, R. H. P. H., Gijsen, M. L. J., Lindner, R. A., Jaenicke, R., Carver, J. A., et al. (1998). The Mammalian Small Heat-Shock Protein Hsp20 Forms Dimers and Is a Poor Chaperone. Eur. J. Biochem. 258, 1014-1021. doi:10.1046/j.1432-1327.1998.2581014.x

van der Smagt, J. J., Vink, A., Kirkels, J. H., Nelen, M., ter Heide, H., Molenschot, M. M. C., et al. (2014). Congenital Posterior Pole Cataract and Adult Onset Dilating Cardiomyopathy: Expanding the Phenotype of aBCrystallinopathies. Clin. Genet. 85, 381-385. doi:10.1111/cge.12169

van Montfort, R. L. M., Basha, E., Friedrich, K. L., Slingsby, C., and Vierling, E. (2001). Crystal Structure and Assembly of a Eukaryotic Small Heat Shock Protein. Nat. Struct. Biol. 8, 1025-1030. doi:10.1038/nsb722

Varlet, A. A., Fuchs, M., Luthold, C., Lambert, H., Landry, J., and Lavoie, J. N. (2017). Fine-tuning of Actin Dynamics by the HSPB8-BAG3 Chaperone Complex Facilitates Cytokinesis and Contributes to its Impact on Cell Division. Cell Stress Chaperones 22, 553-567. doi:10.1007/s12192-017-0780-2

Verschuure, P., Croes, Y., van den IJssel, P. R. L. A., Quinlan, R. A., de Jong, W. W., and Boelens, W. C. (2002). Translocation of Small Heat Shock Proteins to the Actin Cytoskeleton upon Proteasomal Inhibition. J. Mol. Cell Cardiol. 34, 117-128. doi:10.1006/jmcc.2001.1493

Verschuure, P., Tatard, C., Boelens, W. C., Grongnet, J.-F., and David, J. C. (2003). Expression of Small Heat Shock Proteins HspB2, HspB8, Hsp20 and cvHsp in Different Tissues of the Perinatal Developing Pig. Eur. J. Cel Biol. 82, 523-530. doi:10.1078/0171-9335-00337

Vicart, P., Caron, A., Guicheney, P., Li, Z., Prévost, M.-C., Faure, A., et al. (1998). A Missense Mutation in the aB-crystallin Chaperone Gene Causes a DesminRelated Myopathy. Nat. Genet. 20, 92-95. doi:10.1038/1765

Villard, E., Perret, C., Gary, F., Proust, C., Dilanian, G., Hengstenberg, C., et al. (2011). A Genome-wide Association Study Identifies Two Loci Associated with Heart Failure Due to Dilated Cardiomyopathy. Eur. Hear. J. 32, 1065-1076. doi:10.1093/eurheartj/ehr105

Vos, M. J., Kanon, B., and Kampinga, H. H. (2009). HSPB7 Is a SC35 Speckle Resident Small Heat Shock Protein. Biochim. Biophys. Acta (Bba) - Mol. Cel. Res. 1793, 1343-1353. doi:10.1016/j.bbamcr.2009.05.005

Vos, M. J., Zijlstra, M. P., Kanon, B., van Waarde-Verhagen, M. A. W. H., Brunt, E. R. P., Oosterveld-Hut, H. M. J., et al. (2010). HSPB7 Is the Most Potent polyQ Aggregation Suppressor within the HSPB Family of Molecular Chaperones. Hum. Mol. Genet. 19, 4677-4693. doi:10.1093/hmg/ddq398

Wang, X., Osinska, H., Klevitsky, R., Gerdes, A. M., Nieman, M., Lorenz, J., et al. (2001). Expression of R120G- $\alpha$ B-Crystallin Causes Aberrant Desmin and $\alpha B-$ Crystallin Aggregation and Cardiomyopathy in Mice. Circ. Res. 89, 84-91. doi:10.1161/hh1301.092688

Wang, M., Ding, H., Kang, J., Hu, K., Lu, W., Zhou, X., et al. (2016). Association between Polymorphisms of the HSPB7 Gene and Cheyne-Stokes Respiration with central Sleep Apnea in Patients with Dilated Cardiomyopathy and Congestive Heart Failure. Int. J. Cardiol. 221, 926-931. doi:10.1016/j.ijcard. 2016.07.107

Watson, G. W., and Andley, U. P. (2010). Activation of the Unfolded Protein Response by a Cataract-Associated aA-Crystallin Mutation. Biochem. Biophys. Res. Commun. 401, 192-196. doi:10.1016/j.bbrc.2010.09.023

Waudby, C. A., Knowles, T. P. J., Devlin, G. L., Skepper, J. N., Ecroyd, H., Carver, J. A., et al. (2010). The Interaction of $\alpha B$-Crystallin with Mature $\alpha$-Synuclein Amyloid Fibrils Inhibits Their Elongation. Biophys. J. 98, 843-851. doi:10.1016/ j.bpj.2009.10.056

Weeks, S. D., Baranova, E. V., Heirbaut, M., Beelen, S., Shkumatov, A. V., Gusev, N. B., et al. (2014). Molecular Structure and Dynamics of the Dimeric Human
Small Heat Shock Protein HSPB6. J. Struct. Biol. 185, 342-354. doi:10.1016/j.jsb. 2013.12.009

Wettstein, G., Bellaye, P. S., Micheau, O., and Bonniaud, P. (2012). Small Heat Shock Proteins and the Cytoskeleton: an Essential Interplay for Cell Integrity? Int. J. Biochem. Cel Biol. 44, 1680-1686. doi:10.1016/j.biocel. 2012.05.024

Wilhelmus, M. M. M., Boelens, W. C., Otte-Höller, I., Kamps, B., Kusters, B., MaatSchieman, M. L. C., et al. (2006a). Small Heat Shock Protein HspB8: its Distribution in Alzheimer's Disease Brains and its Inhibition of Amyloid- $\beta$ Protein Aggregation and Cerebrovascular Amyloid- $\beta$ Toxicity. Acta Neuropathol. 111, 139-149. doi:10.1007/s00401-005-0030-z

Wilhelmus, M. M. M., Boelens, W. C., Otte-Höller, I., Kamps, B., de Waal, R. M. W., and Verbeek, M. M. (2006b). Small Heat Shock Proteins Inhibit Amyloid- $\beta$ Protein Aggregation and Cerebrovascular Amyloid- $\beta$ Protein Toxicity. Brain Res. 1089, 67-78. doi:10.1016/j.brainres.2006.03.058

Wilhelmus, M. M. M., Otte-Holler, I., Wesseling, P., de Waal, R. M. W., Boelens, W. C., and Verbeek, M. M. (2006c). Specific Association of Small Heat Shock Proteins with the Pathological Hallmarks of Alzheimer's Disease Brains. Neuropathol. Appl. Neurobiol. 32, 119-130. doi:10.1111/j.1365-2990.2006. 00689.x

Wu, T., Mu, Y., Bogomolovas, J., Fang, X., Veevers, J., Nowak, R. B., et al. (2017). HSPB7 Is Indispensable for Heart Development by Modulating Actin Filament Assembly. Proc. Natl. Acad. Sci. USA 114, 11956-11961. doi:10.1073/pnas. 1713763114

Wu, D., Vonk, J. J., Salles, F., Vonk, D., Haslbeck, M., Melki, R., et al. (2019). The N Terminus of the Small Heat Shock Protein HSPB7 Drives its polyQ Aggregation-Suppressing Activity. J. Biol. Chem. 294, 9985-9994. doi:10. 1074/jbc.RA118.007117

Wu, W., Sun, X., Shi, X., Lai, L., Wang, C., Xie, M., et al. (2021). Hsp22 Deficiency Induces Age-Dependent Cardiac Dilation and Dysfunction by Impairing Autophagy, Metabolism, and Oxidative Response. Antioxidants 10, 1550. doi:10.3390/antiox10101550

Wyttenbach, A., Sauvageot, O., Carmichael, J., Diaz-Latoud, C., Arrigo, A.-P., and Rubinsztein, D. C. (2002). Heat Shock Protein 27 Prevents Cellular Polyglutamine Toxicity and Suppresses the Increase of Reactive Oxygen Species Caused by Huntingtin. Hum. Mol. Genet. 11, 1137-1151. doi:10. 1093/hmg/11.9.1137

Xi, J. H., Bai, F., McGaha, R., and Andley, U. P. (2006). Alpha-crystallin Expression Affects Microtubule Assembly and Prevents Their Aggregation. FASEB j. 20, 846-857. doi:10.1096/fj.05-5532com

Xi, J.-h., Bai, F., Gross, J., Townsend, R. R., Menko, A. S., and Andley, U. P. (2008). Mechanism of Small Heat Shock Protein Function In Vivo: A Knock-In Mouse Model Demonstrates that the R49c Mutation in Alpha A-Crystallin Enhances Protein Insolubility and Cell Death. J. Biol. Chem. 283, 5801-5814. doi:10.1074/ jbc.M708704200

Xia, C.-h., Liu, H., Chang, B., Cheng, C., Cheung, D., Wang, M., et al. (2006). Arginine 54 and Tyrosine 118 Residues of aA-Crystallin Are Crucial for Lens Formation and Transparency. Invest. Ophthalmol. Vis. Sci. 47, 3004-3010. doi:10.1167/iovs.06-0178

Xu, H., Piao, Z., Ma, X., Huang, L., Zhou, P., Yu, W., et al. (2019). A Functional Polymorphism in the Promoter of aA-crystallin Increases the Risk of nAMD. Int. J. Clin. Exp. Pathol. 12, 1782-1787. Available at: http://www.ncbi.nlm.nih. gov/pubmed/31933998.

Yalcintepe, S., Gurkan, H., Gungor Dogan, I., Demir, S., Ozemri Sag, S., Manav Kabayegit, Z., et al. (2021). The Importance of Multiple Gene Analysis for Diagnosis and Differential Diagnosis in Charcot Marie Tooth Disease. Turkish Neurosurg. 31, 888-895. doi:10.5137/1019-5149.JTN.33661-21.3

Yang, Z., Wang, Y., Lu, Y., and Zhao, X. (2011). Molecular Characterization of Rat cvHsp/HspB7 In Vitro and its Dynamic Molecular Architecture. Mol. Med. Rep. 4, 105-111. doi:10.3892/mmr.2010.382

Yang, K., Meinhardt, A., Zhang, B., Grzmil, P., Adham, I. M., and Hoyer-Fender, S. (2012). The Small Heat Shock Protein ODF1/HSPB10 Is Essential for Tight Linkage of Sperm Head to Tail and Male Fertility in Mice. Mol. Cel. Biol. 32, 216-225. doi:10.1128/MCB.06158-11

Yang, Z., Su, D., Li, Q., Ma, Z., Yang, F., Zhu, S., et al. (2013). A R54L Mutation of CRYAA Associated with Autosomal Dominant Nuclear Cataracts in a Chinese Family. Curr. Eye Res. 38, 1221-1228. doi:10.3109/02713683.2013. 811260 
Yang, K., Grzmil, P., Meinhardt, A., and Hoyer-Fender, S. (2014). Haplo-deficiency of ODF1/HSPB10 in Mouse Sperm Causes Relaxation of Head-To-Tail Linkage. Reproduction 148, 499-506. doi:10.1530/REP-14-0370

Yang, X.-D., Cen, Z.-D., Cheng, H.-P., Shi, K., Bai, J., Xie, F., et al. (2017). L-3-nButylphthalide Protects HSPB8 K141N Mutation-Induced Oxidative Stress by Modulating the Mitochondrial Apoptotic and Nrf2 Pathways. Front. Neurosci. 11, 402. doi:10.3389/fnins.2017.00402

Yerbury, J. J., Gower, D., Vanags, L., Roberts, K., Lee, J. A., and Ecroyd, H. (2013). The Small Heat Shock Proteins aB-crystallin and Hsp27 Suppress SOD1 Aggregation In Vitro. Cell Stress Chaperones 18, 251-257. doi:10.1007/ s12192-012-0371-1

Yew, E. H. J., Cheung, N. S., Choy, M. S., Qi, R. Z., Lee, A. Y.-W., Peng, Z. F., et al. (2005). Proteasome Inhibition by Lactacystin in Primary Neuronal Cells Induces Both Potentially Neuroprotective and Pro-apoptotic Transcriptional Responses: a Microarray Analysis. J. Neurochem. 94, 943-956. doi:10.1111/j. 1471-4159.2005.03220.x

Ylikallio, E., Konovalova, S., Dhungana, Y., Hilander, T., Junna, N., Partanen, J. V., et al. (2015). Truncated HSPB1 Causes Axonal Neuropathy and Impairs Tolerance to Unfolded Protein Stress. BBA Clin. 3, 233-242. doi:10.1016/j. bbacli.2015.03.002

Yoshida, K.-i., Aki, T., Harada, K., M.A. Shama, K., Kamoda, Y., Suzuki, A., et al. (1999). Translocation of HSP27 and MKBP in Ischemic Heart. Cel Struct. Funct. 24, 181-185. doi:10.1247/csf.24.181

Yu, L., Liang, Q., Zhang, W., Liao, M., Wen, M., Zhan, B., et al. (2019). HSP22 Suppresses Diabetes-Induced Endothelial Injury by Inhibiting Mitochondrial Reactive Oxygen Species Formation. Redox Biol. 21, 101095. doi:10.1016/j. redox.2018.101095

Yu, H., Liu, K., and Lu, P. (2021a). Polymorphisms in CRYAA Promoter with Susceptibility to Cataract: A Meta-Analysis. Semin. Ophthalmol. 36, 1-8. doi:10. 1080/08820538.2021.1903943

Yu, Y., Xu, J., Qiao, Y., Li, J., and Yao, K. (2021b). A New Heterozygous Mutation in the Stop Codon of CRYAB (p.X176Y) Is Liable for Congenital Posterior Pole Cataract in a Chinese Family. Ophthalmic Genet. 42, 139-143. doi:10.1080/ 13816810.2020.1855665

Zarsky, H. A., Cheng, M., van der Hoorn, F. A., and van der Hoorn, F. A. (2003). Novel RING Finger Protein OIP1 Binds to Conserved Amino Acid Repeats in Sperm Tail Protein ODF11. Biol. Reprod. 68, 543-552. doi:10.1095/biolreprod. 102.009076

Zavialov, A., Benndorf, R., Ehrnsperger, M., Zav'yalov, V., Dudich, I., Buchner, J., et al. (1998). The Effect of the Intersubunit Disulfide Bond on the Structural and Functional Properties of the Small Heat Shock Protein Hsp25. Int. J. Biol. Macromol. 22, 163-173. doi:10.1016/s0141-8130(98) 00014-2
Zeng, L., Cao, Y., Wu, Z., Huang, M., Zhang, G., Lei, C., et al. (2019). A Missense Mutation of the HSPB7 Gene Associated with Heat Tolerance in Chinese Indicine Cattle. Animals 9, 554. doi:10.3390/ani9080554

Zhai, J., Lin, H., Julien, J.-P., and Schlaepfer, W. W. (2007). Disruption of Neurofilament Network with Aggregation of Light Neurofilament Protein: a Common Pathway Leading to Motor Neuron Degeneration Due to CharcotMarie-Tooth Disease-Linked Mutations in NFL and HSPB1. Hum. Mol. Genet. 16, 3103-3116. doi:10.1093/hmg/ddm272

Zhang, H., Rajasekaran, N. S., Orosz, A., Xiao, X., Rechsteiner, M., and Benjamin, I. J. (2010). Selective Degradation of Aggregate-Prone CryAB Mutants by HSPB1 Is Mediated by Ubiquitin-Proteasome Pathways. J. Mol. Cell Cardiol. 49, 918-930. doi:10.1016/j.yjmcc.2010.09.004

Zhang, L., Zhang, Y., Liu, P., Cao, W., Tang, X., and Su, S. (2011). Congenital Anterior Polar Cataract Associated with a Missense Mutation in the Human Alpha Crystallin Gene CRYAA. Mol. Vis. 17, 2693-2697. Available at: http:// www.ncbi.nlm.nih.gov/pubmed/22065922.

Zhang, X., Wang, X., Zhu, H., Kranias, E. G., Tang, Y., Peng, T., et al. (2012). Hsp20 Functions as a Novel Cardiokine in Promoting Angiogenesis via Activation of VEGFR2. PLoS One 7, e32765. doi:10.1371/journal.pone. 0032765

Zourlidou, A., Payne Smith, M. D., and Latchman, D. S. (2004). HSP27 but Not HSP70 Has a Potent Protective Effect against a-synuclein-induced Cell Death in Mammalian Neuronal Cells. J. Neurochem. 88, 1439-1448. doi:10.1046/j. 1471-4159.2003.02273.x

Conflict of Interest: The authors declare that the research was conducted in the absence of any commercial or financial relationships that could be construed as a potential conflict of interest.

Publisher's Note: All claims expressed in this article are solely those of the authors and do not necessarily represent those of their affiliated organizations, or those of the publisher, the editors and the reviewers. Any product that may be evaluated in this article, or claim that may be made by its manufacturer, is not guaranteed or endorsed by the publisher.

Copyright (c) 2022 Tedesco, Cristofani, Ferrari, Cozzi, Rusmini, Casarotto, Chierichetti, Mina, Galbiati, Piccolella, Crippa and Poletti. This is an openaccess article distributed under the terms of the Creative Commons Attribution License (CC BY). The use, distribution or reproduction in other forums is permitted, provided the original author(s) and the copyright owner(s) are credited and that the original publication in this journal is cited, in accordance with accepted academic practice. No use, distribution or reproduction is permitted which does not comply with these terms. 


\section{GLOSSARY}

AA Amino acid

ACD $\alpha$-Crystallin Domain

AD Alzheimer's Disease

ALS Amyotrophic Lateral Sclerosis

$\mathbf{A} \boldsymbol{\beta}$ Amyloid $\beta$

BAG3 Bcl-2 Associated Athanogene 3

CASA Chaperone-Assisted Selective Autophagy

CHIP/STUB1 Carboxy-terminus of HSC70 interacting protein

CMT2 Charcot-Marie-Tooth type 2

CT51 Cancer/Testis Antigen 51

CTD C-terminal Domain

cUPR Cytosolic Unfolded Protein Response

dHMNII distal Hereditary Motor Neuropathy type II

DKO Double Knock-out

eIF2 $\alpha$ Eukaryotic initiation factor- $2 \alpha$

ER Endoplasmic Reticulum

HRI eIF2 $\alpha$ kinase heme-regulated inhibitor

HSP70/HSPA Heat Shock Protein 70

HTT Huntingtin

I/R Ischemia/Reperfusion

iPSCs Induced Pluripotent Stem Cells

KD Knock-down

Keap1 Kelch-like ECH-associated protein 1

KI Knock-in

KO Knock-out

LLPS Liquid-Liquid Phase Separation

MFM Myofibrillar Myopathy
MKBP Myotonic dystrophy protein Kinase Binding Protein

MNs Motoneurons

MW Molecular Weight

NDs Neurodegenerative Diseases

NF Neurofilament

Nrf2 Nuclear factor (erythroid-derived 2)-like 2

NTD N-terminal Domain

ODF1 Outer Dense Fibre protein 1

ODF2 Outer Dense Fibre protein 2

OIP1 ODF1-interacting protein

polyQ Polyglutamine

PQC Protein Quality Control

PTM Post-translational modification

RBP RNA binding protein

SBMA Spinal and Bulbar Muscular Atrophy

SGs Stress Granules

sHSPs or HSPBs small Heat Shock Proteins or Heat Shock Proteins B

SMN Survival Motor Neuron

SNCA a-synuclein

snRNP Small nuclear ribonucleoprotein

SOD1 Superoxide Dismutase 1

SPAG Sperm-associated antigen

SQSTM1/p62 Sequestosome1/p62

TG Transgenic

UPR Unfolded Protein Response

UPS Ubiquitin Proteasome System

WT Wild-type 